SIMULATION OF CIRCULATING FLUIDIZED BED COMBUSTORS

FIRING INDIGENOUS LIGNITE

A THESIS SUBMITTED TO

THE GRADUATE SCHOOL OF NATURAL AND APPLIED SCIENCES

$\mathrm{OF}$

MIDDLE EAST TECHNICAL UNIVERSITY

BY

MERT ÖZKAN

IN PARTIAL FULLFILLMENT OF THE REQUIREMENTS

FOR

THE DEGREE OF MASTER OF SCIENCE

IN

CHEMICAL ENGINEERING

NOVEMBER 2010 
Approval of the thesis:

\section{SIMULATION OF CIRCULATING FLUIDIZED BED COMBUSTORS FIRING INDIGENOUS LIGNITE}

submitted by MERT ÖZKAN in partial fulfillment of the requirements for the degree of Master of Science in Chemical Engineering Department, Middle East Technical University by,

Prof.Dr. Canan Özgen

Dean, Graduate School of Natural and Applied Sciences

Prof.Dr. Gürkan Karakaş

Head of Department, Chemical Engineering

Prof.Dr. Nevin Selçuk

Supervisor, Chemical Engineering Dept., METU

\section{Examining Committee Members:}

Prof.Dr. Faruk Arınç

Mechanical Engineering Dept., METU

Prof.Dr. Nevin Selçuk

Chemical Engineering Dept., METU

Asst.Prof.Dr. Görkem Külah

Chemical Engineering Dept., METU

Asst.Prof.Dr. Nimeti Döner

Mechanical Engineering Dept., Dumlupınar University

Dr. Yusuf Göğebakan

MIMAG-SAMKO Energy Technologies

Date: 
I hereby declare that all information in this document has been obtained and presented in accordance with academic rules and ethical conduct. I also declare that, as required by these rules and conduct, I have fully cited and referenced all material and results that are not original to this work.

Name, Last name $\quad$ : Mert Özkan

Signature 


\begin{abstract}
SIMULATION OF CIRCULATING FLUIDIZED BED COMBUSTORS FIRING INDIGENOUS LIGNITE
\end{abstract}

\author{
Özkan, Mert \\ M. S., Department of Chemical Engineering \\ Supervisor: Prof. Dr. Nevin Selçuk
}

November 2010, 134 pages

\begin{abstract}
A comprehensive model, previously developed for a rectangular parallelepiped shaped $0.3 \mathrm{MW}_{\mathrm{t}}$ circulating fluidized bed combustor (CFBC) fired with high calorific value coal burning in sand and validated against experimental data is adapted to cylindrical configuration and is extended to incorporate $N O_{x}$ formation and reduction reactions and pressure drops around cyclone, downcomer and loop seal. Its predictive accuracy is tested by applying it to the simulation of Middle East Technical University (METU) $150 \mathrm{~kW}_{\mathrm{t}}$ CFBC burning low calorific value indigenous lignite with high Volatile Matter/Fixed Carbon (VM/FC) ratio in its own ash and comparing its predictions with measurements. Favorable comparisons are obtained between the predicted and measured temperatures, pressure profiles and emissions of gaseous species. Results reveal that predictive accuracy in pressure profile strongly depends on the correlation utilized for entrainment in dilute zone and that accuracy in $N O$ emission requires data on
\end{abstract}


partitioning of coal nitrogen into char- $\mathrm{N}$ and volatile- $\mathrm{N}$ and is affected significantly by dilute zone oxygen content.

Keywords: Circulating fluidized bed, Turkish lignite, $N O_{x}$ emission, mathematical modeling. 


\title{
$\ddot{0} \mathbf{z}$
}

\section{YERLİ LINYITT YAKAN DOLAŞIMLI AKIŞKAN YATAKLI YAKICILARIN BENZETIŞíi}

\author{
Özkan, Mert \\ Yüksek Lisans, Kimya Mühendisliği Bölümü \\ Tez Yöneticisi: Prof. Dr. Nevin Selçuk
}

Kasım 2010, 134 sayfa

Önceden geliştirilen, yüksek 1sıl değerli kömürü kumda yakan, dikdörtgen paralelyüz şekle sahip bir 0,3 $\mathrm{MW}_{\mathrm{t}}$ dolaşımlı akışkan yataklı yakıcıdan (DAYY) alınan ve deneysel verilerle geçerliliği ispatlanmış kapsamlı bir model, silindirik koordinatlara adapte edilmiş ve NO oluşum ve indirgenme reaksiyonlarıyla; siklon, iniş borusu ve geri dönüş vanası etrafındaki basınç düşmesini kapsayacak şekilde genişletilmiştir. Model öngörülerinin doğruluğu, modelin, düşük kalorifik değere ve yüksek uçucu madde/sabit karbon oranına sahip yerli linyit yakan Orta Doğu Teknik Üniversitesi'ndeki (ODTÜ) 150 kWt DAYY'a uygulanmasıyla ve ölçümlerle öngörülerin kıyaslanmasıyla test edilmiştir. Sıcaklık ve basınç profilleriyle gaz emisyonlarının öngörülen ve ölçülen değerleri arasında olumlu karşılaştırmalar elde edilmiştir. Sonuçlar, basınç öngörülerinin doğruluğunun, tanecik seyreltik bölgedeki katı parçacık miktarının yukarı yönlü azalmasının belirlenmesi için kullanılan korelasyona, NO emisyonu öngörülerinin 
doğruluğunun ise kömürdeki azotun kok azotuna ve uçucu azota bölünme oranına ve tanecik seyreltik bölgedeki oksijen içeriğine güçlü bir şekilde bağlı olduğunu ortaya koymuştur.

Anahtar Kelimeler: Dolaşımlı akışkan yatak, Türk linyiti, $N O_{x}$ emisyonu, matematiksel modelleme. 
To My Beloved Parents

viii 


\section{ACKNOWLEDGEMENTS}

I would like to express my deepest gratitude to my supervisor Prof. Dr. Nevin Selçuk for all guidance and encouragement during the preparation of this thesis work.

I also thank to my friends for their continuous support for the completion of the study; Mehmet Yusuf Kaptan, Sena Yüzbaşı, Güzide Aydın and İlker Soner.

I am so grateful to Rafet Özkan for his support and invaluable help in all aspects during the struggling period that I have been coping with.

I wish to express my deepest appreciation to my uncle Ceyhun Özkan and my cousin Harun Özkan for their help and guidance during the completion of this work.

I also want to thank to my brother Dr. İbrahim Ali Özkan and his wife Dr. Kerry Bullock Özkan for their everlasting inspiration.

Finally, I would like to thank my beloved mother and late father and for their unshakable faith, continuous support, life-time encouragement and efforts on me. 


\section{TABLE OF CONTENTS}

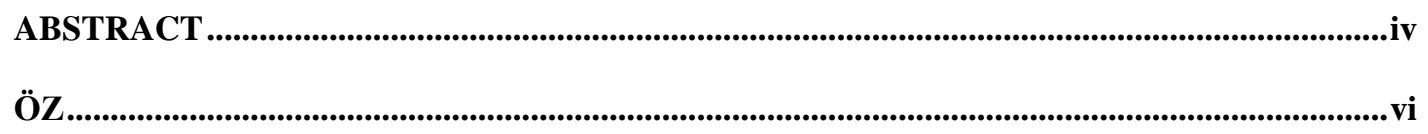

ACKNOWLEDGEMENTS.........................................................................................................

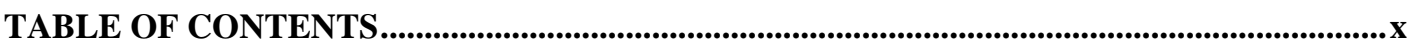

LIST OF FIGURES ............................................................................................................................xii

LIST OF TABLES ...........................................................................................................................xiii

LIST OF SYMBOLS.............................................................................................................................................

\section{CHAPTERS}

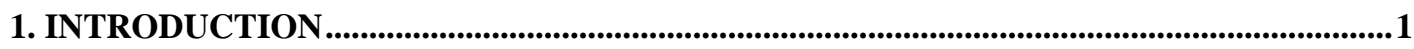

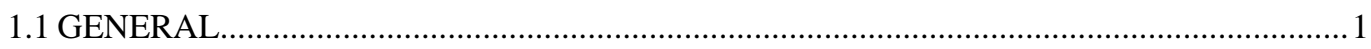

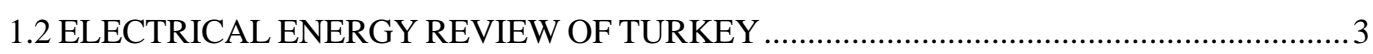

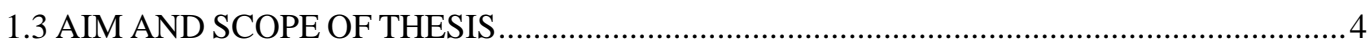

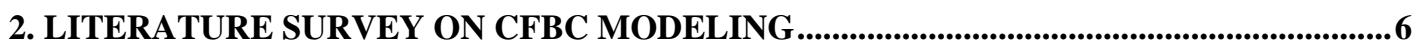

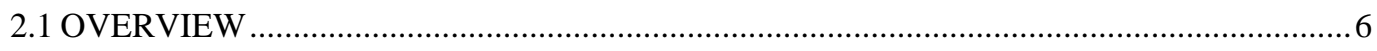

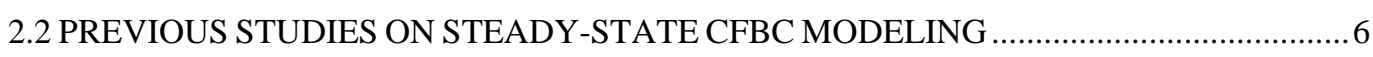

3. STEADY-STATE CFBC MODEL WITH NO FORMATION AND REDUCTION ...............15

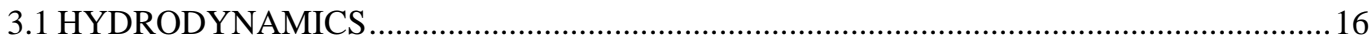

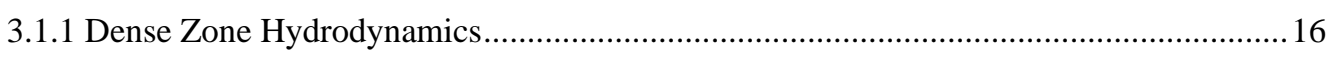

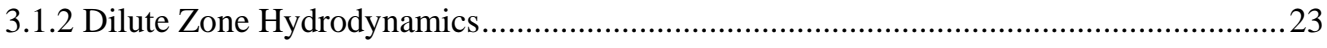

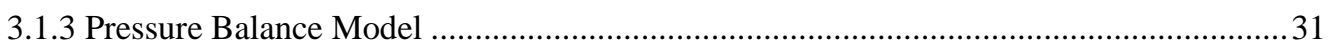

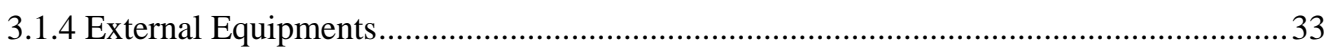

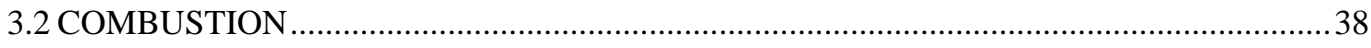

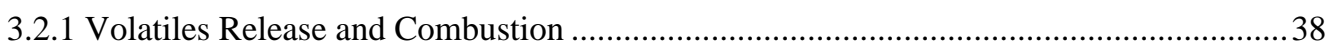

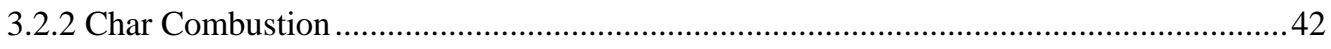

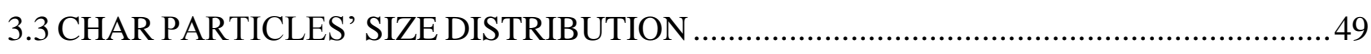

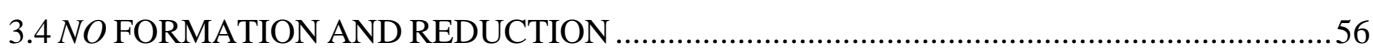


3.5 MASS AND ENERGY BALANCE EQUATIONS ....................................................59

3.5.1 Mass and Energy Balance In Dense Zone ..............................................................59

3.5.2 Mass and Energy Balance In Dilute Zone ...................................................................... 75

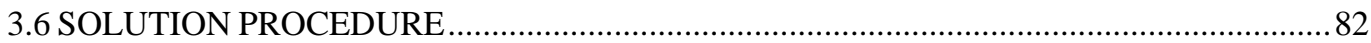

4. EXPERIMENTAL SET-UP AND CONDITIONS ............................................................85

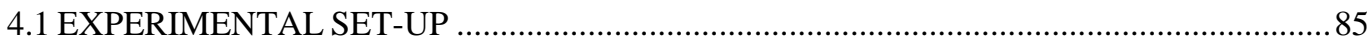

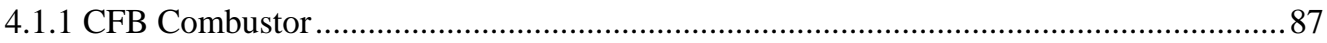

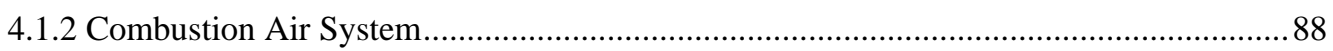

4.1.3 Solids Handling and Feeding System ....................................................................... 90

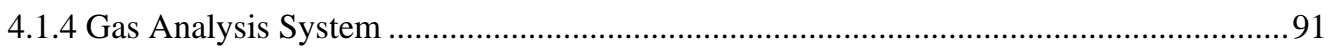

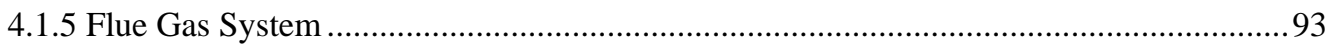

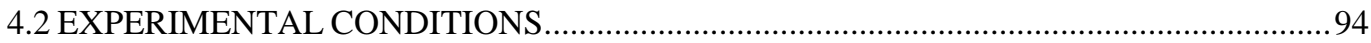

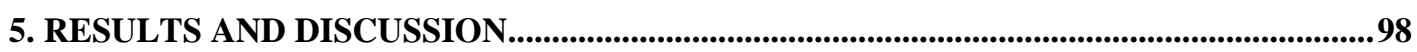

6. CONCLUSIONS ............................................................................................................................................... 103

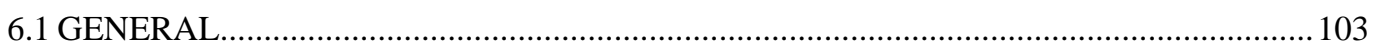

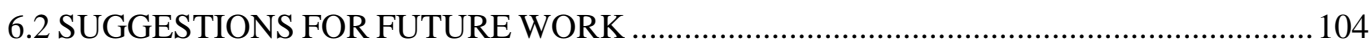

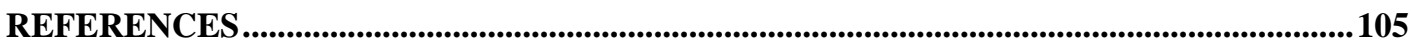

APPENDICES

A. DERIVATION OF CARBON AND CHAR-N CONSUMPTION RATE...............................117

B. DERIVATION OF ROSIN-RAMMLER SIZE DISTRIBUTION FUNCTIONS.................119

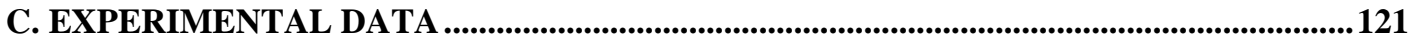

D. THERMOPHYSICAL PROPERTIES ..............................................................................130

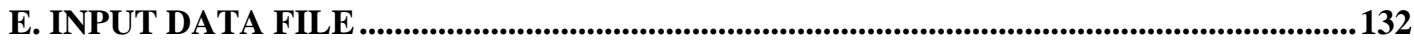




\section{LIST OF FIGURES}

Figure 1.1 World net electricity generation by fuel [1].................................. 1

Figure 1.2 Future projections of the fuels in electricity generation [3]................. 2

Figure 3.1 Schematic diagram of the physical system.................................... 15

Figure 3.2 Main pressure data points in a CFBC............................................ 32

Figure 3.3 A typical cyclone and its dimensions [17] .................................... 33

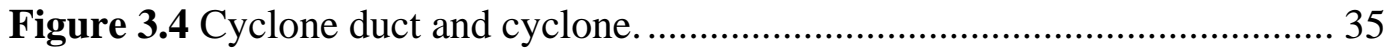

Figure 3.5 Vertical Aeration and weir sections of loop seal.............................. 36

Figure 3.6 Schematic diagram for char population balance.............................. 50

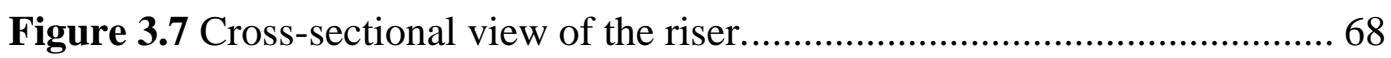

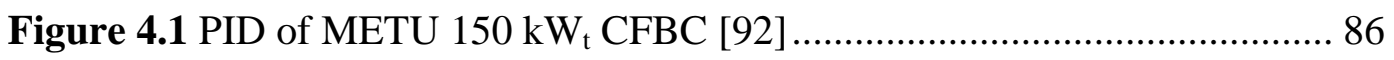

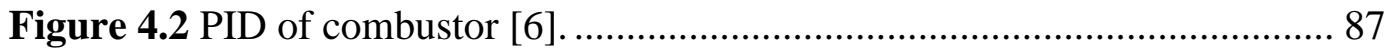

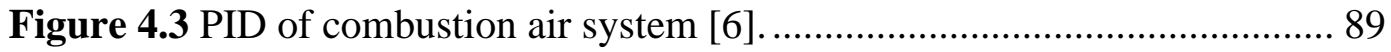

Figure 4.4 PID of solids handling and feeding system [6] ............................. 90

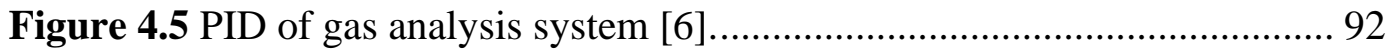

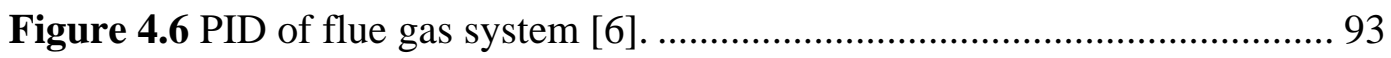

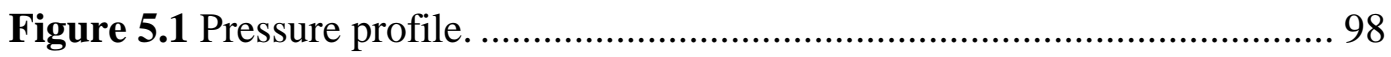

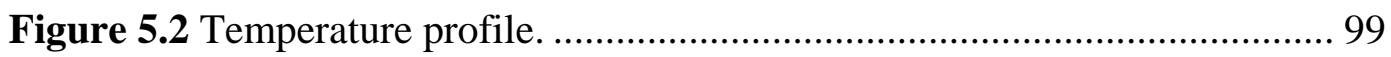

Figure 5.3 Concentration profiles along the combustor and emissions. ............ 100

Figure 5.4 $N O$ concentration profile along the combustor and emission........... 101

Figure 5.5 Predicted and experimental particle size distributions. ................... 102 


\section{LIST OF TABLES}

Table 2.1 Summary of steady-state CFBC models in literature........................ 13

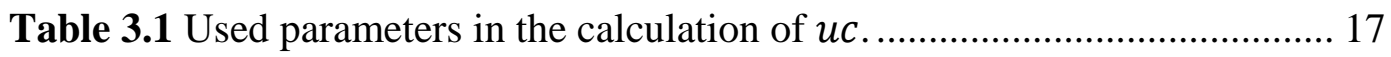

Table 3.2 Correlations and estimations for transition velocities....................... 17

Table 3.3 Parameters used in the estimation of annular layer thickness............. 25

Table 3.4 Correlations utilized for estimation of annular layer thickness........... 26

Table 3.5 Parameters utilized for the kinetic expression of Field et al. [73] ....... 45

Table 3.6 Parameters utilized for the oxygen diffusivity expression [73]. .......... 46

Table 3.7 Parameters utilized for the kinetic expression of Hottel et al. [81]...... 48

Table 3.8 Reactions considering $N O$ formation and reduction $[84,85]$............. 57

Table 3.9 Values of $\epsilon$ utilized for the convergence check. .............................. 84

Table 4.1 Characteristics of Çan lignite. ........................................................... 95

Table 4.2 Çan lignite ash composition............................................................. 96

Table 4.3 Opearating parameters of the METU $150 \mathrm{~kW}_{\mathrm{t}}$ CFBC........................ 97

Table 5.1 Experimental and predicted emissions........................................... 101

Table C.1 Steady-State temperature measurements along the combustor. ........ 121

Table C.2 Steady-State pressure measurements along the combustor.............. 122

Table C.3 Chemical analysis of bag filter ash and bed drain.......................... 123

Table C.4 Particle size distribution of loop seal ash..................................... 124

Table C.5 Particle size distribution of bed drain............................................ 125

Table C.6 Particle size distribution of bag filter ash..................................... 126

Table D.1 Molecular weights of the elements............................................... 130

Table D.2 Standard heats of combustion and vaporization............................. 130

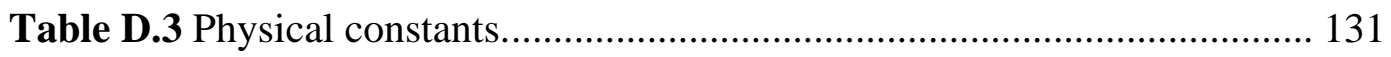




\section{LIST OF SYMBOLS}

a Decay constant, $1 / m$

A Cross-sectional area, $m^{2}$

$A_{0} \quad$ Area of distributor plate per orifice, $m^{2}$

$A_{c} \quad$ Inlet area of cyclone, $m^{2}$

Ar Archimedes number, dimensionless

$A_{r} \quad$ Cross sectional area of riser, $m^{2}$

$b \quad$ Rosin-Rammler size distribution function parameter, dimensionless

c Fraction of unreacted coal on dry-ash-free basis, dimensionless

$c_{p} \quad$ Specific heat capacity, $\mathrm{J} / \mathrm{kg} \cdot \mathrm{K}$

C Concentration, $\mathrm{mol} / \mathrm{m}^{3}$

$\bar{C} \quad$ Average concentration, $\mathrm{mol} / \mathrm{m}^{3}$

$C_{c y} \quad$ Velocity head coefficient

$C_{d} \quad$ Drag coefficient, dimensionless

$D \quad$ Riser diameter, $m$; Cyclone diameter, $m$; Diameter, $m$

$D_{d} \quad$ Dust exit diameter of cyclone, $m$

$D_{e} \quad$ Gas exit diameter of cyclone, $m$

$d_{b}(z)$ Bubble size, $m$

$\bar{d}_{b} \quad$ Mean bubble size, $m$

$D_{e} \quad$ Diameter of vortex finder, $m$

$d_{p} \quad$ Particle diameter, $m$

$d_{p 50} \quad$ Cut diameter of cyclone, $m$

$\mathcal{D} \quad$ Diffusivity of oxygen in nitrogen, $\mathrm{m}^{2} / \mathrm{s}$

$D_{t} \quad$ Diameter of riser, $m$

E Entrainment rate, $\mathrm{kg} / \mathrm{m}^{2} \cdot \mathrm{s}$; Activation energy, $\mathrm{J} / \mathrm{mol}$

$E_{0} \quad$ Mean activation energy, $\mathrm{J} / \mathrm{mol}$ 
$f \quad$ Parameter in Equation 3.4, dimensionless

$f_{r} \quad \mathrm{CO} / \mathrm{CO}_{2}$ product ratio, dimensionless

$f(E)$ Activation energy distribution function for devolatilization, $\mathrm{mol} / \mathrm{J}$

F $\quad$ Flow rate, $\mathrm{kg} / \mathrm{s}$

$F r_{D} \quad$ Froude number based on riser diameter, dimensionless

$g \quad$ Gravitational acceleration, $\mathrm{m} / \mathrm{s}^{2}$

$G_{s} \quad$ Net solid circulation flux, $\mathrm{kg} / \mathrm{m}^{2} \mathrm{~s}$

$G_{s h} \quad$ Solid mass flux based on horizontal section area of cyclone connection

$h \quad$ Individual heat transfer coefficient, $\mathrm{J} / \mathrm{m}^{2} \cdot s \cdot K$

$h_{f} \quad$ Gas side heat transfer coefficient, $\mathrm{J} / \mathrm{m}^{2} \cdot \mathrm{s} \cdot K$

$H \quad$ Height of riser, $m$; Height of cyclone inlet, $m$

$H_{d} \quad$ Height of dense zone, $m$

$H_{f} \quad$ Height of dilute zone, $m$

$\Delta H^{\circ} \quad$ Heat of reaction at standard state, $\mathrm{J} / \mathrm{mol}$

$k \quad$ First and $n$th order reaction rate constant for devolatilization, $1 / s$; Thermal conductivity, $\mathrm{J} / \mathrm{m} \cdot \mathrm{s} \cdot \mathrm{K}$

$k_{C O} \quad$ Reaction rate constant for $\mathrm{CO}$ combustion, $\mathrm{mol}^{n} / \mathrm{m}^{3 n} \cdot s$

$k_{f} \quad$ Film mass transfer coefficient, $\mathrm{m} / \mathrm{s}$

$k_{i} \quad$ Reaction rate constant for $i$ th devolatilization reaction, $1 / s$

$k_{1,2}$ First order reaction rate constants for competing reactions model of devolatilization, $1 / s$

$k_{0} \quad$ Pre-exponential factor for first and $n$th order devolatilization, $1 / s$; Preexponential factor for $\mathrm{CO} / \mathrm{CO}_{2}$ product ratio expression, dimensionless; Pre-exponential factor for $n$th order surface reaction rate constant for carbon consumption, $\mathrm{mol}^{3 n-2} / \mathrm{mol}^{n-1} \cdot s$; Pre-exponential factor for $C O$ combustion, $\mathrm{mol}^{\mathrm{n}} / \mathrm{m}^{3 n} \cdot \mathrm{s}$

$k_{s} \quad n$th order surface reaction rate constant for carbon combustion, $\mathrm{mol}^{3 n-2} / \mathrm{mol}^{n-1} \cdot s$

$K_{1} \quad$ Parameter in Equation 3.11, dimensionless 
$K_{2} \quad$ Parameter in Equation 3.11, dimensionless

$K_{b e} \quad$ Interphase mass transfer coefficient, $1 / s$

$L \quad$ Length, $m$

$L_{b} \quad$ Length of cylindrical part of cyclone, $m$

$L_{c} \quad$ Length of conical part of cyclone, $m$

$L_{w} \quad$ Lentgh of the weir section, $m$

$M \quad$ Solid hold-up, $\mathrm{kg}$; Molecular weight, $\mathrm{kg} / \mathrm{mol}$

$n$ Molar flow-rate, $\mathrm{mol} / \mathrm{s}$; Rosin-Rammler size distribution function parameter, dimesionless; Reaction rate order, dimensionless

$n_{C} \quad$ Carbon consumption rate, $\mathrm{mol} / \mathrm{m}^{3} \cdot \mathrm{s}$

$N \quad$ The number of rotations that the gas follows

$N_{H} \quad$ Number of inlet velocity heads, dimensionless

$N_{d} \quad$ Number of grid points in dense zone, dimensionless

$N_{f} \quad$ Number of grid points in dilute zone, dimensionless

$N_{p} \quad$ Number of grid points for char particle radius, dimensionless

$N_{d w} \quad$ Number of grid points in dense zone wall, dimensionless

$P \quad$ Pressure, $\mathrm{Pa}$

$\operatorname{Pr} \quad$ Prandtl number, dimensionless

$\triangle P \quad$ Pressure drop, $P a$

$P(r) \quad$ Size distribution function, $1 / m$

$q \quad$ Heat flux, $J / m^{2} \cdot s$

$Q \quad$ Volumetric flow rate, $\mathrm{m}^{3} / \mathrm{s}$; Energy generation/loss rate, $\mathrm{J} / \mathrm{s}$

$R \quad$ Ideal gas constant, $\mathrm{J} / \mathrm{mol} \cdot \mathrm{K}$; Radius, $m$

$\boldsymbol{R}$ Energy generation/loss rate in dilute zone, $\mathrm{J} / \mathrm{m}^{3} \cdot \mathrm{s}$

$R_{f w}$ Thermal resistance across the dilute zone wall, $\mathrm{J} / \mathrm{m}^{2} \cdot \mathrm{s} \cdot \mathrm{K}$

Re Reynolds number, dimensionless

$R e_{c} \quad$ Reynolds number based on transition velocity, dimensionless

$R e_{D} \quad$ Reynolds number based on riser diameter, dimensionless

$R e_{m f}$ Reynolds number based on minimum fluidization velocity; dimensionless 
$R e_{p} \quad$ Reynolds number based on particle diameter, dimensionless

$R e_{t} \quad$ Reynolds number based on terminal velocity, dimensionless

$\mathfrak{R}(r) \quad$ Shrinkage rate of char particles, $\mathrm{m} / \mathrm{s}$

$r \quad$ Spatial independent variable, $m$

$r_{C} \quad$ Carbon consumption rate on the surface of char particle, $\mathrm{mol} / \mathrm{m}^{2} \cdot \mathrm{s}$

$r_{C O} \quad$ Rate of $C O$ combustion, $\mathrm{mol} / \mathrm{m}^{3} \cdot \mathrm{s}$

$r_{\max } \quad$ Maximum particle radius, $m$

$r_{\min } \quad$ Minimum particle radius, $m$

Sc Schmidt number, dimensionless

$u \quad$ Velocity, $m / s$

$u_{0} \quad$ Superficial gas velocity, $\mathrm{m} / \mathrm{s}$

$u_{b} \quad$ Bubble rising velocity, $\mathrm{m} / \mathrm{s}$

$u_{c} \quad$ Transition velocity to turbulent fluidization, $\mathrm{m} / \mathrm{s}$

$U_{g} \quad$ Superficial velocity at riser, $\mathrm{m} / \mathrm{s}$

$U_{g h} \quad$ Average velocity at cyclone connection, $\mathrm{m} / \mathrm{s}$

$u_{m f} \quad$ Minimum fluidization velocity, $\mathrm{m} / \mathrm{s}$

$u_{s} \quad$ Solid velocity, $\mathrm{m} / \mathrm{s}$

$u_{t} \quad$ Terminal velocity, $\mathrm{m} / \mathrm{s}$

$u_{t f} \quad$ Throughflow velocity, $\mathrm{m} / \mathrm{s}$

$v \quad$ Fraction of volatiles released, dimensionless

$v_{\infty} \quad$ Fraction of volatiles released at $t=\infty$, dimensionless

$v_{\infty, i}$ Fraction of volatiles released at $t=\infty$ for $i$ th devolatilization reaction, dimensionless

$V \quad$ Volume, $m^{3}$

$V_{c} \quad$ The velocity along the circular path

$V_{\text {in }} \quad$ Cyclone inlet velocity, $\mathrm{m} / \mathrm{s}$

$t \quad$ Time, $s$

$T \quad$ Temperature, $K$

$T_{\infty} \quad$ Ambient Temperature, $K$ 
W Width of cyclone inlet, $m$

$W(r)$ Dummy variable used for solution of char particle size distribution, $\mathrm{kg} / \mathrm{m}$

$W\left(d_{p}\right)$ Fractional mass of particles having diameter $d_{p}$

$x_{v l} \quad$ Fraction of volatile matter released to dense zone, dimensionless

$x_{N, c} \quad$ Fraction of char bound nitrogen, dimensionless

$y \quad$ Mole fraction, dimesionless

$z \quad$ Spatial independent variable, $m$

\section{Greek Letters}

$\alpha \quad$ Thermal diffusivity, $\mathrm{m}^{2} / \mathrm{s}$

$\delta \quad$ Bubble phase volume fraction, dimensionless

$\delta_{a} \quad$ Annular layer thickness, $m$

$\phi_{s} \quad$ Sphericity, dimensionless

$\psi \quad$ Dummy variable defined in Equation $3.159, \mathrm{~K} / \mathrm{m}$

$\eta_{c y c} \quad$ Cyclone efficiency, dimensionless

$\epsilon \quad$ Emissivity, dimensionless

$\varepsilon \quad$ Volume fraction, dimensionless; Voidage in loop seal, dimesionless

$\bar{\varepsilon} \quad$ Cross-sectional average volume fraction, dimensionless

$\varepsilon_{m f} \quad$ Voidage at minimum fluidization, dimensionless

$\kappa(r) \quad$ Elutriation rate constant, $1 / s$

$\kappa^{*}(r)$ Elutriation rate constant, $\mathrm{kg} / \mathrm{m}^{2} \cdot \mathrm{s}$

$\lambda^{\circ}{ }_{\mathrm{H}_{2} \mathrm{O}}$ Latent heat of vaporization, $\mathrm{J} / \mathrm{kg}$

$\mu \quad$ Viscosity, $N \cdot s / m^{2}$

$\sigma \quad$ Standard deviation of activation energy distribution, $J / \mathrm{mol}$; StefanBoltzman constant, $\mathrm{J} / \mathrm{m}^{2} \cdot \mathrm{s} \cdot \mathrm{K}^{4}$

$\rho \quad$ Density, $\mathrm{kg} / \mathrm{m}^{3}$

$\zeta \quad$ Mechanism factor for $\mathrm{CO} / \mathrm{CO}_{2}$ product ratio, dimensionless 


\section{Subscripts}

$\begin{array}{ll}0 & \text { Feed } \\ 1 & \text { Bed drain } \\ 2 & \text { Riser exit } \\ 3 & \text { Recycle } \\ 4 & \text { Fly ash } \\ a & \text { Air } \\ a s h & \text { Ash } \\ b & \text { Bubble } \\ c & \text { Char } \\ C & \text { Carbon } \\ c y c & \text { Cyclone } \\ c o m b & \text { Combustible } \\ d & \text { Dense zone } \\ d c & \text { Downcomer } \\ d w & \text { Dense zone wall } \\ e & \text { Emulsion, Exit } \\ f & \text { Dilute zone } \\ f c & \text { Fixed carbon } \\ f w & \text { Dilute zone wall } \\ g & \text { Gas } \\ h & \text { Cyclone duct } \\ \text { min } & \text { Minimum } \\ m a & \text { Dense zone surface; Outer surface } \\ m f & \text { Minimum fluidization } \\ & \end{array}$




$\begin{array}{ll}p & \text { Particle } \\ p r i & \text { Primary } \\ p s & \text { Pressure seal } \\ r & \text { r-direction } \\ s & \text { Particle surface } \\ s-l s & \text { Particle density in the loop seal } \\ r e c & \text { Recycle } \\ r e f & \text { Reference } \\ r x n & \text { Reaction } \\ s & \text { Solid, particle surface } \\ \text { sec } & \text { Secondary } \\ \text { sus } & \text { Suspension } \\ \text { vm } & \text { Volatile matter } \\ w & \text { Wall } \\ z & \text { z-direction }\end{array}$

\section{Abbreviations}

CFB Circulating Fluidized Bed

CFBC Circulating Fluidized Bed Combustion/Combustor

FC Fixed Carbon

HHV Higher Heating Value

$\mathrm{kW}_{\mathrm{t}} \quad$ KiloWatt Thermal

LHV Lower Heating Value

METU Middle East Technical University

$\mathrm{MW}_{\mathrm{e}} \quad$ MegaWatt Electric

MW $_{\mathrm{t}}$ MegaWatt Thermal

ODE Ordinary Differential Equation 


\section{CHAPTER 1}

\section{INTRODUCTION}

\subsection{GENERAL}

Due to increase in population, industrialization and development in technology; electrical energy requirement of the world is increasing rapidly. To meet this demand, coal, which offers greatest proven reserves, is utilized as a major energy source for power generation. As illustrated in Figure 1.1, coal constitutes nearly $50 \%$ of the world's electricity generation [1].

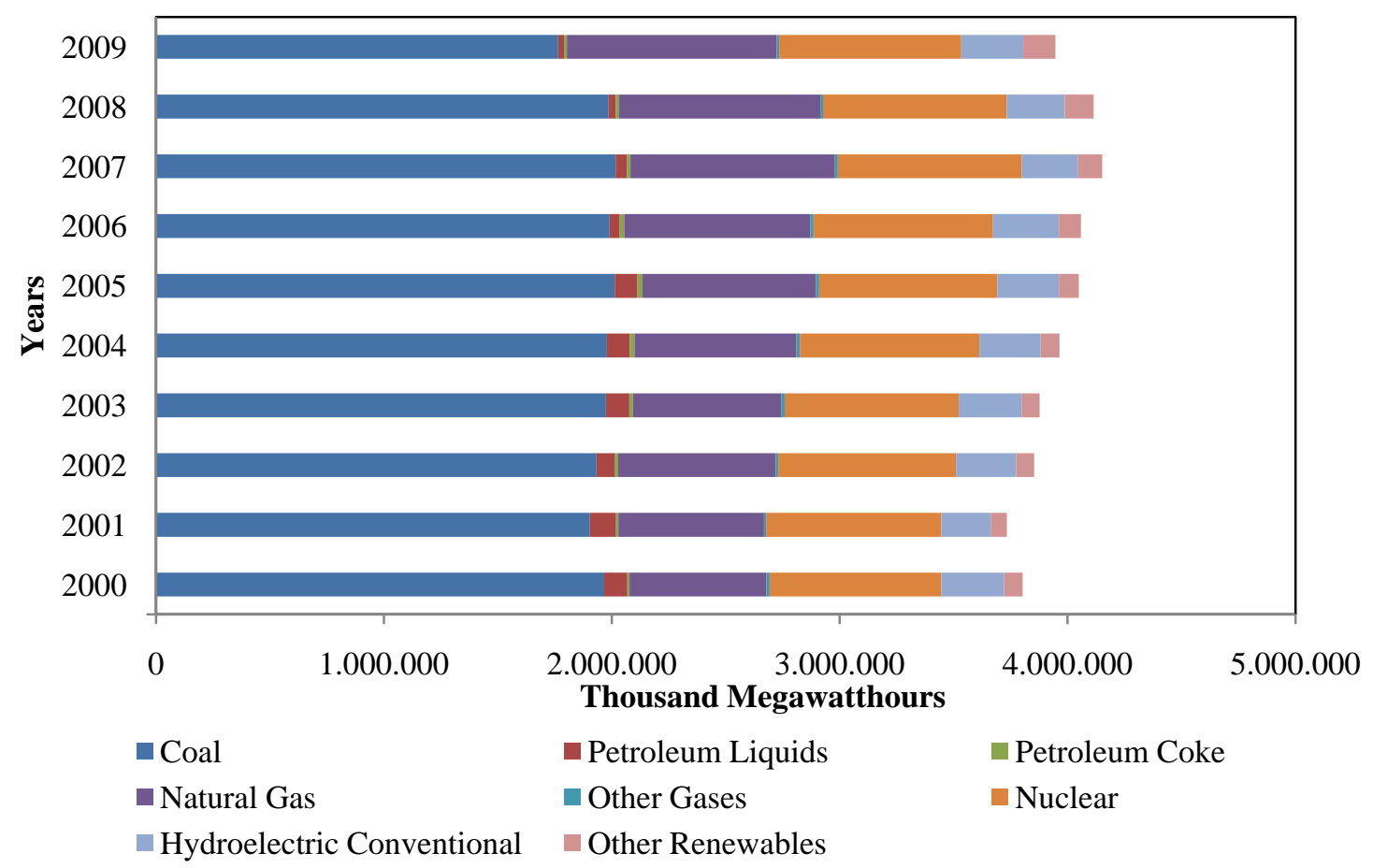

Figure 1.1 World net electricity generation by fuel [1]. 
In the following 25 years, the share of coal in electricity production will remain the same at $42 \%$, while renewables will show slight increase [3]. Yet, coal will still maintain its major energy source role.

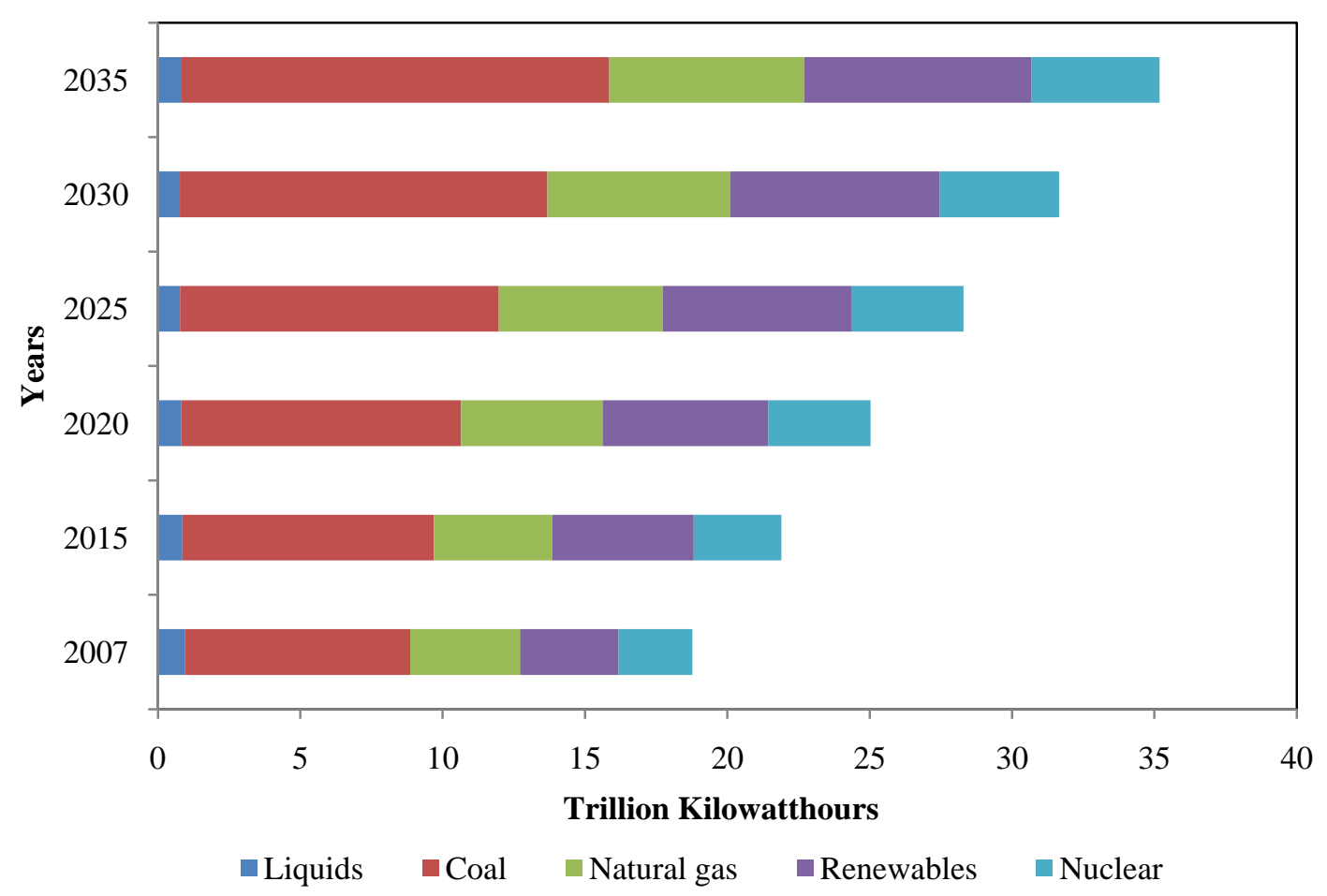

Figure 1.2 Future projections of the fuels in electricity generation [3].

Besides these mentioned importance of coal, it is the most distributed energy source around the world according to the Statistical Review of World Energy 2010 made by BP [2]. Other types of energy resources are concentrated in certain areas such as Middle East, Europe and Eurasia. Coal, however, is available more than 100 countries distributed in all continents, with high reserve/consumption ratio (nearly 119 years) compared to other types of fuels which results in low price and continous supply [2]. 


\subsection{ELECTRICAL ENERGY REVIEW OF TURKEY}

In Turkey, plants utilizing hydro power has a dominancy on plants utilizing natural gas and coal regarding installed capacity. Among the fossil fuels, natural gas has the share of $61.3 \%$ and it is predicted to conserve its leading position in electrical energy production from fossil fuels [4].

It is unlikely to switch to another energy source for transportation since significant technological improvement is necessary in short term. In addition, due to environmental issues, utilization of natural gas in residential heating is necessary. However, in electrical energy generation, utilization of coal dominates other sources all around the world. In order to increase the use of indigenous reserves, and to diversify the utilized energy sources in electricity generation, lignite should be considered.

Turkey has distributed lignite reserves nearly all over the country. One of the characteristics of lignite is its low heating value. These heating values vary between $1,000-5,000 \mathrm{kcal} / \mathrm{kg}$ with $79.9 \%$ of the lignite has the heating value lower than $2500 \mathrm{kcal} / \mathrm{kg}$ [5].

The other possible energy sources for electricity production in Turkey are; hard coal and asphaltite. Hard coal reserves are mostly located in Northert part of the country. It has a higher calorific value (varying between $5,500-6,000 \mathrm{kcal} / \mathrm{kg}$ ) than lignite with lower moisture and ash contents. Yet, due to high cost of mining it is not likely to utilize this resource in electricity generation other than the power plant located in Çatalağzı [6]. Asphaltite reserves are mostly located in southeastern part of the country. Although, asphaltite has higher calorific value $(5,500 \mathrm{kcal} / \mathrm{kg})$ than lignite, it has a high sulfur content similar to lignite. In addition, both hard coal and asphaltite reserves are lower than the 3.9 billion tones 
of operatable lignite reserves, which are 1.1 billion tones and 79 million tones respectively. Hence, it can be concluded that lignite seems to be the only indigenous coal option in power generation.

Lignite reserves are utilized mostly in pulverized coal firing systems. This is a technology used by the countries having high quality coals. Yet, Turkish lignite has high moisture, ash and sulfur contents and should be utilized accordingly. Due to lignites having low ash fusion temperatures, using them in pulverized coal boilers results in the sticking of the lignite ash on heat transfer surfaces hence retarding the rate of heat transfer from the combustion side. In order to compensate this, coal feed is increased. But, this leads to higher gaseous pollutant emissions as well as high coal consumption [7]. Therefore, introduction of clean coal combustion technologies is necessary.

\subsection{AIM AND SCOPE OF THESIS}

Advantages of circulating fluidized bed combustion (CFBC) technology such as the ability to burn wide variety of fuels efficiently and environmentally friendly have led to a steady increase in its commercial use over the past decades. Increasing number of CFB boiler installations has led to the development of mathematical models in order to analyze new design, to optimize the process and to predict the emission and thermal performances over a broad range of operating conditions. There exists a significant number of studies on mathematical modeling of CFBCs burning high calorific value coals in open literature [8-17]. However, a comprehensive model that considers combustion of low quality coals such as lignites and its validation against measurements is not available to date.

Although this technology is regarded as a mature technology with its well-known low $N O_{x}$ emission due to uniform and low combustion temperature, dependence 
on local coal properties and the trend in increasingly restrictive legislations on emissions have been keeping the topic attractive for further research.

Lignite is not only the world's most abundant fossil fuel, but also one of the two major indigenous sources of energy in Turkey with an estimated quantity of 12.4 billion tons of reserves. This resource is characterized by low calorific value, high volatile matter and ash contents. Adaptation of CFB combustion technology to these resources necessitate development of comprehensive CFBC models as well as measurements taken on CFBC test facilities for testing the predictive accuracy of these models. These measurements have recently been made available on a 150 $\mathrm{kW}_{\mathrm{t}}$ CFBC Test Facility fired with an indigenous lignite in Chemical Engineering Department of Middle East Technical University (METU). The present study provides an extension of a comprehensive model [17] previously developed and validated against experimental data taken on a $0.3 \mathrm{MW}_{\mathrm{t}} \mathrm{CFBC}$ fired with high calorific value coal burning in sand for incorporation of $N O$ formation and reduction reactions and pressure drops around cyclone, downcomer and loop seal. The model is based on conservation equations for energy and chemical species in conservative form for both dense and dilute zones considering hydrodynamics, volatiles release and combustion, char combustion, char particles temperature and size distribution, heat transfer to both cooling water channels and refractory for steady state simulation of CFBCs. Assessment of predictive accuracy of the model was carried out by applying it to the prediction of the steady state behaviour of METU $150 \mathrm{~kW}_{\mathrm{t}}$ Atmospheric CFBC Test Rig and comparing its predictions with measurements available on the same rig. 


\section{CHAPTER 2}

\section{LITERATURE SURVEY ON CFBC MODELING}

\subsection{OVERVIEW}

To improve designs and operating conditions of existing or new boiler systems, mathematical modeling of circulating fludized bed combustion is crucial. Since modeling all the aspects included in CFBCs is challenging, researchers developed different approaches for the best representation of the physical and chemical phenomena occuring in the combustor. In this chapter, previous modeling studies on CFBCs are presented.

\subsection{PREVIOUS STUDIES ON STEADY-STATE CFBC MODELING}

Being one of the earliest studies in this area, Hyppanen et al. [8] developed a three-dimensional model to study the performance of an industrial size CFB utilizing Colombian Coal. Model basically includes volatile matter, char combustion, sulfur removal, fundamental mass balance equations based on reaction rates, attrition, fragmentation, bed drain discharge and cyclone efficiency. In order to account for particle size distribution inside the combustor, five particle size fractions are utilized. Results of the model was presented in three dimensions. These are oxygen concentration, volatiles weight fraction, gas velocity, sulfur 
dioxide and temperature profiles. Effects of solid-flow profile, secondary air injection and non-uniform devolatilization were studied on these results. Comparison and validation of the model results with the experimental data were not carried out.

Following Hyppanen et al., Hannes et al. [9] presented a 1.5D mathematical model for an industrial scale CFB. This model includes dense bed, transition and freeboard zones in hydrodynamics, gas exchange between bubble and emulsion phases and gas exchange between core and annulus phases regarding fluidization and hydrodynamics. Fragmentation, attrition, shrinking, exit effects, cyclone efficiency and bottom bed discharge were taken into consideration in solid balances. Results were presented as gas concentration and furnace temperature profiles in axial direction. Satisfactory agreement was reported between measurements and predictions.

Again, in another study of Hannes et al. [10], 1.5D steady-state model was introduced. Model considers combustor hydrodynamics as dense zone with a probability for disappearing under high superficial velocities and dilute zone with exponential solids decay. Solid material in the combustor were classified depending on cyclone efficiency, segregation in bed drain, discharge and abrasivity of particles. Homogeneous and catalytic reactions were taken into account for $N O_{x}$ formation and reduction and sulfur retention. Core and annulus phases were assumed to be present. Combustion and gas reactions were considered as coal drying, devolatilization and char combustion. Comparison of the model results were carried out against the experimental data obtained from four different industrial scale CFBs utilizing high calorific value coals. Although, satisfactory agreement was reported for plant performance prediction, it was pointed out that there exists a necessity for a better understanding of the $N O_{x}$ formation processes. 
A CFB process model is developed by Remberg et al. [11] which enables to examine the complete behavior of the FBC or single process units. Process model was divided into two which are configuration and mathematical models. Each are composed of gas turbine, furnace and water steam parts. These parts were examined by utilizing fundamental balance equations, models, constitutive and constraint equations. In the furnace part, in addition to balance equations, particle size distribution of char, limestone and ash, fluid dynamics, coal drying and devolatilization, gas phase reactions and gas-solid reactions, heat transfer from/to ash particles, char particles and heat exchange surfaces were taken into consideration. Results were presented for steady-state operation in terms of temperature, pressure drop and voidage profiles. Validation of the model prediction with the experimental findings was not presented in the study.

Another comprehensive CFBC model is developed by Gharebaagh et al. [12] This model is composed of hydrodynamic parameters, reaction model and kinetic subroutines. The CFBC is divided into two different hydrodynamic regions, which are turbulent dense zone and exponentially decaying dilute zone. Dilute zone is composed of acceleration and fully developed zones in both of which only axial variation is taken into account. Reaction model is like most CFBC models composed of devolatilization, volatile combustion, char combustion, $N O_{x}$ formation and $\mathrm{SO}_{2}$ adsorption. In the results; $\mathrm{NO}_{x}$ emissions, $\mathrm{O}_{2}$ concentration profile, combustion efficiency, $\mathrm{SO}_{2}$ emission, $\mathrm{CO}$ emissions were presented. The comparison of these results were done against 14 different operating conditions of CANMET CFBC. The agreement between model predictions and experimental data were found to be satisfactory.

In the study of Ducarne et al. [13], combustion of municipal solid waste in a 25 $\mathrm{kW}_{\mathrm{t}} \mathrm{CFB}$ was examined. Formation and destruction of various gaseous pollutants are included in the scope of this study. For the description of axial voidage profile, 
a model which employs bed height in an exponential function for the calculation of bed density is utilized. In the dense zone, it is assumed that gas and the solids are perfectly mixed and both dense and dilute zones are assumed to be in plug flow. Devolatilization of waste particles, combustion of char and volatiles, acid gas recapturing by calcium, homogeneous and heterogeneous reactions for $N O$ and $\mathrm{N}_{2} \mathrm{O}$ formation and reduction are considered in the model. The effects of temperature, excess air, addition of calcium, moisture of waste and air staging were examined by comparing model results with the experimental data. Two different carbon combustion mechanisms are included in the model. The first considers shrinkage of char, i.e. decrease in diameter, and the second considers decrease in density of the char particle, as the char particle burns. Both models were reported to give satisfactory agreement with the measurements.

Impact of horizontal solid and gas mixing was examined by Knoebig et al. [14] on CFBs with low height to diameter ratio. In this study, three-dimensional model of combustion of coal in a circulating fluidized bed with a rectangular cross-section is developed. The bottom fluidization regime is assumed as bubbling and the upper fluidization regime is assumed as dilute upward flowing solid suspension and dense downward flowing cluster phase near the combustor wall. Since both radial and axial variation in flow structure were considered, flow in the dilute zone is assumed to be fully developed. The model is basically composed of three parts which are, gas-solid flow structure, reaction kinetic model for local combustion and convection and dispersion of gaseous species with reactions. The model was set to simulate the $12 \mathrm{MW}_{\mathrm{t}} \mathrm{CFB}$ boiler in Chalmers University of Technology, results of which was intended to be utilized for future $\mathrm{NO}, \mathrm{N}_{2} \mathrm{O}$ and $\mathrm{SO}_{2}$ emission predictions. It was stated that results suggest strong influence of gas and solids mixing on gaseous emissions of the CFB. 
Another coal combustion model in CFBC was proposed by Huilin et al. [15]. The model includes combustion of char particles, hydrodynamics and heat transfer in both dense and dilute zones. The flue gas temperature, the chemical gas species concentrations and char concentration were predicted by the model. From the hydrodynamics point of view, the dense zone fluidization regime was assumed to be turbulent bubbling regime which differs from bubbling beds in calculations of bubble diameter and particle velocities. In dilute zone, again variations in both axial and radial directions are taken into account. Instantaneous drying and timedependent devolatilization of char particles are assumed. Since time required for volatile combustion is relatively small, it is also assumed to take place instantaneously. Shrinking core model, including both controls of chemical reaction and gas film diffusion, is employed. Results are presented as gaseous species concentrations, gas temperature, char particles' concentration, heat flux and $\mathrm{SO}_{2}$ concentration. Although it was reported that validation of the model was carried out utilizing the experimental findings from the $35 t / h$ commercial CFB boiler with low circulation, it is also stated that there is a need for more experimental data for the confirmation of the model's reliability.

In the study of Adanez et al. [16], a mathematical model, including turbulent CFB hydrodynamics, the kinetics of coal combustion and sulphur retention, was presented. The impacts of temperature, excess air, air velocity, $\mathrm{Ca} / \mathrm{S}$ molar ratio, coal and limestone particle size distributions on carbon combustion efficiency and sulphur retention were examined. For the experimental validation, two different types of coals were used in the experiments one of which have high $V M / F C$ and moisture content and the other have lower $V M / F C$ and moisture content. Turbulent fluidization regime is assumed in the dense zone. For the voidage prediction, parameters of the correlation proposed by Werther and Wein [18] are adjusted. Core-annulus flow structure with exponential decrease of the bulk density with the furnace height is assumed for axial voidage profile estimation. 
Exponential decay coefficient to be utilized for voidage calculations is obtained from adjusting the constants used in the equation given by Adanez et al. [19], to have favorable comparison with the experimental findings. In addition to these, char population balance and sulphur retention were also included in the model. As a result, carbon combustion efficiency and sulphur retention capability of the bed were predicted for various operating conditions. A good comparison was reported between the predictions and the experimental data.

Besides these reviewed studies, modeling of coal combustion in CFBCs are further performed by researchers for multipollutant control, coupling heat transfer with radiative heat transfer models, effect of riser exit geometries on axial bed-towall heat transfer and particulate clustering effects on desulphurization and $N O$ emission [20, 21, 22, 23, 24].

In the recent studies of Gungor et al. [25, 26, 27], burning of Turkish lignite in CFB conditions was investigated. In these models, bottom zone is assumed to be bubbling fluidized bed in turbulent fluidization regime and core-annulus flow structure is considered in the upper zone. Although core-annulus flow is assumed in dilute zone, these models were given as 1D models. Yet, no input parameters were presented which are required for core-annulus flow such as external solids circulation rate, downward solids velocity and solid volume fraction of strands and clusters. Limited number of particle size classifications is taken into account with no governing equation for char population balance that is essential to account for the actual phenomena. There exists no temperature profile prediction along the combustors and for the temperature dependent parameters a mean temperature value is utilized $[26,27,28]$. Validation of the models were performed on CFBCs operating above the atmospheric pressure, however models were developed for atmospheric conditions. 
Present study, on the other hand, provides a model based on conservation equations for energy and chemical species in conservative form for both dense and dilute zones considering hydrodynamics, volatiles release and combustion, char combustion, char particles' temperature and size distribution and heat transfer to both waterwalls and refractory for steady-state simulation of an atmospheric $150 \mathrm{~kW}_{\mathrm{t}} \mathrm{CFBC}$ utilizing Turkish lignite. 
Table 2.1 Summary of steady-state CFBC models in literature.

\begin{tabular}{|c|c|c|c|c|c|c|c|c|c|c|}
\hline Reference & Year & 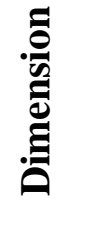 & $\mathbf{A}$ & B & $\mathbf{C}$ & D & $\mathbf{E}$ & $\mathbf{F}$ & $\mathbf{G}$ & $\mathbf{H}$ \\
\hline $\begin{array}{c}\text { Hyppanen } e t \\
\text { al. [8] }\end{array}$ & 1991 & $3 \mathrm{D}$ & YES & $\mathrm{NO}$ & YES & YES & YES & YES & $\mathrm{NO}$ & $\mathrm{NO}$ \\
\hline $\begin{array}{c}\text { Hannes et al. } \\
{[9,10]}\end{array}$ & $\begin{array}{c}1995 \\
\& \\
1997\end{array}$ & $1.5 \mathrm{D}$ & YES & YES & YES & YES & YES & YES & YES & YES \\
\hline $\begin{array}{c}\text { Remberg et al. } \\
{[11]}\end{array}$ & 1997 & $1 \mathrm{D}$ & YES & YES & YES & YES & YES & YES & YES & NO \\
\hline $\begin{array}{c}\text { Gharebaagh } e t \\
\text { al.[12] }\end{array}$ & 1998 & $1 \mathrm{D}$ & YES & $\mathrm{NO}$ & YES & YES & YES & YES & YES & YES \\
\hline $\begin{array}{c}\text { Ducarne et al. } \\
\text { [13] }\end{array}$ & 1998 & $1 \mathrm{D}$ & YES & NO & YES & $\mathrm{NO}$ & YES & YES & YES & YES \\
\hline $\begin{array}{c}\text { Knoebig et } \\
a l .[14]\end{array}$ & 1999 & $3 \mathrm{D}$ & YES & NO & YES & YES & $\mathrm{NO}$ & $\mathrm{NO}$ & $\mathrm{NO}$ & $\mathrm{NO}$ \\
\hline $\begin{array}{c}\text { Huilin et } \\
\text { al.[15] }\end{array}$ & 2000 & 1D & YES & YES & YES & YES & YES & YES & $\mathrm{NO}$ & YES \\
\hline $\begin{array}{c}\text { Adanez et } \\
\text { al.[16] }\end{array}$ & 2001 & $1.5 \mathrm{D}$ & YES & YES & YES & YES & YES & YES & $\mathrm{NO}$ & YES \\
\hline Mao et al.[20] & 2004 & $3 \mathrm{D}$ & YES & $\mathrm{NO}$ & $\mathrm{NO}$ & $\mathrm{NO}$ & $\mathrm{NO}$ & YES & $\mathrm{NO}$ & $\mathrm{NO}$ \\
\hline Hua et al.[21] & 2005 & $3 \mathrm{D}$ & YES & YES & $\mathrm{NO}$ & $\mathrm{NO}$ & YES & $\mathrm{NO}$ & $\mathrm{NO}$ & YES \\
\hline $\begin{array}{c}\text { Göğebakan } \\
{[17]}\end{array}$ & 2006 & $1.5 \mathrm{D}$ & YES & YES & YES & YES & YES & $\mathrm{NO}$ & $\mathrm{NO}$ & YES \\
\hline $\begin{array}{c}\text { Gungor } \text { et al. } \\
{[25,26,27]}\end{array}$ & $\begin{array}{c}2007 \\
\& \\
2009\end{array}$ & $1 \mathrm{D}$ & YES & NO & YES & YES & $\mathrm{NO}$ & YES & YES & YES \\
\hline
\end{tabular}


Table 2.1 Summary of steady-state CFBC models in literature (cont'd).

\begin{tabular}{|c|c|c|c|c|c|c|c|c|c|c|}
\hline Reference & Year & 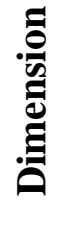 & $\mathbf{A}$ & B & $\mathbf{C}$ & D & $\mathbf{E}$ & $\mathbf{F}$ & $\mathbf{G}$ & H \\
\hline $\begin{array}{c}\text { Gnanapragasam } \\
\text { et al.[22] }\end{array}$ & 2008 & $1 \mathrm{D}$ & YES & $\mathrm{NO}$ & $\mathrm{NO}$ & $\mathrm{NO}$ & YES & $\mathrm{NO}$ & NO & $\mathrm{NO}$ \\
\hline $\begin{array}{c}\text { Shuyan } e t \\
\text { al.[23] }\end{array}$ & 2008 & $2 \mathrm{D}$ & YES & $\mathrm{NO}$ & $\mathrm{NO}$ & $\mathrm{NO}$ & $\mathrm{NO}$ & YES & YES & $\mathrm{NO}$ \\
\hline $\begin{array}{c}\text { Gnanapragasam } \\
\text { et al. }[24]\end{array}$ & 2008 & $2 \mathrm{D}$ & YES & $\mathrm{NO}$ & $\mathrm{NO}$ & $\mathrm{NO}$ & YES & $\mathrm{NO}$ & $\mathrm{NO}$ & YES \\
\hline $\begin{array}{c}\text { Gungor et } \\
\text { al.[28] }\end{array}$ & 2009 & $2 \mathrm{D}$ & YES & NO & YES & YES & $\mathrm{NO}$ & $\mathrm{NO}$ & YES & YES \\
\hline
\end{tabular}

\section{Nomenclature}
A: Hydrodynamics
B: Particle Size Distribution
C: Char Combustion
D: Volatiles Relase and Combustion
E: Energy Balance
$\mathrm{F}: S O_{x}$ Retention
G: $N O_{x}$ Emission
H: Validation 


\section{CHAPTER 3}

\section{STEADY-STATE CFBC MODEL WITH NO FORMATION AND REDUCTION}

The physical system under consideration is a continuously operated CFBC fed with coal of wide size distribution and equipped with cyclone, downcomer and loop seal. Removal of heat is achived by cooling channels placed around the refractory.

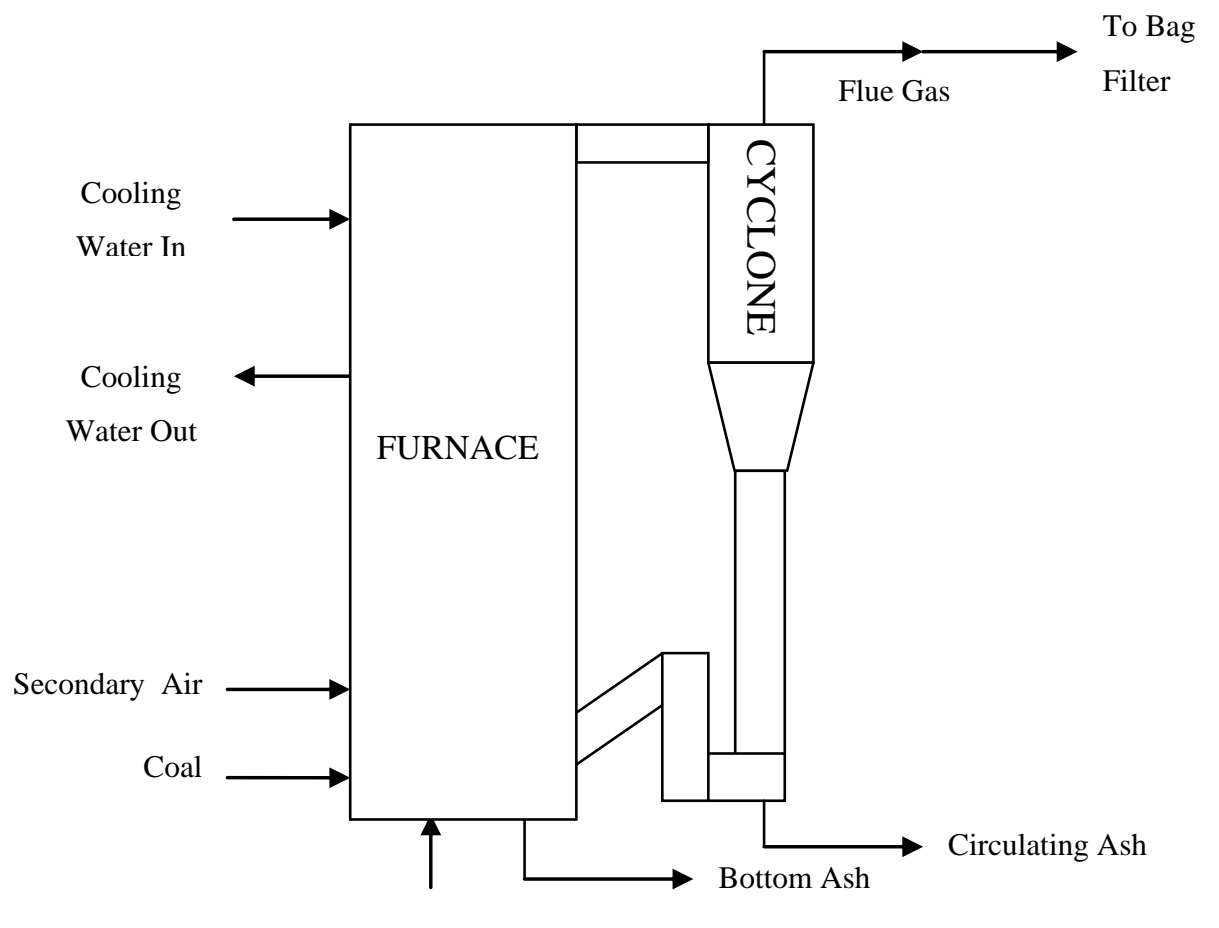

Primary Air

Figure 3.1 Schematic diagram of the physical system. 


\subsection{HYDRODYNAMICS}

Fluidization regime and flow characteristics in a fluidized bed combustor determine the pressure drop along the combustor and residence time of particles which are the essential components of design and modeling studies. Besides these, gas and solids contact area, heat and mass transfer rates and reaction kinetics parameters are highly influenced by hydrodynamics of the riser.

There is a common agreement in many modeling studies which divides the CFBC riser into two hydrodynamically differring regions. These are called dense and dilute zones as named by their amount of solid material content [29, 30, 31, 32].

In the study of Basu and Fraser [33], it is reported that the dense zone is assumed to be between the distributor plate and secondary air injection in many CFBCs. Hence, in this study dense zone is assumed to be between the distributor plate and the secondary air port.

\subsubsection{Dense Zone Hydrodynamics}

Due to high solid content, dense zone in the CFBC riser is important. There are two main fluidization regime assumptions stated in the literature which are bubbling and turbulent bed fluidization regimes [34, 35, 36, 37].

According to the study of $\mathrm{Bi}$ et al. [38], turbulent fluidization regime is between bubbling and fast fluidization regimes. In order to spot the fluidization regime in the dense zone, a parameter called bubble to turbulent transition velocity is calculated. Dense zone, having superficial velocity under this calculated velocity is assumed to be in bubbling fluidization regime while higher superficial velocity represents turbulent bed conditions. 
There are many empirical correlations estimating bubbling to turbulent transition velocity. Used parameters, correlations and estimated transition velocities are shown in Table 3.1 and Table 3.2 respectively.

Table 3.1 Used parameters in the calculation of $u_{c}$.

\begin{tabular}{|c|c|}
\hline Parameter & Value \\
\hline Gas Density, $\left(\rho_{g}\right), \mathrm{kg} / \mathrm{m}^{3}$ & 0.31 \\
\hline Gas Viscosity, $\left(\mu_{g}\right), N \cdot \mathrm{s} / \mathrm{m}^{2}$ & $4.6 \times 10^{-5}$ \\
\hline Particle Density, $\left(\rho_{p}\right), \mathrm{kg} / \mathrm{m}^{3}$ & 1850 \\
\hline Average Particle Size, $\left(d_{p}\right), \mu m$ & 1550 \\
\hline
\end{tabular}

Table 3.2 Correlations and estimations for transition velocities.

\begin{tabular}{|c|c|c|}
\hline Reference & Correlation & $\begin{array}{c}\text { Estimated Transition } \\
\text { Velocity }\left(\boldsymbol{u}_{\boldsymbol{c}}, \boldsymbol{m} / \boldsymbol{s}\right)\end{array}$ \\
\hline Lee and Kim[39] & $R e_{c}=0.7 A r^{0.485}$ & 5.80 \\
\hline Leu et al.[40] & $R e_{c}=0.568 A r^{0.578}$ & 11.12 \\
\hline Horio[41] & $R e_{c}=0.936 A r^{0.472}$ & 6.88 \\
\hline Nakajima et al.[42] & $R e_{c}=0.663 A r^{0.467}$ & 4.65 \\
\hline Bi and Grace[43] & $R e_{c}=1.243 A r^{0.447}$ & 7.25 \\
\hline Bi and Grace[43] & $R e_{c}=0.565 A r^{0.461}$ & 3.75 \\
\hline
\end{tabular}

From Table 3.2, it can be seen that estimated transition velocities vary widely. Therefore, average of these transition velocities, i.e. $6.57 \mathrm{~m} / \mathrm{s}$, is considered. Since this value is above the typical dense zone gas velocities encountered in CFBCs $(\sim 5 \mathrm{~m} / \mathrm{s})$, dense zone fluidization regime of the combustor is assumed to be bubbling. 
Hydrodynamic representation of the dense zone is obtained by modified twophase model of Johnson et al. [44] which is developed for Geldart Group B and D particles under high gas velocity. In this study, solid material corresponds to Group D in Geldart Classification according to its fluidization properties.

$$
u_{0}=(1-\delta) u_{m f}+\delta u_{b}+u_{t f}
$$

In Equation (3.1), there are three flow velocities which constitutes overall gas flow. These are,

- The flow through the emulsion phase $\left(u_{m f}\right)$

- The flow of the bubbles $\left(\delta u_{b}\right)$

- The flow through and between the bubbles $\left(u_{t f}\right)$

The main flow assumptions in the dense zone are;

- Well-mixed solids in emulsion phase,

- Gas is assumed to be in plug flow in both phases (bubble and emulsion).

In Equation (3.2), the bubble rise velocity is expressed as [45];

$$
u_{b}=0.711\left(g \bar{d}_{b}\right)^{1 / 2}+u_{0}-u_{m f}
$$

And fraction of bubble phase in the dense zone is estimated by the correlation proposed by Johnsson et al. [44] which is shown in Equation (3.3). 


$$
\delta=\frac{1}{1+\frac{1.3}{f}\left(u_{0}-u_{m f}\right)^{-0.8}}
$$

The parameter $f$ in this equation is defined as,

$$
f=\left[0.26+0.70 \exp \left(-3000 \bar{d}_{p}\right)\right]\left[0.15+\left(u_{0}-u_{m f}\right)\right]^{-0.33}
$$

Another important parameter in dense zone hydrodynamics is the bubble size which is predicted by the correlation given by Darton et al. [46] given in Equation (3.5).

$$
d_{b}(z)=0.54\left(u_{0}-u_{m f}\right)^{0.4}\left(z+4 \sqrt{A_{0}}\right)^{0.8} g^{-0.2}
$$

Bubble phase is assumed to have no solid material content and mean bubble size is estimated by the Equation (3.6).

$$
\bar{d}_{b}=\frac{1}{H_{d}} \int_{0}^{H_{d}} d_{b}(z) d z
$$

In Equation (3.7), spatial and temporal averaged values of the dense zone voidage is given in terms of bubble fraction and voidage at minimum fluidization;

$$
\varepsilon_{g, d}=(1-\delta) \varepsilon_{m f}+\delta
$$

Hence, the volume fraction of solids is;

$$
\varepsilon_{s, d}=1-\varepsilon_{g, d}
$$


Voidage at minimum fluidization is need to be found in order to estimate the gas volume fraction in dense zone, i.e. dense bed voidage. Broadhurst and Becker [47] proposed the correlation given in Equation (3.9) for the estimation of voidage at minimum fluidization conditions.

$$
\varepsilon_{m f}=0.586 \phi_{s}^{-0.72} A r^{-0.029}\left(\frac{\rho_{g}}{\rho_{s}}\right)^{0.021}
$$

In Equation (3.9), $A r$, i.e. Archimedes number, is;

$$
A r=\frac{\rho_{g}\left(\rho_{s}-\rho_{g}\right) \bar{d}_{p}^{3} g}{\mu_{g}^{2}}
$$

In Equations (3.4) \& (3.5), minimum fluidization velocity is needed. This parameter is obtained by the Ergun Equation [48] stated as;

$$
K_{1} R e_{m f}^{2}-K_{2} R e_{m f}-A r=0
$$

where, the parameters $K_{1}, K_{2}$ are defined as;

$$
\begin{gathered}
K_{1}=\frac{1.75}{\varepsilon_{m f}^{3} \phi_{s}} \\
K_{2}=\frac{150\left(1-\varepsilon_{m f}\right)}{\varepsilon_{m f}^{3} \phi_{s}^{2}}
\end{gathered}
$$

Solving Equation (3.11) for $R e_{m f}$; 


$$
R e_{m f}=\sqrt{\frac{1}{4}\left(\frac{K_{2}}{K_{1}}\right)^{2}+\left(\frac{1}{K_{1}}\right) A r-\frac{1}{2}\left(\frac{K_{2}}{K_{1}}\right)}
$$

Hence, minimum fluidization velocity is;

$$
u_{m f}=\frac{R e_{m f} \mu_{g}}{d_{p} \rho_{g}}
$$

Considering modified two phase model and utilization of bubble fraction for the dense zone yields the bubble flow fraction as,

$$
Q_{b}=A_{d} \delta u_{b}
$$

and emulsion phase flow rate is;

$$
Q_{e}=A_{d}(1-\delta) \varepsilon_{m f} u_{m f}
$$

Then, ratio of the bubble phase flow to the emulsion phase flow is,

$$
\frac{Q_{b}}{Q_{e}}=\frac{u_{b} \delta}{u_{m f}(1-\delta) \varepsilon_{m f}}
$$

Realizing that,

$$
\frac{n_{b}}{n_{e}}=\frac{Q_{b}}{Q_{e}}
$$

Combining Equation (3.19) with (3.18) yields, 


$$
\frac{n_{b}}{n_{e}}=\frac{u_{b} \delta}{u_{m f}(1-\delta) \varepsilon_{m f}}
$$

As mass is conserved at the base of the dense bed;

$$
n_{a, p r i}=n_{b}+n_{e}
$$

Again, combining Equation (3.21) with the Equation (3.20) and rearraging yields molar flow rate in bubble and emulsion phase are stated in Equations (3.22) \& (3.23), respectively.

$$
\begin{aligned}
& @_{Z}=0, n_{b}=n_{a, p r i} \frac{1}{1+\frac{u_{m f}}{u_{b}} \frac{(1-\delta)}{\delta} \varepsilon_{m f}} \\
& @_{Z}=0, n_{e}=n_{a, p r i} \frac{1}{1+\frac{u_{b}}{u_{m f}} \frac{\delta}{(1-\delta) \varepsilon_{m f}}}
\end{aligned}
$$

In the modified two-phase model, gas exchange between bubble and emulsion phases takes place. Since the particles are assumed to exist only in emulsion phase (i.e. bubble phase is particle free), the bubble phase is considered to be $\mathrm{O}_{2}$ rich medium while emulsion phase $\mathrm{O}_{2}$ concentration is low. Besides, there exist some intermediate compounds produced in emulsion phase and further oxidation of these compounds take place in the bubble phase. Hence, gas exchange between these two phases is necessary and crucial. In CFBs, lateral gas exchange coefficient is defined by gas throughflow rate to bubble volume. If diffusive effects on the interphase mass transfer coefficient is ignored, the lateral gas exchange coefficient can be obtained as; 


$$
K_{b e}=4 \frac{u_{t f}}{\bar{d}_{b}}
$$

Finally, as all hydrodynamic parameters are calculated, solid material hold-up $\left(M_{s, d}\right)$ and pressure drop in dense bed $\left(\Delta P_{d}\right)$ are obtained in Equations (3.25) \& (3.26) respectively.

$$
\begin{gathered}
M_{s, d}=\left(\varepsilon_{c, d} \rho_{c}+\varepsilon_{i, d} \rho_{i}\right) V_{d} \\
\Delta P_{d}=\left(\varepsilon_{c, d} \rho_{c}+\varepsilon_{i, d} \rho_{i}\right) g H_{d}
\end{gathered}
$$

\subsubsection{Dilute Zone Hydrodynamics}

To predict the physical and chemical processes taking place in the dilute zone, information on solid material distribution and hydrodynamic structure is necessary. Dilute zone is generally considered to be composed of two phases which are [49];

i) Lean solid suspension with low solids concentration moving in upward direction called core phase.

ii) Dense region with high solids concentration moving in downward direction relative to core phase which is called annulus phase [50, 51].

Although these two phases are distributed into the dilute zone, location of a certain phase mainly depends on its place in the dense zone. Due to the low superficial velocity in the vicinity of the riser wall, annulus phase which has relatively higher solid concentration than the core phase, is located near the riser wall and moves downward. General movement of the core phase is in upward 
direction and located in the middle section relatively far away from the wall. This hydrodynamic phenomena is called core-annulus flow structure [52, 53, 54].

There are various dilute zone hydrodynamic models in the litreature. Yet, the capability of these models to represent the actual physical phenomena in the riser is questionable. In the study of Harris and Davidson [55], modeling of the hydrodynamics in the dilute zone of a CFB is divided classified into 3 categories regarding their approach to the solution of the hydrodynamic problem. The first two, employ assumptions considering the solid volume fraction change only in axial direction or axial and radial direction. Besides these two, there exist models utilizing fundamental equations from fluid dynamics predicting gas-solid flow which constitutes the $3^{\text {rd }}$ category. Although they are appropriate for the prediction of local flow structure CFB risers and effects of geometry [56], they are not widely applied due to their complex flow behavior expression [57].

One of the most common assumption in all modeling studies is that separation of the CFBC riser into hydrodynamically differing regions which are dense zone's having constant volume fraction and dilute zone's having exponentially decaying solid volume fraction. This assumption also holds in this study.

Considering the dilute zone of the riser as variation exists only in axial direction is simple and prediction agrees very well with the experimental results [57]. Only disadvantage is inconvenience of the empirical and semi-empirical coefficients with the experimental conditions.

To decide on the fluidization regime in the dilute zone (i.e. consideration of radial change in suspension density and solid volume fraction is necessary or not) annular layer thickness $\left(\delta_{a}\right)$, which is defined as the radial length from the bed wall to the point where zero particle flux exists in the riser, should be known. This thickness decreases as height in the dilute zone increases. 
Parameters used in the estimation of annular layer thicknesses and calculated thicknesses are shown in Table 3.3 and 3.4 respectively.

Estimated average annular layer thicknesses are ranging from $0.0179 \mathrm{~m}$ to $0.0295 \mathrm{~m}$ and their average is $0.0224 \mathrm{~m}$. Comparing this average with the actual riser diameter of the test rig to be modeled $(0.25 \mathrm{~m})$, and considering the decrease of the annular layer thickness as going up in the riser, it can be concluded that the net effect of annular layer on the physical and chemical phenomena in dilute zone is minimum. Hence, solid volume fraction and suspension density in the dilute zone are assumed to change in only axial direction in this study.

Table 3.3 Parameters used in the estimation of annular layer thickness.

\begin{tabular}{|c|c|}
\hline Riser Diameter $(D), m$ & 0.25 \\
\hline Riser Overall Height, $(H), m$ & 8 \\
\hline Superficial Gas Velocity in the Riser, $\left(u_{g}\right), \mathrm{m} / \mathrm{s}$ & 5.10 \\
\hline Particle Density, $\left(\rho_{p}\right), \mathrm{kg} / \mathrm{m}^{3}$ & 1850 \\
\hline Reynolds number based on riser diameter, $\left(\mathrm{Re}_{D}\right),-$ & 8783 \\
\hline Froude number based on riser diameter, $\left(F r_{D}\right),-$ & 10.61 \\
\hline Average of cross-sectional voidage, $\bar{\varepsilon}_{s},-$ & 0.34 \\
\hline Solids circulation rate, $G_{s}, \mathrm{~kg} / \mathrm{m}^{2} s$ & 0.019 \\
\hline
\end{tabular}


Table 3.4 Correlations utilized for estimation of annular layer thickness.

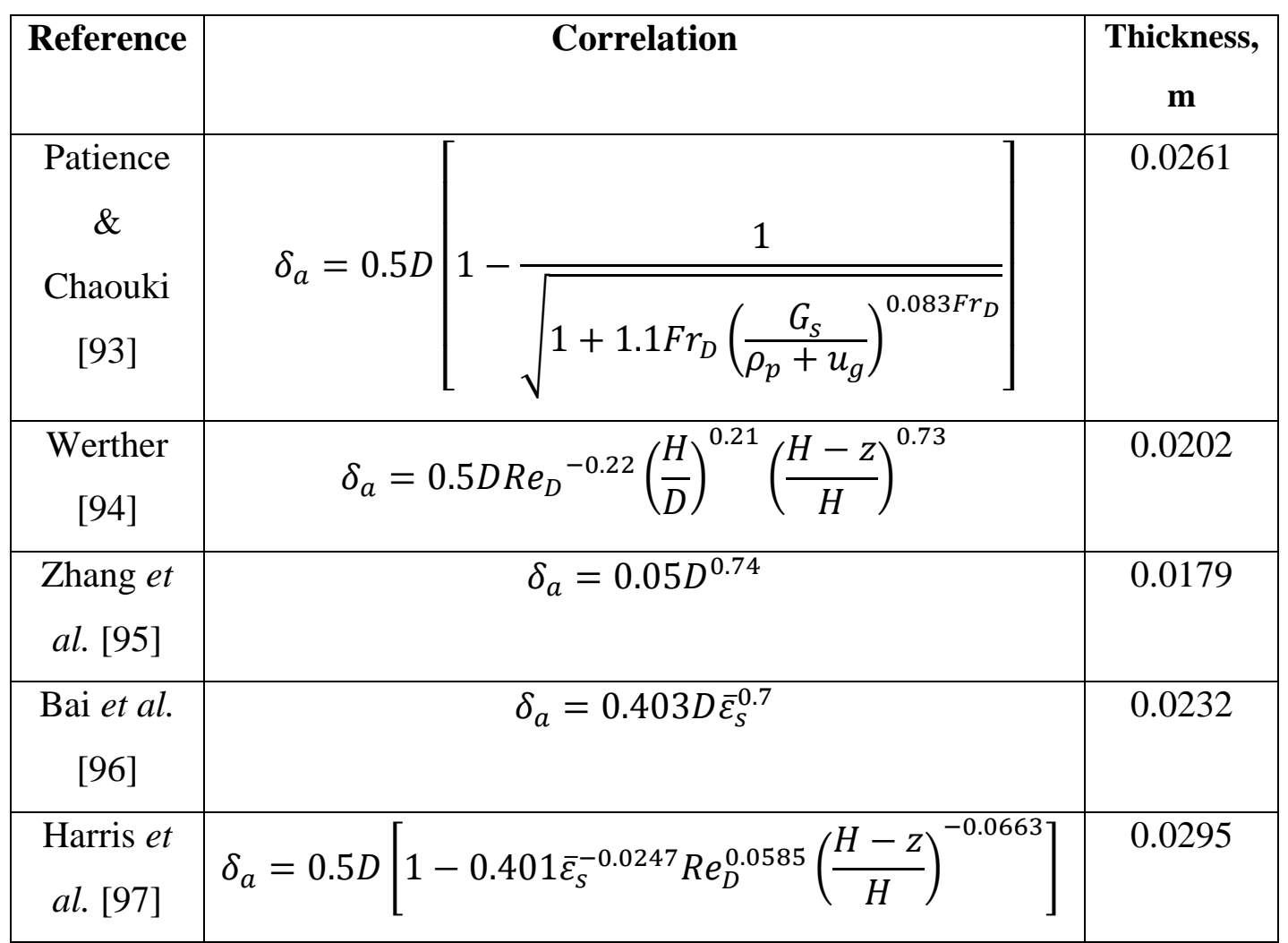

Dilute zone starts from the surface of the dense zone and ends at the riser exit. Solid volume fraction in dilute zone shows an exponential decrease as the height increases $[49,58]$.

In the study of Kunii and Levenspiel, exponential decrease in solid material content is described as shown below,

$$
\varepsilon_{s, f}(z)=\varepsilon_{s, d} \exp (-a z)
$$

where $a$ is the decay coefficient of entrainment and $\varepsilon_{s, d}$ is the volume fraction of solids at the surface of dense zone. In the study of Choi et al. [59], empirical 
correlation is given for the prediction of solid material distribution in the dilute zone which uses gas velocity, temperature, particle size and density.

$$
\begin{gathered}
a=\frac{1}{d_{p}} \exp \left(-11.2+210 \frac{d_{p}}{D_{t}-d_{p}}\right)\left[\frac{d_{p} \rho_{g}\left(u_{0}-u_{m f}\right)}{\mu_{g}}\right]^{-0.492} \\
{\left[\frac{\rho_{g} g d_{p}}{\rho_{g}\left(u_{0}-u_{m f}\right)^{2}}\right]^{0.725}\left(\frac{\rho_{p}-\rho_{g}}{\rho_{g}}\right)^{0.731} C_{d}^{-1.47}}
\end{gathered}
$$

and drag coefficient $C_{d}$ is given by,

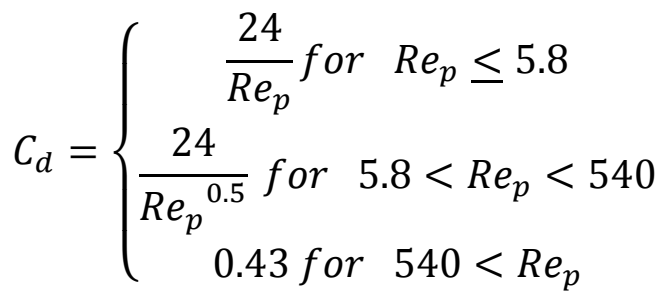

and definition of particle Reynolds number, $R e_{p}$, is

$$
R e_{p}=\frac{d_{p} u_{0} \rho_{g}}{\mu_{g}}
$$

Equation (3.28) is valid for riser diameters from 0.05 to $0.4 \mathrm{~m}$, particle diameters from 46 to $720 \mu \mathrm{m}$, particle densities from 930 to $3050 \mathrm{~kg} / \mathrm{m}^{3}$ gas velocities from 0.3 to $6.2 \mathrm{~m} / \mathrm{s}$, and temperatures from 24 to $600^{\circ} \mathrm{C}$ [59].

Estimation of solid volume fraction distribution along the dilute zone is done by combining Equation (3.27) with (3.28). Solid material volume fraction at the dense zone surface is, 


$$
\varepsilon_{s, o}=\varepsilon_{s, d} \frac{u_{0, d}}{u_{0, f}}
$$

and the char and inert particles' volume fractions at dense zone surface are given in Equations (3.32) \& (3.33) respectively.

$$
\begin{aligned}
& \varepsilon_{c, o}(r)=\varepsilon_{s, o} \frac{M_{c, d} P_{c, d}(r) \Delta / \rho_{c}}{\frac{M_{c, d}}{\rho_{c}}+\frac{M_{i, d}}{\rho_{i}}} \\
& \varepsilon_{i, o}(r)=\varepsilon_{s, o} \frac{M_{i, d} P_{i, d}(r) \Delta r / \rho_{i}}{\frac{M_{c, d}}{\rho_{c}}+\frac{M_{i, d}}{\rho_{i}}}
\end{aligned}
$$

With the use of Equation (3.27), char and inert particles' volume fraction with size $r$ at height $z$ in the dilute zone is estimated as given in Equations (3.34) \& (3.35) below,

$$
\begin{gathered}
\varepsilon_{c, f}(r, z)=\varepsilon_{c, o}(r) \exp \left(-a_{c} z\right) \\
\varepsilon_{i, f}(r, z)=\varepsilon_{i, o}(r) \exp \left(-a_{i} z\right)
\end{gathered}
$$

Net upward velocity of the particles is equal to the difference between gas velocity and their terminal velocity, which is given in Equation (3.36).

$$
u_{s}=\left(u_{g}-u_{t}\right)
$$

Calculation of the char and inert particles are achieved by the use of the definition of terminal velocity and given as, 


$$
\begin{aligned}
& E_{c, f}(r, z)=\varepsilon_{c, f}(r, z) \rho_{c}\left(u_{g}-u_{t, c}\right) \\
& E_{i, f}(r, z)=\varepsilon_{i, f}(r, z) \rho_{i}\left(u_{g}-u_{t, i}\right)
\end{aligned}
$$

Terminal velocities of the particles in dilute zone are calculated by the following equations [60],

$$
u_{t}=\left\{\begin{array}{c}
\frac{g\left(\rho_{p}-\rho_{g}\right) d_{p}{ }^{2}}{18 \mu_{g}} \text { for } R e_{t} \leq 0.4 \\
{\left[\frac{4\left(\rho_{p}-\rho_{g}\right)^{2} g^{2} d_{p}{ }^{3}}{225 \rho_{g} \mu_{g}}\right] \text { for } 0.4<R e_{t} \leq 500} \\
{\left[\frac{3.1 g\left(\rho_{g}-\rho_{g}\right) d_{p}}{\rho_{g}}\right]^{0.5} \text { for } 500<R e_{t} \leq 200,000}
\end{array}\right.
$$

where $R e_{t}$ is,

$$
R e_{t}=\frac{d_{p} u_{t} \rho_{p}}{\mu_{g}}
$$

Assuming the possibility of the existance of particles of size $r$ at any height in dilute zone is proportional to their presence in the dense bed, estimation of the size distribution of char and inert particles' is achieved by the following equations.

$$
\begin{aligned}
& F_{c}(z) P_{c, f}(r, z)=E_{c, f}(r, z) A_{f} P_{c, d}(r) \\
& F_{i}(z) P_{i, f}(r, z)=E_{i, f}(r, z) A_{f} P_{i, d}(r)
\end{aligned}
$$


Both sides of Equations (3.41) \& (3.42) are multiplied by $d r$ and integration from $r_{\text {min }}$ to $r_{\text {max }}$ yields,

$$
\begin{gathered}
F_{c}(z)=A_{f} \int_{r_{\text {min }}}^{r_{\max }} E_{c, f}(r, z) P_{c, d}(r) d r \\
F_{i}(z)=A_{f} \int_{r_{\text {min }}}^{r_{\max }} E_{i, f}(r, z) P_{i, d}(r) d r
\end{gathered}
$$

Size distributions of char and inert particles are;

$$
\begin{aligned}
& P_{c, f}(r, z)=\frac{A_{f} E_{c, f}(r, z) P_{c, d}(r)}{F_{c}(z)} \\
& P_{i, f}(r, z)=\frac{A_{f} E_{i, f}(r, z) P_{i, d}(r)}{F_{i}(z)}
\end{aligned}
$$

And finally, solids hold-up in dilute zone, $M_{s, f}$, and pressure drop, $\Delta P_{f}$, are obtained as follows;

$$
\begin{gathered}
M_{s, f}=\left(\bar{\varepsilon}_{c, f} \rho_{c}+\bar{\varepsilon}_{i, f} \rho_{i}\right) V_{f} \\
\Delta P_{f}=\left(\bar{\varepsilon}_{c, f} \rho_{c}+\bar{\varepsilon}_{i, f} \rho_{i}\right) g H_{f}
\end{gathered}
$$




\subsubsection{Pressure Balance Model}

For hydrodynamically steady-state conditions, pressure over the CFBC should be balanced. Schematic diagram and main pressure data points in a CFBC are illustrated in Figure 3.3.

To apply pressure balance around the $\mathrm{CFBC}$, the pressure drop values around the main parts of the combustor should be known. The pressure drop around the downcomer equals to the pressure drop values around the riser, cyclone and loop seal.

$$
\Delta P_{d c}=\Delta P_{l s}+\Delta P_{r}+\Delta P_{c}
$$

The pressure drop values in Equation (3.49) are given as follows;

$$
\begin{aligned}
& \Delta P_{l s}=P_{6}-P_{2} \\
& \Delta P_{r}=P_{2}-P_{4} \\
& \Delta P_{c}=P_{4}-P_{5} \\
& \Delta P_{d c}=P_{5}-P_{6}
\end{aligned}
$$

To predict the experimental conditions pressure drop correlation around the cyclone, downcomer and loop seal are presented in the following sections. 


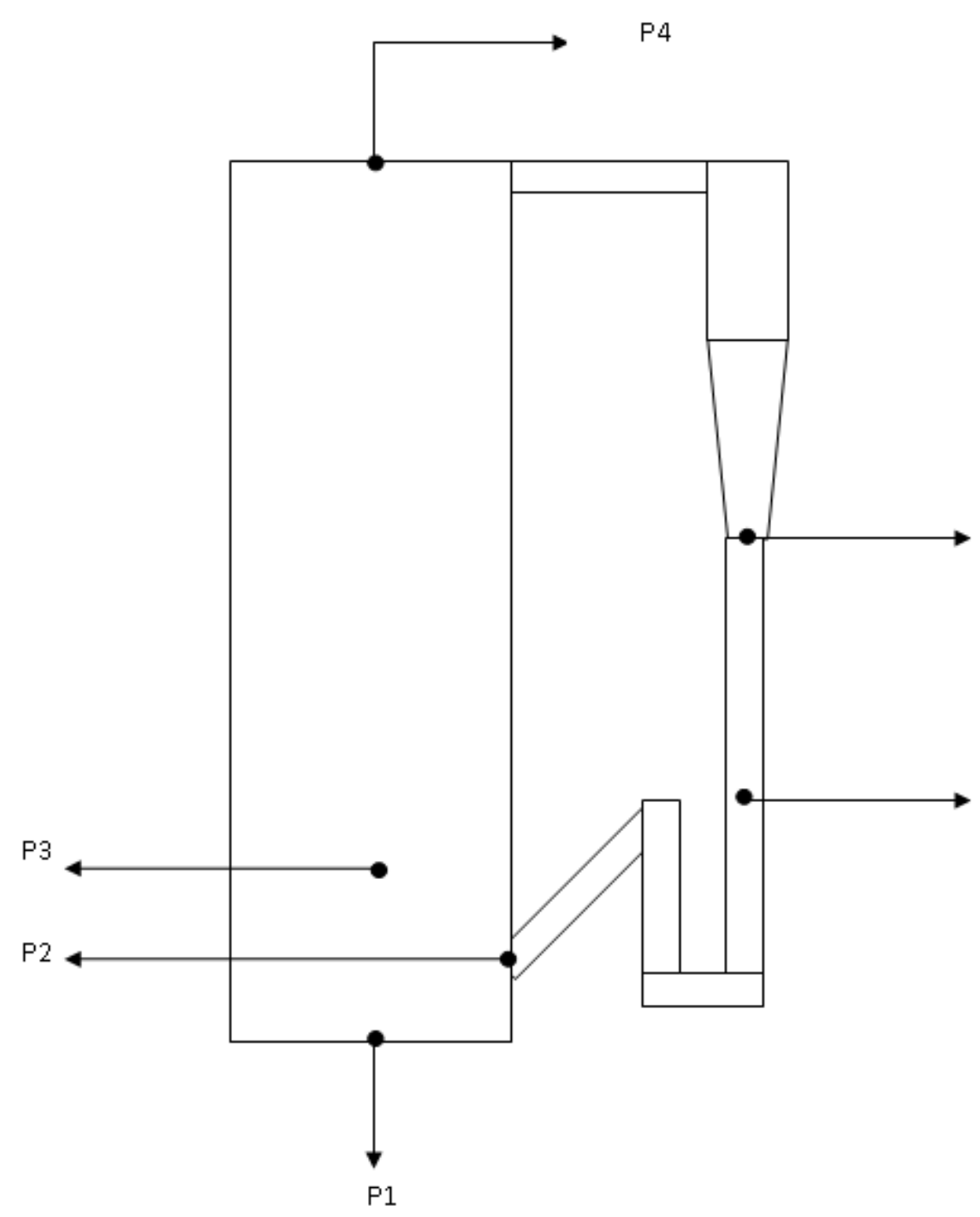

Figure 3.2 Main pressure data points on the CFBC. 


\subsubsection{External Equipments}

\subsubsection{Cyclone}

Cyclones are devices that utilize centrifugal force for the separation of solids from

a gas stream. A schematic diagram of a typical cyclone is illustrated in Figure 3.4.

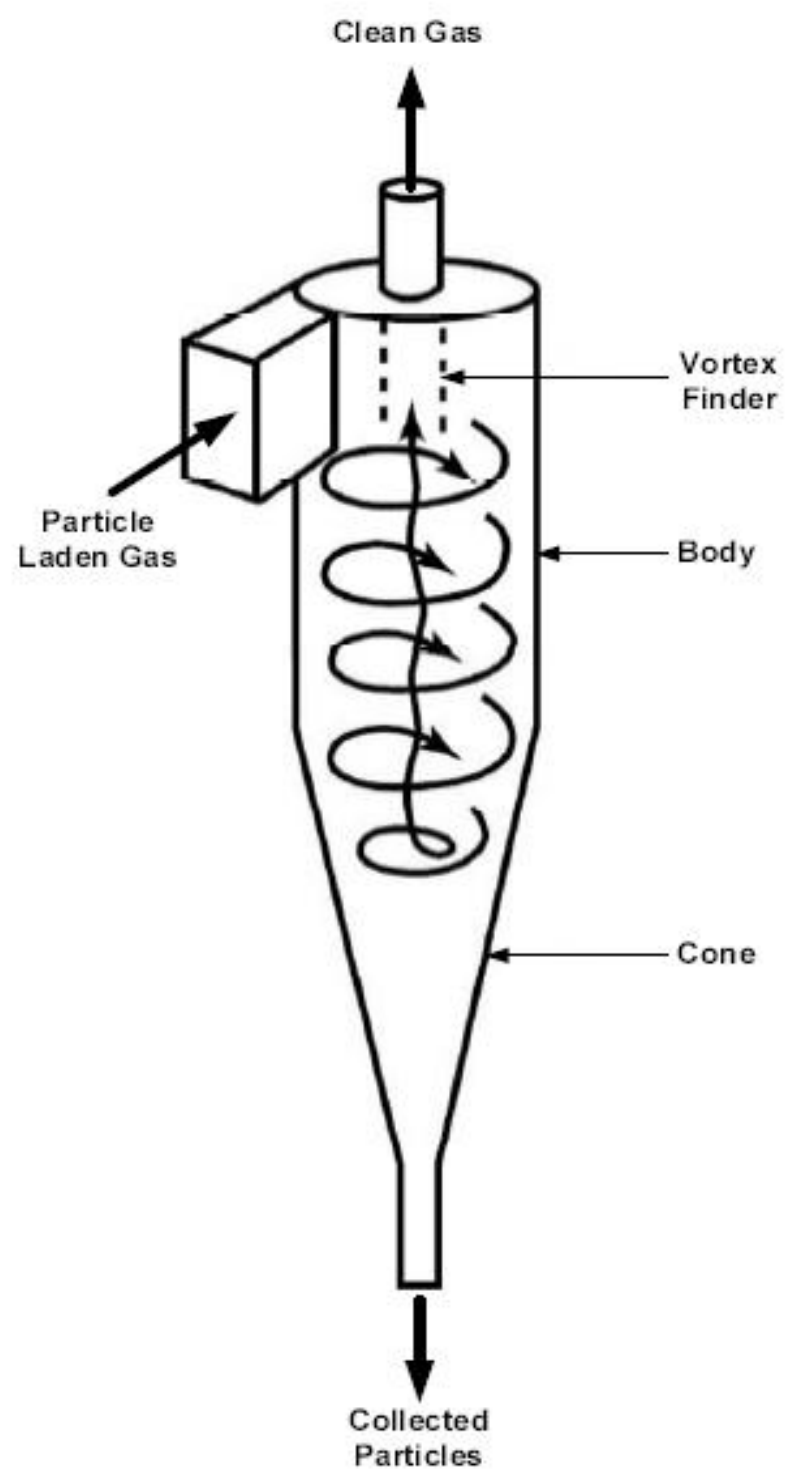

Figure 3.3 A typical cyclone and its dimensions [17]. 
There are mainly 2 assumptions for the calculation of particle capture efficiency which are the block flow and the mixed flow assumptions [61]. The equations obtained from these assumptions are stated respectively.

$$
\begin{gathered}
\eta=\frac{\pi N V_{c} D^{2} \rho_{p}}{9 W_{i} \mu} \\
\eta=1-\exp \left(\frac{\pi N V_{c} D^{2} \rho_{p}}{9 W_{i} \mu}\right)
\end{gathered}
$$

These assumptions are the two extreme cases and actual physical phenomena is in between. For this reason, the real physical phenomena can be predicted by fitting empirical data according to the equation given below [6].

$$
\eta=\frac{\left(\frac{D}{D_{c u t}}\right)^{2}}{1+\left(\frac{D}{D_{c u t}}\right)^{2}}
$$

In Equation (3.56), $D_{\text {cut }}$, i.e. cut diameter of the cyclone, is defined as the diameter of the particle that the capture efficiency takes the value 0.50 . If $D$ is substituted by $D_{\text {cut }}$ and $\eta$ is substituted by 0.5 in Equation (3.54), i.e. block flow assumption, and rearraging yields the definition of the cut diameter [6].

$$
D_{c u t}=\left(\frac{9 W_{i} \mu}{2 \pi N V_{c} \rho_{\text {part }}}\right)^{1 / 2}
$$




\section{Cyclone Duct}

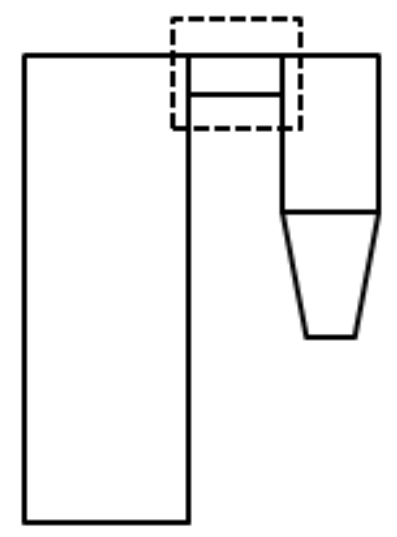

Cyclone

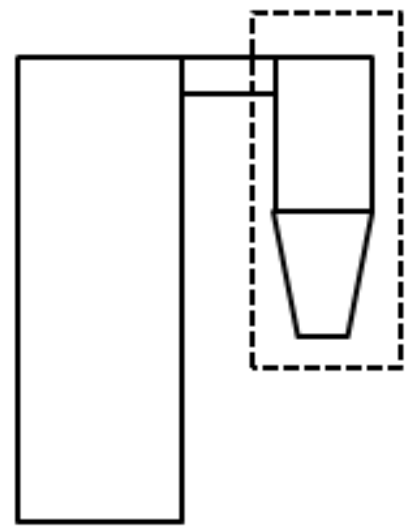

Figure 3.4 Cyclone duct and cyclone.

As seen on Figure 3.4, for pressure drop analysis, cyclone section is examined in two parts which are the connecting duct located between riser and cyclone and cyclone itself. In the study of Kim et al. [62] pressure drop correlations for these parts are stated as;

$$
\begin{gathered}
\Delta P_{h}=G_{s h}\left(2.84+0.0108 U_{g h}{ }^{2}\right) \\
\Delta P_{C}=\frac{C_{c y}\left(\frac{A_{r}}{A_{c}}\right)^{2} \rho_{g} U_{g}{ }^{2}}{2}
\end{gathered}
$$

\subsubsection{Downcomer}

Downcomer is located between the cyclone and loop seal. Its function is transportation of solids from the exit of the cyclone to the entrance of the loop seal. Hydrodynamic state of the solids in downcomer is between fixed bed and minimum fluidization. As stated in the pressure balance model section, static 
pressure in downcomer provides the necessary force for the solids to return to riser. Pressure drop in downcomer is estimated by utilizing the pressure balance around the combustor as given in Equation (3.49).

\subsubsection{Loop Seal}

In order to provide solid circulation rate, loop seal is utilized. Solid circulation rate mainly depends on solid material load of the combustor and overall pressure drop around the combustor.

\section{Vertical Aeration}

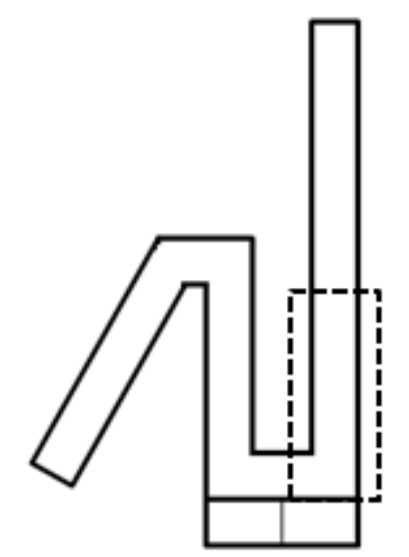

\section{Weir}

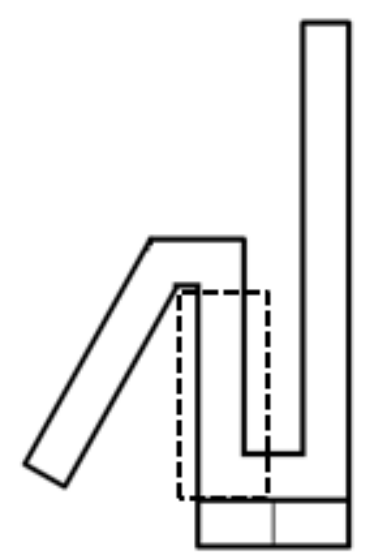

Figure 3.5 Vertical Aeration and weir sections of loop seal.

Movement of solids is provided by the fluidization air given at the bottom of the loop seal. Fluidization regime inside the loop seal is assumed to be bubbling. For the pressure drop analysis, loop seal is examined in two parts which are weir and vertical aeration sections. Pressure drop around the loop seal is the sum of the pressure drops around these two sections. 


$$
\Delta P_{l s}=\Delta P_{w}+\Delta P_{v a}
$$

The pressure drop per unit length presented in the study of Kim et al. [62] for the weir and vertical aeration sections are given in Equations (3.61) \& (3.62) respectively.

$$
\begin{gathered}
\left(\frac{\Delta P}{L}\right)_{w}=\rho_{s-l s}(1-\varepsilon) g \\
\left(\frac{\Delta P}{L}\right)_{v a}=0.0056 G_{s d}{ }^{0.51} \rho_{b u l k}{ }^{2.01} d_{p}{ }^{-0.97} D_{l s}{ }^{-0.76}
\end{gathered}
$$

And the voidage at the loop seal is defined as [62];

$$
\varepsilon=\frac{1}{2.1}\left[0.4+\left[4\left(\frac{\mu \rho_{g} u_{0}}{d_{p}{ }^{2}\left[\rho_{g}\left(\rho_{s}-\rho_{g}\right) \phi_{s}{ }^{2} g\right]}\right)^{0.43}\right]^{1 / 3}\right]
$$




\subsection{COMBUSTION}

Coal is a heterogeneous material showing different chemical and physical characteristics. This results in a very compex combustion path. There are two kinds of analysis for the description of coal composition which are the proximate and ultimate analyses.

In this study, coal particles are assumed to release all volatile matter and moisture content instantaneously. Following these, coal particles' temperature starts to increase and rapidly reaches to a steady-state value. When the temperature of the coal is equal to its ignition temperature, char, which is defined as the residue after volatiles and moisture is released from the coal particle, starts to burn taking much longer time compared to its devolatilization [63, 64]. Hence, instantaneous devolatilization is assumed in this study.

\subsubsection{Volatiles Release and Combustion}

Volatiles are defined as the gaseous products that are found in the coal matrix. At ambient conditions. Predicting the devolatilization process is diffucult since process is composed of very complex physical and chemical steps. Contribution of the volatiles to the gaseous combustion products is significant. Most important factors that affect the pattern of devolatilization are; coal analysis, coal pore structure and particle size, temperature, heating rate, type of the reactor and whether the atmosphere is oxidizing or reducing.

There are various models predicting the coal devolatilization process kinetically. One of the simplest is the single decomposition reaction. This reaction is assumed to take place in first or $n$th order. Yet, these models are incapable to account for the asymptotic yield and they predict lower activation energies than expected [65, 66]. Hence, more complex devolatization models should be employed. For that 
reason, models that consider number of parallel [65] or competing [67] independent reactions can be utilized.

Devolatilization with independent parallel reactions are occuring with first order reactions given as,

$$
\operatorname{coal}_{i} \stackrel{k_{i}}{\rightarrow} \text { volatiles }_{i}+\text { char }_{i}
$$

First order rate equation for reaction $i$ is defined in Equation (3.64).

$$
\frac{d v_{i}}{d t}=k_{i}\left(v_{\infty, i}-v_{i}\right)
$$

For the yields of volatile matter evolved from reactions are obtained by the integration of the Equation (3.64) for non-isothermal conditions.

$$
v_{i}=v_{\infty, i}\left[1-\exp \left(-\int_{0}^{t} k_{i} d t\right)\right]
$$

Arrhenius equation is utilized for the estimation of reaction rate constants. For the evaluation of rate constants, single pre-exponential factor is utilized.

$$
k_{i}=k(E)=k_{0} \exp \left(-\frac{E}{R T}\right)
$$

Activation energies for different reactions change in the range $E_{\min }$, to $E_{\max }$ according to a probability density function $f(E)$ [65]. The Gaussian distribution for $f(E)$ is; 


$$
f(E)=\left[\frac{(2 \pi)^{1 / 2}}{\sigma}\right]^{-1} \exp \left[-\frac{\left(E-E_{0}\right)^{2}}{2 \sigma^{2}}\right]
$$

and,

$$
\int_{0}^{\infty} f(E) d E=1
$$

There are four different parameters to be supplied to parallel independent reaction mechanism which are: $v_{\infty}, k_{0}, E_{0}$, and $\sigma$. These parameters can easiliy be supplied to the model. One set of parameters, which are $k_{0}, E_{0}$, and $\sigma$, can be utilized for different heating conditions while $v_{\infty}$ changes as the variation occurs in heating conditions and temperature .

The other option for the prediction of devolatilization kinetics is assuming that number of competing independent reactions take place [67]. Although this model gives satisfactory results, it is more appropriate for high temperatures. Since low temperatures are observed in fluidized bed combustors, utilization of parallel independent reaction mechanism is recommended [68].

Due to increased heat and mass transfer rates in CFBs, instantaneous devolatilization assumption is reasonable. In addition, devolatilization takes place only in dense zone and there exists an equal volatile distribution along the combustor [17].

Released volatile matter is assumed to be consumed by the following set of parallel reactions in the combustor.

$$
\mathrm{C}+1 / 2 \mathrm{O}_{2} \rightarrow \mathrm{CO}
$$




$$
2 \mathrm{H}+1 / 2 \mathrm{O}_{2} \rightarrow \mathrm{H}_{2} \mathrm{O}
$$

$$
\mathrm{S}+\mathrm{O}_{2} \rightarrow \mathrm{SO}_{2}
$$

$$
2 N \rightarrow N_{2}
$$

$$
2 \mathrm{O} \rightarrow \mathrm{O}_{2}
$$

$$
\mathrm{H}_{2} \mathrm{O} \rightarrow \mathrm{H}_{2} \mathrm{O}
$$

The composition of volatile matter released into the bed can be estimated as;

$$
\begin{gathered}
x_{C, V M}=\frac{\left(x_{C}-x_{f c}\right)}{x_{V M}} \\
x_{O, V M}=\frac{x_{O}}{x_{V M}} \\
x_{H, V M}=\frac{x_{H}}{x_{V M}} \\
x_{S, V M}=\frac{x_{S, \text { comb }}}{x_{V M}} \\
x_{N, V M}=\frac{x_{N}}{x_{V M}}
\end{gathered}
$$


The volatile combustion is assumed to take place in both emulsion and bubble phases as the operating temperatures of fluidized bed combustors $\left(850^{\circ} \mathrm{C}\right)$ is above the critical temperature $\left(\sim 800^{\circ} \mathrm{C}\right)$ below which homogeneous gas phase reactions are inhibited due to radical-quenching on inert solids [69-72].

\subsubsection{Char Combustion}

In CFBs, due to high mass transfer rates and degree of mixing, rate of combustion of char particles is fast.

Emulsion phase constitutes highest amount of char particles. Hence, heterogeneous reaction between the carbon that is bound to char and oxygen takes place in emulsion phase. This heterogen reaction mechanism may be composed of mass transfer through the gas film surrounding the particle, oxygen diffusion through char pores and chemical reaction between oxygen and carbon. There are standard models for describing consumption of carbon which are;

- The Uniform Reaction Model (diameter is constant, density is decreasing)

- The Shrinking Particle Model (density is constant, diameter is decreasing)

- The Shrinking Core Model (diameter of core is decreasing with a layer of ash surrounds the burning core)

Relative importance of these models to one another changes with a function of;

- Temperature of the bed

- Hydrodynamics

- Oxygen concentration in bed

- Size of the particles

- Reactivity of char 
Oxygen penetration into a burning char particle is limited. Hence reaction takes place in the outer thin layer of the char particle [73]. Thus, combustion reaction is not uniformly taking place inside the char particle. For this reason, shrinking particle model is assumed in this study.

Heterogenous reactions for char combustion are;

$$
\begin{gathered}
C_{(s)}+1 / 2 O_{2} \rightarrow \mathrm{CO}_{(g)} \\
C_{(s)}+O_{2(g)} \rightarrow \mathrm{CO}_{2(g)} \\
C_{(s)}+\mathrm{CO}_{2(g)} \rightarrow 2 \mathrm{CO}_{(g)}
\end{gathered}
$$

and homogeneous reaction is;

$$
\mathrm{CO}_{(g)}+1 / 2 \mathrm{O}_{2(g)} \rightarrow \mathrm{CO}_{2(g)}
$$

There are two options for $C O$ oxidation in CFBs. These are the single film model in which $\mathrm{CO}$ oxidation takes place in the free stream and the double film model in which $C O$ oxidation takes place in the boundary layer surrounding the char particle [17]. Since measurements contradict with the double film model for its higher temperature prediction [74] and $\mathrm{CO}_{2}$ reduction which is taken into account in double film model is generally not considered to take place due to low temperature values in FBCs [75], single film model is utilized in this study.

In the study of Linjewile and Agarwal [76], the Arrhenius expression for the product ratio $[\mathrm{CO}] /\left[\mathrm{CO}_{2}\right]$ which is given in Equation (3.74) was reported to be between 0.2 and 12. The major product was $C O$ for fluidized bed combustors utilizing solid particle size between $500 \mu \mathrm{m}$ to $2 \mathrm{~mm}$. 


$$
\frac{[\mathrm{CO}]}{\left[\mathrm{CO}_{2}\right]}=f_{r}=K_{0} \exp \left(-\frac{E}{R T_{p}}\right)
$$

Mechanism factor is defined as,

$$
\zeta=\frac{1+2 f_{r}}{1+f_{r}}
$$

and this factor is utilized in the stoichiometric coefficients of the following reaction.

$$
C_{(s)}+\frac{1}{\zeta} \rightarrow 2\left(1-\frac{1}{\zeta}\right) \mathrm{CO}+\left(\frac{2}{\zeta}-1\right) \mathrm{CO}_{2}
$$

This factor varies in the range from 1 to 2 . If $\zeta=1$ product is only $\mathrm{CO}_{2}$, and if $\zeta=2$ product becomes only $\mathrm{CO}$.

The main steps in the char combustion are the external mass transfer and surface reaction which are implied by the assumption of shrinking particle and single film model. Experimental studies in the literature propose limiting models for these two steps according to the size of the char particles [77]. Yet, fluidized bed systems utilize solid material with wide size distribution. For this reason, transition between these steps should be considered [78]. Hence, in this study, both mass transfer and reaction resistances are taken into account.

To estimate the char combustion rate, pore diffusion and internal chemical reaction rates are considered together in the apparent rate constant in the $n$th order rate equation. The order of this reaction, given in Equation (3.76), is based on the external surface area of the char particle. 


$$
r_{C, S}=k_{s} C_{O_{2}, S}^{n}
$$

Arrhenius equation is utilized for the rate constant;

$$
k_{s}=k_{0} \exp \left(-\frac{E}{R T_{p}}\right)
$$

Rate expression coefficients of Field et al. [73] are used and the reaction order is taken as 1 [79].

Table 3.5 Parameters utilized for the kinetic expression of Field et al. [73]

\begin{tabular}{|c|c|}
\hline Parameter & Value \\
\hline$k_{0}, \frac{m}{s}$ & $595 T_{p}$ \\
\hline$E, \frac{J}{m o l}$ & 17976 \\
\hline
\end{tabular}

Using the equality of oxygen diffusion rate to surface reaction rate,

$$
k_{f}\left(\bar{C}_{O_{2}, e}-C_{O_{2}, S}\right)=\frac{k_{s}}{\zeta} C_{O_{2}, S}
$$

Rearranging Equation (3.78) for the oxygen concentration at the surface of the char particle yields,

$$
C_{O_{2}, s}=\frac{\bar{C}_{O_{2}, e}}{\frac{k_{s}}{\zeta k_{f}}+1}
$$

Combining Equations (3.78 \& 3.79) gives char combustion rate in terms of average emulsion phase oxygen concentration. 


$$
r_{C, e}=\frac{\zeta}{\frac{1}{k_{f}}+\frac{\zeta}{k_{s}}} \bar{C}_{O_{2}, e}
$$

$k_{f}$ in Equation (3.80) is obtained from the study Basu and Subbarao [80];

$$
k_{f}=\frac{\mathcal{D}}{d_{p}}\left[2+0.6\left(R e_{t}\right)^{1 / 2} S c^{1 / 3}\right]
$$

where $R e_{t}$ and $S c$ are defined as;

$$
\begin{gathered}
R e_{t}=\frac{d_{p} u_{t} \rho_{p}}{\mu_{g}} \\
S c=\frac{\mu_{g}}{\mathcal{D} \rho_{g}}
\end{gathered}
$$

Oxygen diffusivity is approximated by the expression given by Field et al. [73];

$$
\mathcal{D}=\mathcal{D}_{\text {ref }}\left[\frac{T}{T_{\text {ref }}}\right]^{n} \frac{P_{\text {ref }}}{P}
$$

Table 3.6 Parameters utilized for the oxygen diffusivity expression [73].

\begin{tabular}{|c|c|}
\hline Parameter & Value \\
\hline$D_{r e f}, \frac{m^{2}}{s}$ & $2.01 \times 10^{-5}$ \\
\hline$T_{r e f}, K$ & 298.15 \\
\hline$P_{r e f}, P a$ & $1.01325 \times 10^{5}$ \\
\hline$n,-$ & 1.5 \\
\hline
\end{tabular}


In order to evaluate char particles' size distribution, shrinkage rate of char particles is necessary. Equality of the rate of carbon removal to the rate of combustion at char surface yields,

$$
\frac{d}{d t}\left[\frac{4}{3} \pi r^{3} \rho_{c} \frac{x_{f c}}{x_{f c}+x_{a s h}}\right]=-4 \pi r^{2} M_{C} r_{C, e}
$$

Solving Equation (3.85) for shrinkage rate of char particles results in;

$$
\mathfrak{R}(r)=\frac{d r}{d t}=-\frac{3}{\rho_{c}} \frac{x_{f c}+x_{a s h}}{x_{f c}} M_{c} r_{C, e}
$$

For the $C O$ oxidation, various kinetic laws may be employed. These laws propose coefficients for the equation in the following form;

$$
r_{C O}=k_{C O} C_{C O}^{\alpha} C_{O_{2}}^{\beta} C_{H_{2} O}^{\gamma}
$$

with,

$$
k_{C O}=k_{0} \exp \left(-\frac{E}{R T}\right)
$$

In this study, coefficients are obtained from Hottel et al. [81] which are given in Table 3.7. 
Table 3.7 Parameters utilized for the kinetic expression of Hottel et al. [81].

\begin{tabular}{|c|c|}
\hline Parameter & Value \\
\hline$k_{0}, \frac{\mathrm{mol}^{n}}{\mathrm{~m}^{3 n_{S}}}$ & $4.75 \times 10^{5}$ \\
\hline$\frac{E}{R}, K$ & 8052 \\
\hline$\alpha,-$ & 1 \\
\hline$\beta,-$ & 0.3 \\
\hline$\gamma,-$ & 0.5 \\
\hline
\end{tabular}




\subsection{CHAR PARTICLES' SIZE DISTRIBUTION}

Particle size distribution estimation has an essential importance for the prediction of the physical and chemical processes occuring in FBCs due to the dependence of carbon consumption to the surface area of char particles.

To derieve an equation for size distribution of char particles the following assumptions are made;

- Rosin-Rammler particle size distribution function is employed to express particle size distribution, $P_{0}(r)$, of char particles going in with feed.

- Solid material content of the dense zone is well-mixed, and show no variation from the particle size distribution of the bed drain stream.

- Rate of elutriation of particle with radius $r$ is proportional to their concentration in the dense zone.

- Char particle densities are assumed to be constant.

- Attrition and fragmentation is assumed to be negligible [82].

- Shrinkage of char particles is caused only by combustion. 


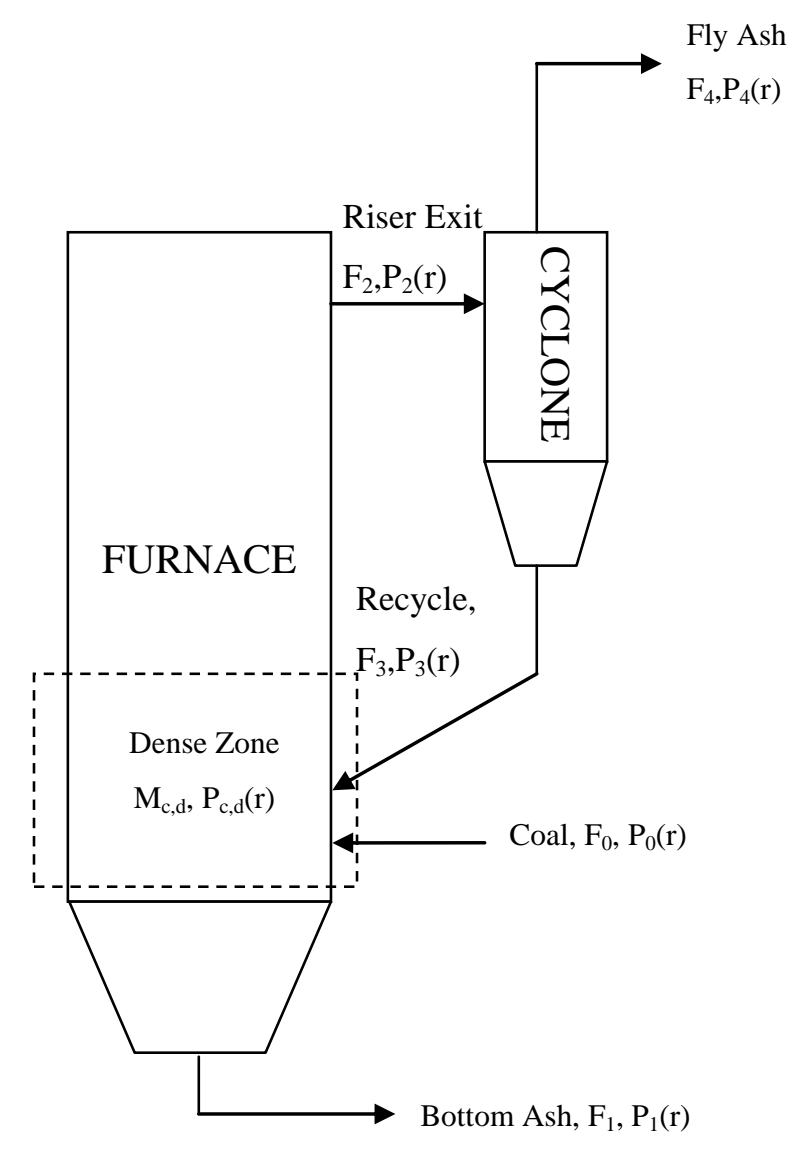

Figure 3.6 Schematic diagram for char population balance.

Starting with the general book-keeping equation for the char particles of sizes between $r$ and $r+\Delta r$ for entire size range contained in the dense zone can be expressed as, 


$$
\begin{aligned}
\left\{\begin{array}{c}
\text { char of size } r \\
\text { accumulated } \\
\text { in the interval } \Delta r
\end{array}\right\} & \\
& =\left\{\begin{array}{c}
\text { char of size } r \\
\text { entering in } \text { feed }
\end{array}\right\}+\left\{\begin{array}{c}
\text { char of size } r \\
\text { entering in recycle }
\end{array}\right\} \\
& -\left\{\begin{array}{c}
\text { char of size } r \\
\text { leaving in bed drain }
\end{array}\right\}-\left\{\begin{array}{c}
\text { char of size } r \\
\text { leaving in carryover }
\end{array}\right\} \\
& +\left\{\begin{array}{c}
\text { char shrinking into } \\
\text { the interval } \Delta \mathrm{r} \\
\text { from a larger size }
\end{array}\right\}-\left\{\begin{array}{c}
\text { char shrinking out } \\
\text { of the interval } \Delta r \\
\text { to a smaller size }
\end{array}\right\} \\
& -\left\{\begin{array}{c}
\text { char mass depleted } \\
\text { in the interval } \Delta r
\end{array}\right\}
\end{aligned}
$$

Expressing Equation (3.89) in mathematical terms,

$$
\begin{aligned}
{\left[M_{c, d} P_{c, d}(r) \Delta r\right.} & ]_{t+\Delta t}-\left[M_{c, d} P_{c, d}(r) \Delta r\right]_{t} \\
& =F_{0} P_{0}(r) \Delta r \Delta t+F_{3} P_{3}(r) \Delta r \Delta t-F_{1} P_{1}(r) \Delta r \Delta t \\
& -F_{2} P_{2}(r) \Delta r \Delta t+\left[M_{c, d} P_{c, d}(r)\left(\frac{d r}{d t}\right) \Delta t\right]_{r} \\
& -\left[M_{c, d} P_{c, d}(r)\left(\frac{d r}{d t}\right) \Delta t\right]_{r+\Delta r}+\frac{3 M_{c, d} P_{c, d}(r)}{r}\left(\frac{d r}{d t}\right) \Delta t
\end{aligned}
$$

Dividing Equation (3.90) by $\Delta r \Delta t$ and taking limit $\lim _{\Delta r, \Delta t \rightarrow 0}$ yields,

$$
\begin{aligned}
\frac{\partial}{\partial t}\left[M_{c, d} P_{c, d}(r)\right] & \\
& =F_{0} P_{0}(r)+F_{3} P_{3}(r)-F_{1} P_{1}(r)-F_{2} P_{2}(r) \\
& -\frac{\partial}{\partial r}\left[M_{c, d} P_{c, d}(r)\left(\frac{d r}{d t}\right)\right]+\frac{3}{r} M_{c, d} P_{c, d}(r)\left(\frac{d r}{d t}\right)
\end{aligned}
$$

Assuming well-mixed solids yields, 


$$
P_{1}(r)=P_{c, d}(r)
$$

and assuming elutriation rate of char particles with radius $r$ yields,

$$
F_{2} P_{2}(r)=\kappa(r) M_{c, d} P_{c, d}(r)
$$

where $\kappa(r)$ is defined as the elutriation rate constant,

$$
\begin{aligned}
\frac{\partial}{\partial t}\left[M_{c, d} P_{c, d}(r)\right] & \\
= & F_{0} P_{0}(r)+F_{3} P_{3}(r)-F_{1} P_{d}(r)-\kappa(r) M_{c, d} P_{c, d}(r) \\
& -\frac{\partial}{\partial r}\left[M_{c, d} P_{c, d}(r)\left(\frac{d r}{d t}\right)\right]+\frac{3}{r} M_{c, d} P_{c, d}(r)\left(\frac{d r}{d t}\right)
\end{aligned}
$$

Correlation for the elutriation rate constant is obtained from the study of Geldart et al. [83], which is given below.

$$
\kappa(r)=\frac{A_{d}}{M_{c, d}} \kappa^{*}(r)
$$

where $\kappa^{*}(r)$ is defined as;

$$
\kappa^{*}(r)=23.7 \rho_{g} u_{0} \exp \left(-5.4 \frac{u_{t}}{u_{0}}\right)
$$

Recycled particles' flow rate is related to elutriation rate of particles having radius $r$ by the use of cyclone efficiency, $\eta_{c y c}(r)$, 


$$
F_{3} P_{3}(r)=\eta_{c y c}(r) F_{2} P_{2}(r)
$$

Combination of Equations (3.93) and (3.97), then replacing in Equation (3.94) yields,

$$
\begin{aligned}
\frac{\partial}{\partial t}\left[M_{c, d} P_{c, d}(r)\right] & \\
= & F_{0} P_{0}(r)-F_{1} P_{d}(r)-\left[1-\eta_{c y c}(r)\right] \kappa(r) M_{c, d} P_{c, d}(r) \\
& -\frac{\partial}{\partial r}\left[M_{c, d} P_{c, d}(r)\left(\frac{d r}{d t}\right)\right]+\frac{3}{r} M_{c, d} P_{c, d}(r)\left(\frac{d r}{d t}\right)
\end{aligned}
$$

Defining a dummy variable $W(r)$,

$$
W(r)=M_{c, d} P_{c, d}(r)
$$

and substituting into Equation (3.98) leads to,

$$
\begin{gathered}
\frac{\partial W(r)}{\partial t}=F_{0} P_{0}(r)-F_{1} \frac{W(r)}{M_{d}}-\left[1-\eta_{c y c}(r)\right] \kappa(r) W(r) \\
-\frac{\partial}{\partial r}[W(r) \Re(r)]+\frac{3}{r} W(r) \Re(r)
\end{gathered}
$$

Finally, setting the temporal derivative to zero for the steady-state condition, gives the working form of the char particles' size distribution.

$$
\begin{gathered}
F_{0} P_{0}(r)-F_{1} \frac{W(r)}{M_{d}}-\left[1-\eta_{c y c}(r)\right] \kappa(r) W(r)-\frac{\partial}{\partial r}[W(r) \Re(r)] \\
+\frac{3}{r} W(r) \Re(r)=0
\end{gathered}
$$


where, $P_{0}(r)$ is defined by the Rosin-Rammler size distribution function,

$$
P_{0}(r)=n b r^{n-1} \exp \left(b r^{n}\right)
$$

Since no solid particles of radius $r_{\max }$ is not possible due to the shrinkage of char particle, boundary condition for the Equation (3.101) is;

$$
@ r=r_{\max } \quad W(r)=0
$$

Solution of $W(r)$, provides the solution of the following unknowns;

- Dense zone char hold-up,

$$
M_{c, d}=\int_{r_{\text {min }}}^{r_{\max }} W(r) d r
$$

- Dense zone char size distribution,

$$
P_{c, d}(r)=\frac{W(r)}{M_{c, d}}
$$

- Riser exit char flow rate,

$$
F_{2}=\int_{r_{\min }}^{r_{\max }} \kappa(r) W(r) d r
$$

- Riser exit char size distribution, 


$$
P_{2}(r)=\frac{\kappa(r) W(r)}{F_{2}}
$$

- Recycle char flow rate,

$$
F_{3}=\int_{r_{\min }}^{r_{\max }} \eta_{c y c}(r) F_{2} P_{2}(r) d r
$$

- Recycle char size distribution,

$$
P_{3}(r)=\frac{\eta_{c y c}(r) F_{2} P_{2}(r)}{F_{3}}
$$

- Fly ash char flow rate,

$$
F_{4}=\int_{r_{\text {min }}}^{r_{\text {max }}}\left[1-\eta_{c y c}(r)\right] F_{2} P_{2}(r) d r
$$

- Fly as char size distribution,

$$
P_{4}(r)=\frac{\left[1-\eta_{c y c}(r)\right] F_{2} P_{2}(r)}{F_{4}}
$$




\subsection{NO FORMATION AND REDUCTION}

Volatile- $\mathrm{N}$ and char-N follow different reaction paths in the $N O$ chemistry. Therefore, estimation of partitioning factor for coal-N release is crucial for $N O$ modeling. As this factor is specific to the coal under consideration it was found by the pyrolysis experiments. Lignite sample was heated to $950^{\circ} \mathrm{C}$ at a rate of $40^{\circ} \mathrm{C} / \mathrm{min}$ and kept isothermal till constant weight. After the pyrolysis, remaining char particles are subject to elemental analysis. The char-N content was found to be $0.24 \%$. Considering the nitrogen content of the lignite on dry basis, $1.1 \%$, $78 \%$ of coal-N was found to be released as volatile-N.

Assuming char nitrogen oxidation is directly proportional to char combustion, for any char particle of radius $r$,

$$
\frac{d}{d t}\left(\frac{4}{3} \pi r^{3} \rho_{c} \frac{x_{N, c}}{x_{f c}+x_{a s h}}\right)=-4 \pi r^{2} M_{N} r_{N, e}
$$

Since the value of $x_{N, c}$ is low, it is not considered in the denominator. Combining Equation (3.112) with (3.85) and solving for $r_{N, e}$,

$$
r_{N, e}=\Re(r) \frac{\rho_{c}}{3 M_{N}} \frac{x_{N, c}}{x_{f c}+x_{a s h}}
$$

Reactions considering $N O$ formation and reduction are given in Table 3.8; 
Table 3.8 Reactions considering $N O$ formation and reduction [84, 85].

\begin{tabular}{|c|c|c|c|}
\hline \# & Reaction & Place & Rate \\
\hline 13 & $\mathrm{~N}_{v o l}+3 / 2 \mathrm{H}_{2} \rightarrow \mathrm{NH}_{3}$ & $\begin{array}{c}\text { Gas } \\
\text { Phase }\end{array}$ & Instantaneous \\
\hline 14 & $N_{(s)}+1 / 2 O_{2} \rightarrow \mathrm{NO}$ & $\begin{array}{l}\text { Char } \\
\text { Surface }\end{array}$ & Proportional to char combustion \\
\hline 15 & $\mathrm{NH}_{3}+5 / 4 \mathrm{O}_{2} \rightarrow \mathrm{NO}+3 / 2 \mathrm{H}_{2} \mathrm{O}$ & $\begin{array}{c}\text { Gas } \\
\text { Phase }\end{array}$ & $2.21 \times 10^{14} \exp \left(\frac{-38160}{T_{d}}\right) C_{N_{3}} \frac{m o l}{m^{3} s}$ \\
\hline 16 & $\mathrm{NO}+2 / 3 \mathrm{NH}_{3} \rightarrow 5 / 6 \mathrm{~N}_{2}+\mathrm{H}_{2} \mathrm{O}$ & $\begin{array}{c}\text { Gas } \\
\text { Phase }\end{array}$ & $2.45 \times 10^{14} \exp \left(\frac{-27680}{T_{d}}\right) C_{N O} C_{N H_{3}} \frac{\mathrm{mol}}{\mathrm{s}}$ \\
\hline 17 & $\mathrm{NO}+\mathrm{Char} \rightarrow 1 / 2 \mathrm{~N}_{2}+\mathrm{CO}$ & $\begin{array}{l}\text { Char } \\
\text { Surface }\end{array}$ & $2.62 \times 10^{3} \exp \left(\frac{-22200}{T_{c}}\right) C_{N O} 0.52 \frac{\mathrm{mol}}{\mathrm{g} \cdot \mathrm{s}}$ \\
\hline 18 & $\mathrm{NO}+\mathrm{CO} \rightarrow 1 / 2 \mathrm{~N}_{2}+\mathrm{CO}_{2}$ & $\begin{array}{l}\text { Char } \\
\text { Surface }\end{array}$ & $1.15 \times 10^{4} \exp \left(\frac{-22800}{T_{c}}\right) C_{N O}{ }^{0.39} C_{C O}^{0.53} \frac{\mathrm{mol}}{\mathrm{g} \cdot \mathrm{s}}$ \\
\hline 19 & $\mathrm{NH}_{3}+5 / 4 \mathrm{O}_{2} \rightarrow \mathrm{NO}+3 / 2 \mathrm{H}_{2} \mathrm{O}$ & $\begin{array}{l}\text { Char } \\
\text { Surface }\end{array}$ & $3.4 \times 10^{-2} C_{\mathrm{NH}_{3}} C_{\mathrm{O}_{2}} \frac{\mathrm{mol}}{\mathrm{g} \cdot \mathrm{s}}$ \\
\hline 20 & $\mathrm{NH}_{3}+5 / 4 \mathrm{O}_{2} \rightarrow \mathrm{NO}+3 / 2 \mathrm{H}_{2} \mathrm{O}$ & $\begin{array}{c}\text { Ash } \\
\text { Surface }\end{array}$ & $3.33 \times 10^{-5} C_{\mathrm{NH}_{3}}{ }^{0.57} C_{\mathrm{O}_{2}}{ }^{0.11} \frac{\mathrm{mol}}{\mathrm{g} \cdot \mathrm{s}}$ \\
\hline 21 & $\mathrm{NH}_{3}+3 / 4 \mathrm{O}_{2} \rightarrow 1 / 2 \mathrm{~N}_{2}+3 / 2 \mathrm{H}_{2} \mathrm{O}$ & $\begin{array}{l}\text { Char } \\
\text { Surface }\end{array}$ & $8.4 \times 10^{-2} C_{\mathrm{NH}_{3}} C_{\mathrm{O}_{2}} \frac{\mathrm{mol}}{\mathrm{g} \cdot \mathrm{s}}$ \\
\hline 22 & $\mathrm{NH}_{3}+3 / 4 \mathrm{O}_{2} \rightarrow 1 / 2 \mathrm{~N}_{2}+3 / 2 \mathrm{H}_{2} \mathrm{O}$ & $\begin{array}{c}\text { Ash } \\
\text { Surface }\end{array}$ & $2.36 \times 10^{-2} \mathrm{C}_{\mathrm{NH}_{3}}{ }^{1.8} \mathrm{C}_{\mathrm{O}_{2}}{ }^{0.07} \frac{\mathrm{mol}}{\mathrm{g} \cdot \mathrm{s}}$ \\
\hline
\end{tabular}

As can be seen from the table, heterogeneous reactions are only considered to take place in the emulsion phase of the dense zone since solid hold-up in the dilute zone is negligible compared to that in the dense zone. It's worth noting that char temperatures obtained from energy balance on char particles are utilized in rate expressions of reactions $17 \& 18$. 
As the char particles' temperatures change with the particle size, considering char particle of size $r$, rate of heterogeneous reactions are obtained from;

$$
r_{N, \text { het }}=M_{d} P(r) r_{N O}
$$

And summing up Equation (3.114) for all char particles yields,

$$
r_{N, h e t}=M_{d} \int_{r_{\min }}^{r_{\max }} P(r) r_{N O} d r
$$




\subsection{MASS AND ENERGY BALANCE EQUATIONS}

\subsubsection{Mass and Energy Balance In Dense Zone}

\subsubsection{Bubble Phase Gaseous Species Conservation}

With the assumption of plug flow of gas in bubble phase, and considering timedependent mass balance on species $j$ between heights $z$ and $z+\Delta z$;

$$
\begin{aligned}
\left\{\begin{array}{c}
\text { species } j \\
\text { accumulated in } \\
\text { control volume }
\end{array}\right\} & \\
& =\left\{\begin{array}{c}
\text { species } j \text { in } \\
\text { by convection } \\
\text { at } \mathrm{z}
\end{array}\right\}-\left\{\begin{array}{c}
\text { species } j \text { out } \\
\text { by convection at } \\
z+\Delta z
\end{array}\right\} \\
& +\left\{\begin{array}{c}
\text { species } j \\
\text { generated or depleted } \\
\text { by chemical reactions }
\end{array}\right\} \\
& +\left\{\begin{array}{c}
\text { species } j \text { transferred } \\
\text { from or to emulsion phase }
\end{array}\right\}
\end{aligned}
$$

Converting Equation (3.116) into mathematical terms with the utilization of the definition of gas interchange coefficient between bubble and emulsion phases;

$$
\begin{aligned}
A_{d} \Delta z \delta\left[\left(C_{j, b}\right)_{t}\right. & \\
& =\Delta t\left(n_{j, b}\right)_{z}-\Delta t\left(n_{j, b}\right)_{z+\Delta \mathrm{z}}+A_{d} \delta \Delta z \Delta t \Re_{j, b} \\
& +A_{d} \delta \Delta z \Delta t K_{b e}\left(C_{j, e}-C_{j, b}\right)
\end{aligned}
$$

Dividing both sides of Equation (3.117) by $A_{b e d} \delta \Delta z \Delta t$ and taking $\lim _{\Delta z, \Delta t \rightarrow 0}$ yields; 


$$
\frac{\partial C_{j, b}}{\partial t}=-\frac{1}{A_{d} \delta} \frac{\partial n_{j, b}}{\partial z}+\mathfrak{R}_{j, b}+\kappa_{b e}\left(C_{j, e}-C_{j, b}\right)
$$

In order to express the left hand side of Equation (3.118) in terms of molar flow rates, ideal gas assumption can be used;

$$
C_{j, b}=\frac{P_{j}}{R T_{d}}
$$

Rewriting Equation (3.119);

$$
C_{j, b}=\frac{P}{R T_{d}} \frac{n_{j, b}}{n_{b}}
$$

Taking the derivative of Equation (3.120) with respect to time yields the term;

$$
\frac{\partial C_{j, b}}{\partial t}=\frac{P}{R}\left[-\frac{n_{j, b}}{n_{b} T_{d}^{2}} \frac{d T_{d}}{d t}+\frac{1}{n_{b} T_{d}} \frac{\partial n_{j, b}}{\partial t}-\frac{n_{j, b}}{n_{b}{ }^{2} T_{d}} \frac{\partial n_{b}}{\partial t}\right]
$$

Combining Equations (3.118) \& (3.121);

$$
\begin{aligned}
\frac{\partial n_{j, b}}{\partial t}=\frac{R T_{d} n_{b}}{P A_{d} \delta} & {\left[A_{d} \delta \Re_{j, b}+A_{d} \delta \kappa_{b e}\left(C_{j, e}-C_{j, b}\right)-\frac{\partial n_{j, b}}{\partial z}\right]+\frac{n_{j, b}}{T_{d}} \frac{d T_{d}}{d t} } \\
& +\frac{n_{j, b}}{n_{b}} \frac{\partial n_{b}}{\partial t}
\end{aligned}
$$

Utilization of steady-state assumption and setting all the temporal derivatives to zero in Equation (3.122) and rearranging yields the working form of the differential equation for the bubble phase gaseous species conservation. 


$$
\frac{\partial n_{j, b}}{\partial z}=A_{d} \delta \Re_{j, b}+A_{d} \delta \kappa_{b e}\left(C_{j, e}-C_{j, b}\right)
$$

Equation (3.22) is used as the boundary condition of Equation (3.123) as,

$$
@_{z}=0, n_{b}=n_{a, p r i} \frac{1}{1+\frac{u_{m f}}{u_{b}} \frac{(1-\delta)}{\delta} \varepsilon_{m f}}
$$

Species generation/depletion term in Equation (3.123), $\mathfrak{R}_{j, b}$, takes the following forms for each species considered;

$j=1\left(O_{2}\right)$

$$
\Re_{1, b}=-0.5 r_{C O, b}-\frac{5}{4}\left(r_{N . h o m}\right)_{R 15}
$$

$j=2(\mathrm{CO})$

$$
\mathfrak{R}_{2, b}=-r_{C O, b}
$$

$j=3\left(\mathrm{CO}_{2}\right)$

$$
\Re_{3, b}=r_{C O, b}
$$

$j=4\left(\mathrm{H}_{2} \mathrm{O}\right)$

$$
\Re_{4, b}=\frac{3}{2}\left(r_{N, h o m}\right)_{R 15}+\frac{1}{V_{b e d} \delta}\left(r_{N, h o m}\right)_{R 16}
$$

$j=5\left(\mathrm{SO}_{2}\right)$

$$
\mathfrak{R}_{5, b}=0
$$


$j=6\left(\mathrm{NH}_{3}\right)$

$$
\Re_{6, b}=-\left(r_{N, h o m}\right)_{R 15}-\frac{2}{3} \frac{1}{V_{b e d} \delta}\left(r_{N, h o m}\right)_{R 16}
$$

$j=7(N O)$

$$
\Re_{7, b}=\left(r_{N, h o m}\right)_{R 15}-\frac{1}{V_{\text {bed }} \delta}\left(r_{N, h o m}\right)_{R 16}
$$

\subsubsection{Emulsion Phase Gaseous Species Conservation}

Assuming plug flow hydrodynamics in emulsion phase, unsteady-state mass balance for any species $j$ between heights $z$ and $z+\Delta z$ is expressed as;

$$
\begin{aligned}
\left\{\begin{array}{c}
\text { species } j \\
\text { accumulated in } \\
\text { control volume }
\end{array}\right\} & \\
& =\left\{\begin{array}{c}
\text { species } j \text { in } \\
\text { by convection } \\
\text { at } z
\end{array}\right\}-\left\{\begin{array}{c}
\text { species } j \text { out } \\
\text { by convection } \\
\text { at } z+\Delta z
\end{array}\right\} \\
& +\left\{\begin{array}{c}
\text { species } j \\
\text { generated or depleted } \\
\text { by chemical reactions }
\end{array}\right\} \\
& +\left\{\begin{array}{c}
\text { species } j \\
\text { transferred from or to } \\
\text { bubble phase }
\end{array}\right\}
\end{aligned}
$$

in mathematical terms,

$$
\begin{aligned}
A_{d} \Delta z(1-\delta) \varepsilon_{m f} & {\left[\left(C_{j, e}\right)_{t+\Delta t}-\left(C_{j, e}\right)_{t}\right] } \\
= & \Delta t\left(n_{j, e}\right)_{z}-\Delta t\left(n_{j, e}\right)_{z+\Delta z}+A_{d}(1-\delta) \varepsilon_{m f} \Delta z \Delta t \Re_{j, e} \\
& +A_{d} \delta \Delta z \Delta t K_{b e}\left(C_{j, b}-C_{j, e}\right)
\end{aligned}
$$


Division of Equation (3.132) by $A_{d}(1-\delta) \varepsilon_{m f} \Delta z \Delta t$ and taking $\lim _{\Delta z, \Delta t \rightarrow 0}$ yields,

$$
\frac{\partial C_{j, e}}{\partial t}=-\frac{1}{A_{d}(1-\delta) \varepsilon_{m f}} \frac{\partial n_{j, e}}{\partial z}+\mathfrak{R}_{j, e}+\frac{\delta}{(1-\delta) \varepsilon_{m f}} \kappa_{b e}\left(C_{j, b}-C_{j, e}\right)
$$

Utilizing ideal gas law for temporal derivative of species' concentration is as follows;

$$
\frac{\partial C_{j, e}}{\partial t}=\frac{P}{R}\left[-\frac{n_{j, e}}{n_{e} T_{d}^{2}} \frac{d T_{d}}{d t}+\frac{1}{n_{e} T_{d}} \frac{\partial n_{j, e}}{\partial t}-\frac{n_{j, e}}{n_{e}^{2} T_{d}} \frac{\partial n_{e}}{\partial t}\right]
$$

Combination of Equations (3.133) \& (3.134) yields,

$$
\begin{gathered}
\frac{\partial n_{j, e}}{\partial t}=\frac{R T_{d} n_{e}}{P A_{d}(1-\delta) \varepsilon_{m f}}\left[A_{d}(1-\delta) \varepsilon_{m f} \Re_{j, e}+A_{d} \delta \kappa_{b e}\left(C_{j, b}-C_{j, e}\right)\right. \\
\left.-\frac{\partial n_{j, e}}{\partial z}\right]+\frac{n_{j, e}}{T_{d}} \frac{d T_{d}}{d t}+\frac{n_{j, e}}{n_{e}} \frac{\partial n_{e}}{\partial t}
\end{gathered}
$$

and setting all temporal derivatives to zero, Equation (3.135) takes the form;

$$
\frac{\partial n_{j, e}}{\partial z}=A_{d}(1-\delta) \varepsilon_{m f} \Re_{j, e}+A_{d} \delta \kappa_{b e}\left(C_{j, b}-C_{j, e}\right)
$$

Again, Equation (3.23) is used as the boundary condition of Equation (3.136);

$$
@_{Z}=0, n_{e}=n_{a, p r i} \frac{1}{1+\frac{u_{b}}{u_{m f}} \frac{\delta}{(1-\delta) \varepsilon_{m f}}}
$$

Species generation/depletion terms in Equation (3.136), $\mathfrak{R}_{j, b}$, takes the following forms for each species considered; 


$$
\begin{aligned}
& j=1\left(O_{2}\right) \\
& \Re_{1, e}=-\frac{F_{v m} x_{v l}}{V_{b e d}(1-\delta) \varepsilon_{m f}}\left[0.5 \frac{x_{C, v m}}{M_{C}}+0.5 \frac{x_{H, v m}}{M_{H_{2}}}+\frac{x_{S, v m}}{M_{S}}-\frac{x_{O, v m}}{M_{O_{2}}}\right] \\
& \quad-0.5 n_{C, e}-0.5 r_{C O, e}-0.5 n_{N, e}-\frac{5}{4}\left(r_{N, h o m}\right)_{R 15} \\
&-\frac{1}{V_{b e d}(1-\delta) \varepsilon_{m f}}\left[\frac{5}{4}\left(r_{N, h e t}\right)_{19}+\frac{5}{4}\left(r_{N, h e t}\right)_{R 20}\right. \\
&\left.+\frac{3}{4}\left(r_{N, h e t}\right)_{R 21}+\frac{3}{4}\left(r_{N, h e t}\right)_{R 22}\right]
\end{aligned}
$$

$j=2(C O)$

$$
\begin{aligned}
\Re_{2, e}=\frac{F_{v m} x_{v l}}{V_{b e d}(1-\delta) \varepsilon_{m f}}\left[\frac{x_{C, v m}}{M_{C}}\right]+n_{C, e}-r_{C O, e} & \\
& +\frac{1}{V_{b e d}(1-\delta) \varepsilon_{m f}}\left[\left(r_{N, h e t}\right)_{R 17}-\left(r_{N, h e t}\right)_{R 18}\right]
\end{aligned}
$$

$j=3\left(\mathrm{CO}_{2}\right)$

$$
\mathfrak{R}_{3, e}=r_{C O, e}+\frac{1}{V_{\text {bed }}(1-\delta) \varepsilon_{m f}}\left(r_{N, h e t}\right)_{R 18}
$$

$$
\begin{aligned}
& j=4\left(\mathrm{H}_{2} \mathrm{O}\right) \\
& \mathfrak{R}_{4, e}=\frac{1}{V_{\text {bed }(1-\delta) \varepsilon_{m f}}}\left[F_{v m} x_{v l} \frac{x_{H, v m}}{M_{H_{2}}}+F_{\text {coal }} \frac{x_{H_{2} O}}{M_{H_{2} O}}-\left(r_{N, h o m}\right)_{R 16}\right] \\
& +\frac{3}{2}\left(r_{N, h o m}\right)_{R 15} \\
& +\frac{3}{2} \frac{1}{V_{\text {bed }}(1-\delta) \varepsilon_{m f}}\left[\left(r_{N, h e t}\right)_{R 19}+\left(r_{N, h e t}\right)_{R 20}\right. \\
& \left.+\left(r_{N, h e t}\right)_{R 21}+\left(r_{N, h e t}\right)_{R 21}\right]
\end{aligned}
$$


$j=5\left(\mathrm{SO}_{2}\right)$

$$
\mathfrak{R}_{5, e}=-\frac{F_{v m} x_{v l}}{V_{b e d}(1-\delta) \varepsilon_{m f}}\left[\frac{x_{S, v m}}{M_{S}}\right]
$$

$j=6\left(\mathrm{NH}_{3}\right)$

$$
\begin{aligned}
\Re_{6, e}=\frac{F_{v m} x_{v l}}{V_{\text {bed }}(1-\delta) \varepsilon_{m f}}\left[\frac{x_{N, v m}}{M_{N}}\right]-\left(r_{N, h o m}\right)_{R 15} & \\
- & \frac{1}{V_{b e d}(1-\delta) \varepsilon_{m f}}\left[\frac{2}{3}\left(r_{N, h o m}\right)_{R 16}+\left(r_{N, h e t}\right)_{R 21}\right. \\
& \left.+\left(r_{N, h e t}\right)_{R 22}\right]
\end{aligned}
$$

$j=7(N O)$

$$
\begin{aligned}
\mathfrak{R}_{7, e}=n_{N, e}+ & \left(r_{N, h o m}\right)_{R 15} \\
& -\frac{1}{V_{\text {bed }}(1-\delta) \varepsilon_{m f}}\left[\left(r_{N, h o m}\right)_{R 16}+\left(r_{N, h e t}\right)_{R 17}\right. \\
& \left.+\left(r_{N, h e t}\right)_{R 18}-\left(r_{N, \text { het }}\right)_{R 19}-\left(r_{N, \text { het }}\right)_{R 20}\right]
\end{aligned}
$$

\subsubsection{Energy Balance For Char Particles}

According to the study of Weimer and Clough [86], assuming uniform temperature inside of the char particle is valid for char particles' having diameters less than $7 \mathrm{~mm}$ under superficial velocities of $3.5 \mathrm{~m} / \mathrm{s}$, and temperature $1235 \mathrm{~K}$. Applying energy balance around the char particle can be expressed as; 


$$
\begin{aligned}
\left.\begin{array}{c}
\text { Energy } \\
\text { Accumulated } \\
\text { in the particle }
\end{array}\right\} & \\
& =\left\{\begin{array}{c}
\text { Energy } \\
\text { Generated } \\
\text { by chemical reaction }
\end{array}\right\}-\left\{\begin{array}{c}
\text { Energy } \\
\text { Loss } \\
\text { by convection }
\end{array}\right\} \\
& -\left\{\begin{array}{c}
\text { Energy } \\
\text { Loss } \\
\text { by radiation }
\end{array}\right\}
\end{aligned}
$$

representation in mathematical terms,

$$
\begin{aligned}
\frac{4}{3} \pi r^{3} \rho_{c} C_{p, c} \frac{d T_{c}}{d t} & \\
& =\frac{4 \pi r^{2} \rho_{c}}{M_{C}} \frac{x_{f c}}{x_{f c}+x_{a s h}} \Delta H_{R 81} \mathfrak{R}(r) \\
& -4 \pi r^{2}\left[h_{p}\left(T_{c}-T_{d}\right)+\sigma \varepsilon\left(T_{c}{ }^{4}-T_{d}{ }^{4}\right)\right]
\end{aligned}
$$

Dividing both sides of Equation (3.145) by $4 \pi r^{2}$ and rearranging yields;

$$
\begin{aligned}
\frac{d T_{c}}{d t}=\frac{3 x_{f c} \Delta H_{R 12}}{r M_{C} C_{p, c}\left(x_{f c}+x_{a s h}\right)} \mathfrak{R}(r) & \\
& \quad-\frac{3}{r \rho_{C} C_{p, c}}\left[h_{p}\left(T_{C}-T_{d}\right)+\sigma \varepsilon\left(T_{c}{ }^{4}-T_{d}{ }^{4}\right)\right]
\end{aligned}
$$

And considering steady-state,

$$
\frac{3 x_{f c} \Delta H_{R 12}}{r M_{C} C_{p, c}\left(x_{f c}+x_{a s h}\right)} \mathfrak{R}(r)=\frac{3}{r \rho_{C} C_{p, c}}\left[h_{p}\left(T_{C}-T_{d}\right)+\sigma \varepsilon\left(T_{c}^{4}-T_{d}^{4}\right)\right]
$$

where $\Delta H_{R 12}$ is the heat released from carbon combustion expressed by, 


$$
\Delta H_{R 12}=\left(2-\frac{2}{\zeta}\right) \Delta H_{R 8}+\left(\frac{2}{\zeta}-1\right) \Delta H_{R 9}
$$

In Equation (3.146), convective heat transfer coefficient is estimated by the use of the correlation given by Wakao et al. [87].

$$
h_{p}=\frac{k_{g}}{d_{p}}\left[2.0+1.1 \operatorname{Re}_{p}{ }^{0.6} \operatorname{Pr}^{0.33}\right]
$$

where,

$$
\begin{gathered}
R e_{p}=\frac{d_{p} u_{0} \rho_{C}}{\mu_{g}} \\
\operatorname{Pr}=\frac{C_{p, c} \mu_{g}}{k_{g}}
\end{gathered}
$$




\subsubsection{Energy Balance For Dense Zone Walls}

Previous model by Göğebakan [17] was developed for a CFBC with a rectangular cross-section. Since the cross-section of the CFBC considered in this study is circular, energy balance equation for dense zone walls should be modified. The assumptions for this calculation are;

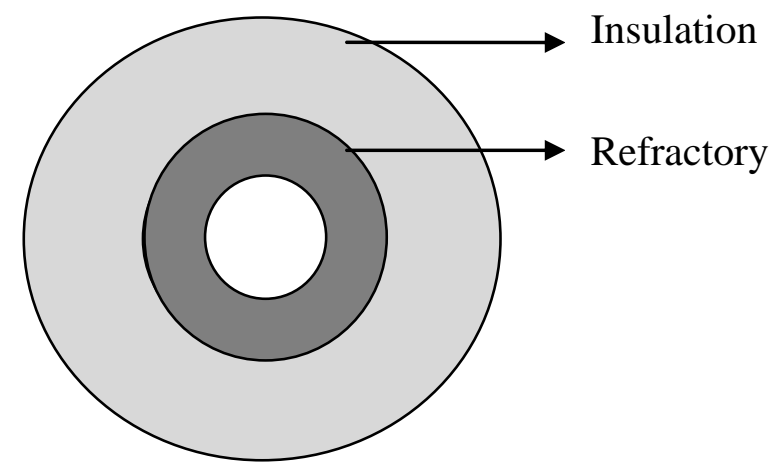

Figure 3.7 Cross-sectional view of the riser.

- One-dimensional heat transfer is assumed in $r$-direction.

- There is no heat transfer resistance in the contact surface of the refractory and insulation material.

- All physical properties are independent of the temperature.

Applying energy balance around the combustor for the finite cylindrical shell element gives;

$$
\left\{\begin{array}{c}
\text { Energy } \\
\text { Accumulated } \\
\text { In the Wall }
\end{array}\right\}=\left\{\begin{array}{c}
\text { Energy In } \\
b y \text { conduction } \\
\text { at } r
\end{array}\right\}-\left\{\begin{array}{c}
\text { Energy Out } \\
b y \text { conduction } \\
a t r+\Delta r
\end{array}\right\}
$$

In mathematical terms, 


$$
A_{r} \Delta r \rho_{w} C_{p, w}\left(\left(T_{d w}\right)_{t+\Delta t}-\left(T_{d w}\right)_{t}\right)=\left(q_{r} A_{r}\right)_{r}-\left(q_{r} A_{r}\right)_{r+\Delta r}
$$

Division of Equation (3.153) by $\Delta r \Delta t$ and taking $\lim _{\Delta t, \Delta r \rightarrow 0}$ with the replacement of $A_{r}=2 \pi\left(r_{0}+r\right) L$ being the cross-sectional area in the direction of the heat transfer, yields;

$$
2 \pi\left(r_{0}+r\right) L \rho_{w} C_{p, w} \frac{\partial T_{d w}}{\partial t}=-\frac{\partial}{\partial t}\left(2 \pi\left(r_{0}+r\right) L q_{r}\right)
$$

Replacement of $q_{r}$ by the Fourier's Law of Heat Conduction, i.e. $q_{r}=-k_{w} \frac{\partial T}{\partial r}$, and expression of $r_{0}$ in terms of the cross-sectional area of the dense zone, i.e. $r_{0}=\sqrt{\frac{A_{d}}{\pi}}$, in Equation (3.154) results in;

$$
\left(\sqrt{\frac{A_{d}}{\pi}}+r\right) \rho_{w} C_{p, w} \frac{\partial T_{d w}}{\partial t}=-\frac{\partial}{\partial r}\left[\left(\sqrt{\frac{A_{d}}{\pi}}+r\right) k_{w}\left(-\frac{\partial T_{d w}}{\partial r}\right)\right]
$$

Expansion of the right-hand side of the Equation (3.155) gives,

$$
-\frac{\partial}{\partial r}\left[\left(\sqrt{\frac{A_{d}}{\pi}}+r\right) k_{w}\left(-\frac{\partial T_{d w}}{\partial r}\right)\right]=\frac{\partial}{\partial r}\left[k_{w} \frac{\partial T_{d w}}{\partial r} \sqrt{\frac{A_{d}}{\pi}}+k_{w} \frac{\partial T_{d w}}{\partial r} r\right]
$$

and evaluation of this resulting equation; 


$$
\begin{array}{r}
\frac{\partial}{\partial r}\left[k_{w} \frac{\partial T_{d w}}{\partial r} \sqrt{\frac{A_{d}}{\pi}}+k_{w} \frac{\partial T_{d w}}{\partial r} r\right] \\
=k_{w} \sqrt{\frac{A_{d}}{\pi}} \frac{\partial^{2} T_{d w}}{\partial r^{2}}+k_{w} \frac{\partial^{2} T_{d w}}{\partial r^{2}} r+\frac{\partial T_{d w}}{\partial r} k_{w}
\end{array}
$$

Combining Equation (3.157) with Equation (3.155) and rearranging yields;

$$
\frac{\partial T_{d w}}{\partial t}=\frac{k_{w}}{\rho_{w} C_{p, w}\left(\sqrt{\frac{A_{d}}{\pi}}+r\right)}\left(\sqrt{\frac{A_{d}}{\pi}} \frac{\partial^{2} T_{d w}}{\partial r^{2}}+r \frac{\partial^{2} T_{d w}}{\partial r^{2}}+\frac{\partial T_{d w}}{\partial r}\right)
$$

Setting the temporal derivative to zero results in the working form of the wall energy balance equation for the dense zone.

$$
\sqrt{\frac{A_{d}}{\pi}} \frac{\partial^{2} T_{d w}}{\partial r^{2}}+r \frac{\partial^{2} T_{d w}}{\partial r^{2}}+\frac{\partial T_{d w}}{\partial r}=0
$$

Equation (3.159) is subject to the following boundary conditions;

$$
\begin{gathered}
@ r=0 \quad h_{w}\left(T-T_{w}\right)=-k_{w} \frac{\partial T_{w}}{\partial r} \\
@ r=R_{w} \quad T_{w}=T_{w, o}
\end{gathered}
$$

To derive the first order ODE form of the Equation (3.159), it is rearranged; 


$$
\left(\sqrt{\frac{A_{d}}{\pi}}+r\right) \frac{\partial^{2} T_{d w}}{\partial r^{2}}+\frac{\partial T_{d w}}{\partial r}=0
$$

And defining the term, $\psi$;

$$
\psi=\frac{d T_{d w}}{d r}
$$

Then, combining with Equation (3.162) yields the working form of the energy balance equation for dense zone wall;

$$
\left(\sqrt{\frac{A_{d}}{\pi}}+r\right) \frac{\partial \psi}{\partial r}+\psi=0
$$

\subsubsection{Energy Balance For Dense Zone}

Assuming single temperature for the bubble and emulsion phases and ignoring the mass of the gas, char and inert particles, energy balance for the dense zone can be expressed by; 


$$
\begin{aligned}
\left\{\begin{array}{c}
\text { Energy Accumulated } \\
\text { in Dense Zone }
\end{array}\right\} & \\
& =\left\{\begin{array}{c}
\text { Energy } \\
\text { Brought by Air }\}
\end{array}\right. \\
& +\left\{\begin{array}{c}
\text { Energy } \\
\text { Generated by Chemical Reactions }
\end{array}\right\} \\
& +\left\{\begin{array}{c}
\text { Energy } \\
\text { Transferred from Char Particles }
\end{array}\right\} \\
& +\left\{\begin{array}{c}
\text { Energy } \\
\text { Transferred from Recycled Particles }
\end{array}\right\} \\
& -\left\{\begin{array}{c}
\text { Energy } \\
\text { Required to Vaporize Moisture in Coal }
\end{array}\right\} \\
& -\left\{\begin{array}{c}
\text { Energy } \\
\text { Lost with Combustion Gases }
\end{array}\right\} \\
& -\left\{\begin{array}{c}
\text { Energy } \\
\text { Lost from Bed Walls }
\end{array}\right\} \\
& -\left\{\begin{array}{c}
\text { Energy } \\
\text { Lost with Elutriated Particles }
\end{array}\right\} \\
& -\left\{\begin{array}{c}
\text { Energy } \\
\text { Lost with Bed Drain Stream }
\end{array}\right\}
\end{aligned}
$$

Individual terms in Equation (3.165) can be expressed in mathematical terms given below;

- Energy brought by the air,

$$
Q_{a}=n_{a} \int_{T_{r e f}}^{T_{a}} C_{p, a} d T
$$

- Energy transferred from char particles,

$$
Q_{p}=\frac{3 M_{c, d}}{\rho_{C}} \int_{r_{\min }}^{r_{\max }}\left[h_{p}\left(T_{c}-T_{d}\right)+\sigma \epsilon\left(T_{c}^{4}-T_{d}^{4}\right)\right] \frac{d r}{r}
$$


- Energy generated by chemical reactions,

$$
\begin{aligned}
Q_{r x n}=A_{d} \Delta H_{R 11}^{\circ} & {\left[\varepsilon_{m f}(1-\delta) \int_{0}^{H_{d}} r_{C O, e} d z+\delta \int_{0}^{H_{d}} r_{C O, b} d z\right] } \\
& +F_{v m} x_{v l}\left[\frac{x_{C, v m}}{M_{C}} \Delta H_{R 2}^{\circ}+\frac{x_{H, v m}}{M_{H_{2}}} \Delta H_{R 3}^{\circ}+\frac{x_{s, v m}}{M_{S}} \Delta H_{R 4}^{\circ}\right] \\
& +\left[\Delta H_{R 15}^{\circ} \int_{0}^{H_{b e d}}\left(r_{R 15, b}\right) d z+\frac{\Delta H_{R 16}^{\circ}}{V_{b e d} \delta} \int_{0}^{H_{b e d}}\left(r_{R 16, b}\right) d z\right] \\
& +V_{b e d}(1-\delta) \varepsilon_{m f}\left[\Delta H_{R 15}^{\circ}\left(r_{R 15, e}\right)+\Delta H_{R 14}^{\circ}\left(n_{N, e}\right)\right] \\
& +\left[\Delta H_{R 16}^{\circ}\left(r_{R 16, e}\right)+\Delta H_{R 17}^{\circ}\left(r_{R 17, e}\right)+\Delta H_{R 18}^{\circ}\left(r_{R 18, e}\right)\right. \\
& +\Delta H_{R 19}^{\circ}\left(r_{R 19, e}\right)+\Delta H_{R 20}^{\circ}\left(r_{R 20, e}\right)+\Delta H_{R 21}^{\circ}\left(r_{R 21, e}\right) \\
& \left.+\Delta H_{R 22}^{\circ}\left(r_{R 22, e}\right)\right]
\end{aligned}
$$

- Energy transferred from recycled particles,

$$
Q_{r e c}=G_{s} A_{f} c_{p, i}\left(T_{r e c}-T_{r e f}\right)
$$

- Energy required to vaporize the moisture in coal,

$$
Q_{\text {vap }}=F_{\text {coal }} x_{\mathrm{H}_{2} \mathrm{O}} \lambda_{\mathrm{H}_{2} \mathrm{O}}^{\circ}
$$

- Energy lost with combustion gases,

$$
Q_{g}=\left(n_{e}+n_{b}\right) \sum_{n=1}^{6} y_{j} \int_{T_{r e f}}^{T_{d}} c_{p, g, j} d T
$$


- Energy lost from bed walls,

$$
Q_{d w}=A_{d w} h_{d w}\left(T_{d}-T_{d w, s}\right)
$$

- Energy lost with elutriated particles,

$$
Q_{c o}=\frac{G_{s} A_{f}}{\left(1-\eta_{c y c}\right)} c_{p, i}\left(T_{d}-T_{r e f}\right)
$$

- Energy lost with bed drain stream,

$$
Q_{b d}=F_{b d} c_{p, i}\left(T_{d}-T_{r e f}\right)
$$

overall cyclone efficiency, $\eta_{c y c}$, is given by;

$$
\eta_{c y c}=\int_{r_{\min }}^{r_{\max }} \eta_{c y c}(r) P_{i, f}\left(r, H_{f}\right) d r
$$

Equation (3.165) can also be expressed as;

$$
\begin{gathered}
\frac{d T_{d}}{d t}=\frac{1}{M_{i} c_{p, i}}\left[Q_{a}+Q_{r x n}+Q_{p}+Q_{r e c}-Q_{v a p}-Q_{g}-Q_{d w}-Q_{c o}\right. \\
\left.-Q_{b d}\right]
\end{gathered}
$$

And setting the temporal derivative to zero, Equation (3.176) takes the following form; 


$$
Q_{a}+Q_{r x n}+Q_{p}+Q_{r e c}-Q_{v a p}-Q_{g}-Q_{d w}-Q_{c o}-Q_{b d}=0
$$

\subsubsection{Mass and Energy Balance In Dilute Zone}

\subsubsection{Dilute Zone Gaseous Species Conservation}

Emulsion and bubble phase gaseous species are combined and then enter to the dilute zone. Dilute zone is assumed to be consisting of a one gaseous phase containing solids distributed according to the exponential decay function mentioned in dilute zone hydrodynamics. Plug flow of gas and solids are assumed to exists in dilue zone unsteady-state mass balance for any species $j$ between heights $z$ and $z+\Delta z$ is expressed as;

$$
\begin{aligned}
\left\{\begin{array}{c}
\text { species } j \\
\text { accumulated in } \\
\text { control volume }
\end{array}\right\} & \\
& =\left\{\begin{array}{c}
\text { species } j \text { in } \\
\text { by convection } \\
\text { at } z
\end{array}\right\}-\left\{\begin{array}{c}
\text { species } j \text { out } \\
\text { by convection } \\
\text { at } z+\Delta z
\end{array}\right\} \\
& +\left\{\begin{array}{c}
\text { species } j \\
\text { generated or depleted } \\
\text { by chemical reactions }
\end{array}\right\}
\end{aligned}
$$

In mathematical terms,

$$
\begin{aligned}
A_{f} \Delta z\left(1-\varepsilon_{s, f}\right) & {\left[\left(C_{j, f}\right)_{t+\Delta t}-\left(C_{j, f}\right)_{t}\right] } \\
& =\Delta t\left(n_{j, f}\right)_{z}-\Delta t\left(n_{j, f}\right)_{z+\Delta z}+A_{f}\left(1-\varepsilon_{s, f}\right) \Delta z \Delta t \Re_{j, f}
\end{aligned}
$$

Division of Equation (3.179) by $A_{f}\left(1-\varepsilon_{s, f}\right) \Delta z \Delta t$ and taking $\lim _{\Delta z, \Delta t \rightarrow 0}$ results in; 


$$
\frac{\partial C_{j, f}}{\partial t}=-\frac{1}{A_{f}\left(1-\varepsilon_{s, f}\right)} \frac{\partial n_{j, f}}{\partial t}+\Re_{j, f}
$$

As done in dense zone gaseous species conservation part, utilization of ideal gas law for the concentration and taking temporal derivative yields,

$$
\frac{\partial C_{j, f}}{\partial t}=\frac{P}{R}\left[-\frac{n_{j, f}}{n_{f} T_{f}^{2}} \frac{\partial T_{f}}{\partial t}+\frac{1}{n_{f} T_{f}} \frac{\partial n_{j, f}}{\partial t}-\frac{n_{j, f}}{n_{f}^{2} T_{f}} \frac{\partial n_{f}}{\partial t}\right]
$$

Combining Equation (3.180) with Equation (3.181) and rearranging yields,

$\frac{\partial n_{j, f}}{\partial t}=\frac{R T_{f} n_{f}}{P A_{f}\left(1-\varepsilon_{s, f}\right)}\left[A_{f}\left(1-\varepsilon_{s, f}\right) \Re_{j, f}-\frac{\partial n_{j, f}}{\partial z}\right]+\frac{n_{j, f}}{T_{f}} \frac{\partial T_{f}}{\partial t}+\frac{n_{j, f}}{n_{f}} \frac{\partial n_{f}}{\partial t}$

Considering steady-state condition;

$$
\frac{\partial n_{j, f}}{\partial z}=A_{f}\left(1-\varepsilon_{s, f}\right) \Re_{j, f}
$$

And the boundary condition for Equation (3.183) is;

$$
@_{Z_{f}}=0 n_{j, f}=n_{j, e}+n_{j, b}+n_{a, s e c} y_{j, a}
$$

Species generation/depletion terms in Equation (3.183), $\mathfrak{R}_{j, f}$, takes the following forms for each species considered; 


$$
\begin{gathered}
j=1\left(O_{2}\right) \\
\Re_{1, f}=-\frac{F_{v m}\left(1-x_{v l}\right)}{V_{f}\left(1-\varepsilon_{S, f}\right)}\left[0.5 \frac{x_{C, v m}}{M_{C}}+0.5 \frac{x_{H, v m}}{M_{H_{2}}}+0.5 \frac{x_{S, v m}}{M_{S}}-\frac{x_{O, v m}}{M_{O_{2}}}\right] \\
\quad-0.5 n_{C, f}-0.5 r_{C O, f}-\frac{5}{4}\left(r_{N, h o m}\right)_{R 15}
\end{gathered}
$$

$$
j=2(\mathrm{CO})
$$

$$
\Re_{2, f}=\frac{F_{v m}\left(1-x_{v l}\right)}{V_{f}\left(1-\varepsilon_{s, f}\right)}\left[\frac{x_{C, v m}}{M_{C}}\right]+n_{C, f}-r_{C O, f}
$$

$$
j=3\left(\mathrm{CO}_{2}\right)
$$

$$
\Re_{3, f}=r_{C O, f}
$$

$$
\begin{aligned}
& j=4\left(H_{2} O\right) \\
& \Re_{4, f}=\frac{F_{v m}\left(1-x_{v l}\right)}{V_{f}\left(1-\varepsilon_{s, f}\right)}\left[\frac{x_{H, v m}}{M_{H_{2}}}\right]+\frac{1}{V_{f}\left(1-\varepsilon_{s, f}\right)}\left(r_{N, h o m}\right)_{R 16}+\left(r_{N, h o m}\right)_{R 15}
\end{aligned}
$$

$$
j=5\left(\mathrm{SO}_{2}\right)
$$

$$
\mathfrak{R}_{5, f}=\frac{F_{v m}\left(1-x_{v l}\right)}{V_{f}\left(1-\varepsilon_{S, f}\right)}\left[\frac{x_{S, v m}}{M_{S}}\right]
$$

$$
\begin{aligned}
& j=6\left(N H_{3}\right) \\
& \Re_{6, f}=\frac{F_{v m}\left(1-x_{v l}\right)}{V_{f}\left(1-\varepsilon_{s, f}\right)}\left[\frac{x_{N, v m}}{M_{N}}\right]-\frac{1}{V_{f}\left(1-\varepsilon_{s, f}\right)}\left(r_{N, h o m}\right)_{R 16}-\left(r_{N, h o m}\right)_{R 15}
\end{aligned}
$$

$$
j=7(N O)
$$

$$
\Re_{7, f}=\left(r_{N, h o m}\right)_{R 15}-\frac{1}{V_{f}\left(1-\varepsilon_{S, f}\right)}\left(r_{N, h o m}\right)_{R 16}
$$


Char bound carbon consumption rate, $n_{C, f}$, in Equations (3.185) \& (3.186), is defined considering the entrained and elutriated char particles;

$$
\begin{gathered}
n_{C, f}=\frac{1}{M_{C}} \frac{x_{f c}}{x_{f c}+x_{a s h}}\left[\rho_{C} \int_{r_{\text {min }}}^{r_{\max }} \frac{\varepsilon_{c, f}(z) P_{c, f}(r, z)}{r} \Re_{f}(r) d r\right. \\
\left.+\frac{F_{2}}{A_{f}} \int_{r_{\text {min }}}^{r_{\text {max }}} \frac{P_{2}(r)}{r\left[u_{0}-u_{t}(r)\right]} \Re_{f}(r) d r\right]
\end{gathered}
$$

\subsubsection{Energy Balance For Dilute Zone Walls}

In order to solve energy balance for dilute zone walls, surface energy balance equation is utilized that is given below,

$$
\left\{\begin{array}{c}
\text { Energy Transferred } \\
\text { from Dilute Zone } \\
\text { to Wall }
\end{array}\right\}=\left\{\begin{array}{c}
\text { Rate of Energy } \\
\text { Transferred through } \\
\text { Wall }
\end{array}\right\}
$$

In mathematical terms,

$$
h_{f}(z)\left[T_{f}(z)-T_{f w}(z)\right]-\frac{\left[T_{f w}(z)-T_{\infty}\right]}{R_{f w}(z)}=0
$$

For the dilute zone, empirical correlation presented in the study of Basu and NAG is utilized for the gas side total heat transfer coefficient [88],

$$
h_{f}(z)=40 \rho_{\text {sus }}(z)^{0.5}
$$

In Equation (3.195), $\rho_{\text {sus }}$ is estimated from; 


$$
\rho_{s u s}(z)=\varepsilon_{c, f}(z) \rho_{c}+\varepsilon_{i, f}(z) \rho_{i}
$$

\subsubsection{Energy Balance For Dilute Zone}

Convective heat transfer, energy loss and generation are considered to solve an energy balance on a volume element of thickness $\Delta z$ in the dilute zone;

$$
\begin{aligned}
\left\{\begin{array}{c}
\text { Energy } \\
\text { Accumulated } \\
\text { In the Control Volume }
\end{array}\right\} & \\
& =\left\{\begin{array}{c}
\text { Energy } \\
\text { In by Convection at } z
\end{array}\right\} \\
& -\left\{\begin{array}{c}
\text { Energy } \\
\text { Out by convection } z+\Delta z
\end{array}\right\} \\
& +\left\{\begin{array}{c}
\text { Energy } \\
\text { Generation within the Control Volume }
\end{array}\right\}
\end{aligned}
$$

And in mathematical terms,

$$
\begin{aligned}
\frac{\partial}{\partial t}\left(A_{f} \Delta z(1-\right. & \left.\left.\varepsilon_{s, f}\right) \rho_{g} c_{p, g}\left(T_{f}-T_{r}\right)\right) \\
& =M_{g} n_{f} c_{p, g} T_{f}-\left.T_{r}\right|_{z}-M_{g} n_{f} c_{p, g} T_{f}-\left.T_{r}\right|_{z+\Delta z} \\
& +A_{f} \Delta z\left(1-\varepsilon_{s, f}\right) \mathcal{R}
\end{aligned}
$$

Division of Equation (3.198), by $A_{f} \Delta z\left(1-\varepsilon_{s, f}\right)$ and taking the $\operatorname{limit} \lim _{\Delta z \rightarrow 0}$ yields;

$$
\frac{\partial}{\partial t}\left(\rho_{g}\left(T_{f}-T_{r}\right)\right)=-\frac{M_{g}}{A_{f}\left(1-\varepsilon_{s, f}\right)} \frac{\partial}{\partial z}\left(n_{f}\left(T_{f}-T_{r}\right)\right)+\frac{\mathcal{R}}{c_{p, g}}
$$


Defining $\Delta T$ and $\rho_{g}$;

$$
\begin{gathered}
\Delta T=\left(T_{f}-T_{r}\right) \\
\rho_{g}=\frac{P M_{g}}{R T_{f}}
\end{gathered}
$$

And replacing these definitions in Equation (3.198);

$$
\frac{P M_{g}}{R} \frac{\partial}{\partial t}\left(\frac{\Delta T}{T_{f}}\right)=-\frac{M_{g}}{A_{f}\left(1-\varepsilon_{s, f}\right)} \frac{\partial}{\partial z}\left(n_{f} \Delta T\right)+\frac{R}{c_{p, g}}
$$

Evaluating the derivatives in Equation (3.202) and rearranging yields;

$$
\frac{\partial T_{f}}{\partial t}=-\frac{R T_{f}^{2} n_{f}}{A_{f}\left(1-\varepsilon_{s, f}\right) P T_{r}} \frac{\partial T_{f}}{\partial z}+\frac{R T_{f}^{2}}{P M_{g} T_{r} c_{p, g}} \boldsymbol{R}-\frac{R T_{f}^{2}\left(T_{f}-T_{r}\right)}{A_{f}\left(1-\varepsilon_{s, f}\right) P T_{r}} \frac{\partial n_{f}}{\partial z}
$$

Setting the temporal derivative to zero for steady-state conditions and setting $\frac{\partial n_{f}}{\partial z}$, to zero for the molar conservation, results in the following working form of the dilute zone energy balance equation;

$$
\frac{d T_{f}}{d z}=\frac{A_{f}\left(1-\varepsilon_{s, f}\right)}{n_{f} c_{p, g}} \boldsymbol{R}
$$

with the following boundary condition,

$$
@ Z_{f}=0 \quad T_{f}=T_{d}
$$


In Equation (3.204), $\boldsymbol{R}$ is the sum of the $R_{r x n}, R_{p}$ and $R_{f w}$ which are the energy generation by chemical reactions, energy transfer from/to particles and energy transfer to dilute zone walls respectively and defined as follows;

$$
\begin{aligned}
& R_{r x n}=\Delta H_{R 11}^{\circ} r_{c o, f} \\
& +\frac{F_{v m}\left(1-x_{v l}\right)}{V_{f}\left(1-\varepsilon_{s, f}\right)}\left[\frac{x_{C, v m}}{M_{C}} \Delta H_{R 2}^{\circ}+\frac{x_{H, v m}}{M_{H_{2}}} \Delta H_{R 3}^{\circ}\right. \\
& \left.+\frac{x_{s, v m}}{M_{S}} \Delta H_{R 4}^{\circ}\right] \\
& R_{p}=\frac{3 F_{2}}{A_{f} \rho_{C}} \int_{r_{\min }}^{r_{\max }} \frac{P_{3}(r)}{r\left(u_{0}-u_{t}(r)\right)}\left[h_{p}\left(T_{c}-T_{f}\right)+\sigma \epsilon\left(T_{c}^{4}-T_{f}^{4}\right)\right] d r \\
& +3 \varepsilon_{c, f}(z) \int_{r_{\min }}^{r_{\max }} \frac{P_{c, f}(r, z)}{r}\left[h_{p}\left(T_{c}-T_{f}\right)\right. \\
& \left.+\sigma \epsilon\left(T_{c}^{4}-T_{f}^{4}\right)\right] d r \\
& +3 \varepsilon_{i, f}(z) \int_{r_{\min }}^{r_{\max }} \frac{P_{i, f}(r, z)}{r}\left[h_{p}\left(T_{i}-T_{f}\right)\right. \\
& \left.+\sigma \epsilon\left(T_{i}^{4}-T_{f}^{4}\right)\right] d r \\
& R_{f w}=-\frac{4 D_{f}}{A_{f}\left(1-\varepsilon_{s, f}\right)} h_{f w}\left(T_{f}-T_{w}\right)
\end{aligned}
$$




\subsection{SOLUTION PROCEDURE}

The input data required by the system model are the configuration of the rig and its internals, air and coal flow rates, coal analysis, all solid and gas properties, inlet temperatures of air and cooling water and the size distribution of feed solids deduced from sieve analysis.

Apart from these input data, application of the model necessitates empirical and semi-empirical correlations from the literature for heat and mass transfer, combustion kinetics, elutriation and entrainment rates. These expressions contain empirical or semi-empirical constants which may not always comply with the experimental conditions of the system to be modeled. Therefore it is a usual practice to adjust some of these constants until a compromise is found to reproduce the measured data as accurately as possible [89]. In this study, minimum number of fitting parameters was utilized. These were exponential decay constant for entrainment, pre-exponential factor for the carbon monoxide oxidation and homogeneous nitrogen reduction reaction.

Direct use of the entrainment rate expression of Choi et al. [59] in the model, leads to higher pressure drop and solid hold-up in the dilute zone compared to measurements. This is considered to be due to the use of wide size distribution of coal feed $(<6.3 \mathrm{~mm})$ typical for fluidized bed combustors, compared to that of Choi et al. [59] $(<0.7 \mathrm{~mm})$ and also to the formation of ash directly from the feed coal particles in this study. To compensate for this discrepancy between the operating conditions, the decay constant of the entrainment rate expression of Choi et al. [59] was multiplied by 10 .

With regard to $C O$, the direct use of the rate expression of Hottel et al. [81] results in an order of magnitude lower $\mathrm{CO}$ concentration prediction than the 
measurement. This is attributed to the use of a rate constant determined at a higher temperature $\left(1400^{\circ} \mathrm{C}\right)$ for a low combustion temperature $\left(850^{\circ} \mathrm{C}\right)$ application. To account for this difference the rate constant of Hottel et al. [81] was multiplied by 0.3 .

Regarding the $N O$ emission, the use of kinetic expression of Johnson et al. [84] for the homogeneous $\mathrm{NO}$ reduction by $\mathrm{NH}_{3}$, led to an order of magnitude lower $\mathrm{NO}$ emission compared to measurement. However, measured $\mathrm{O}_{2}$ concentration (3.63\%) is indicative of a slightly reducing atmosphere slows down the rate of $N O$ reduction reaction. Therefore, the rate constant for $N O$ reduction reaction was multiplied by 0.1 and this value was used for model validation.

As no change is assumed for inert particles' size, particle size distribution function for inert particles is taken as 1 .

The solution procedure starts with making initial guesses for dense zone temperature, $T_{d}$, average emulsion phase $O_{2}$ mole fraction, $\bar{y}_{O_{2}, e}$, dense zone char hold-up, $M_{c, d}$ and dilute zone wall resistance, $R_{f w}$. This is followed by computation of char particles temperatures, $T_{c}(r)$, by using estimated parameters. There are five loops of iterations to be converged for $T_{d}, \bar{y}_{O_{2}, e}, M_{c, d}$ and $R_{f w}$. For each loop, a convergence criterion is set as the absolute difference between calculated and estimated values of the parameters,

$$
\left|\Gamma_{\text {calc }}-\Gamma_{\text {est }}\right|<\epsilon
$$

$\epsilon$ values utilized in the solution of this model is given in Table 3.9. 
Spatial domains of dense zone, dilute zone, char particle radius, bed wall thickness were divided into $\left(N_{d}-1\right),\left(N_{f}-1\right),\left(N_{p}-1\right)$ and $\left(N_{d w}-1\right)$ intervals, respectively, for regular printing of results and for numerical integration. The predictions reported in this study were obtained with $N_{d}, N_{f}, N_{p}$ and $N_{b w}$ values 15, 77, 117 and 11 respectively. The integration of ODEs is carried out by Backward-Differentiation Formula (BDF) method embedded in the ODE solver LSODES [90]. Solution of the non-linear algebraic equations is performed by using the subroutine ZERO [91].

Table 3.9 Values of $\epsilon$ utilized for the convergence check.

\begin{tabular}{|c|c|}
\hline Parameter & $\boldsymbol{\epsilon}$ \\
\hline$M_{c, d}, k g$ & $1.0 \times 10^{-3}$ \\
\hline $\bar{y}_{O_{2}, e},-$ & $1.0 \times 10^{-4}$ \\
\hline $\bar{T}_{c}, K$ & 1.0 \\
\hline$T_{d}, K$ & 1.0 \\
\hline$R_{f w}, \frac{J}{m^{2} \cdot s \cdot K}$ & $5.0 \times 10^{-1}$ \\
\hline
\end{tabular}




\section{CHAPTER 4}

\section{EXPERIMENTAL SET-UP AND CONDITIONS}

\subsection{EXPERIMENTAL SET-UP}

Predictive accuracy of the CFBC model under consideration in this study was tested by comparing its predictions with the experimental data repoted by Batu et al. [92]. The experimental work was carried out on METU $150 \mathrm{~kW}_{\mathrm{t}} \mathrm{CFBC}$ test rig. The test rig designed, constructed and operated under the scope of a former project, "Circulating Fluidized Bed Combustor Test Unit", for the investigation of combustion and emission characteristics of low quality Turkish lignites. The combustor has a circular cross-section with inner diameter of $0.25 \mathrm{~m}$ and a height of $8 \mathrm{~m}$. The combustor is mainly composed of furnace, cooling system, cyclone, downcomer and loop seal with auxilary systems such as air and flue gas systems, solid handling and feeding system, gas analysis system etc. The process and instrumentation diagram of the test rig is shown in Figure 4.1. Details of the combustor and operating conditions can be found in Batu et al. [92]. Bed drain, circulating ash and fly ash were collected from the bottom of the riser, the loop seal and the bag filter respectively. 


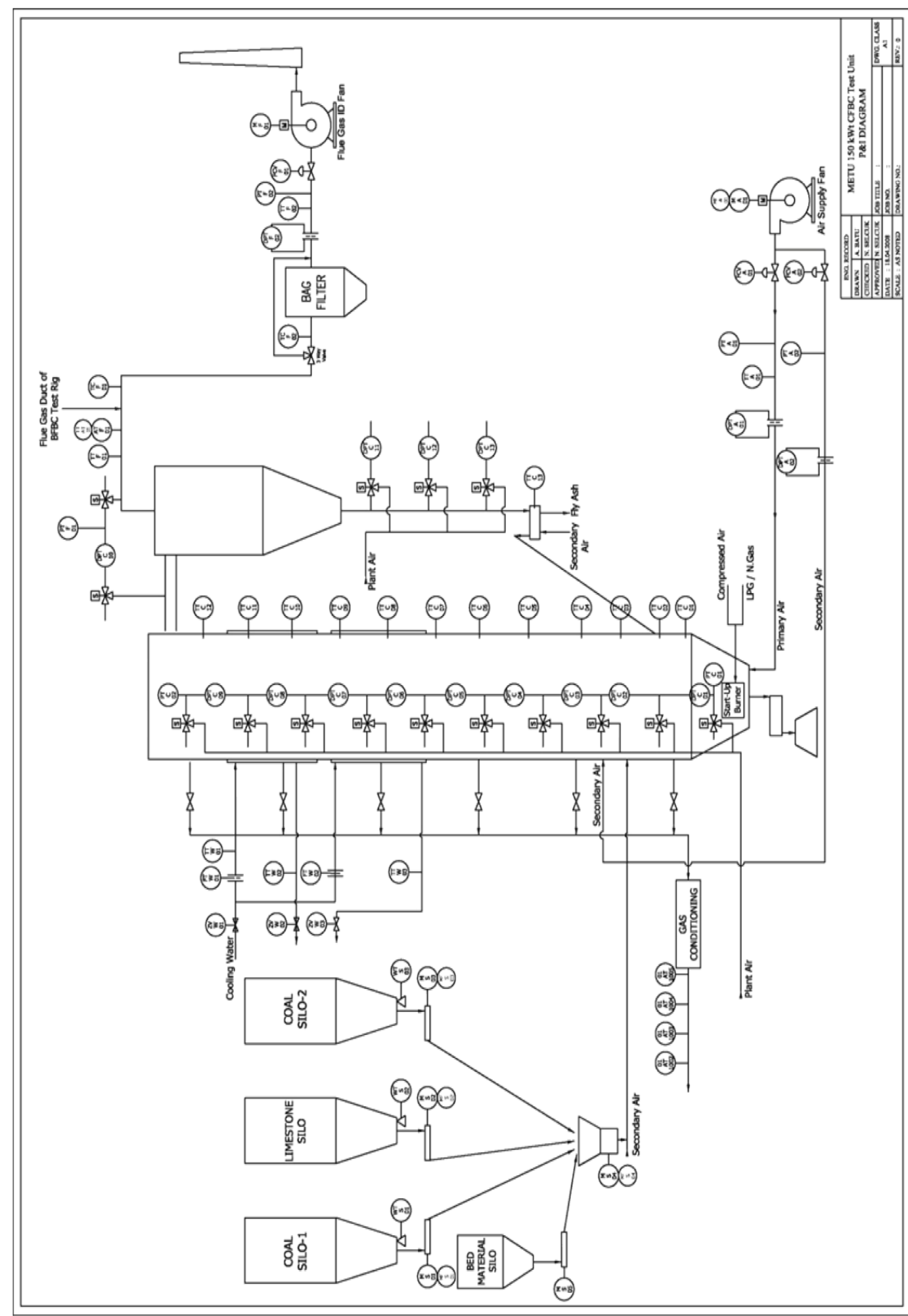

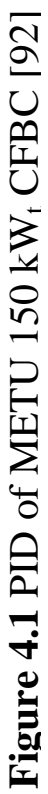




\subsubsection{CFB Combustor}

Combustor is mainly composed of riser, cyclone, downcomer and loop seal. Riser is divided into 5 modules for manufacturing, installation, possible revisions in future and temperature control reasons. J-valve is placed at the return leg of cyclone for sealing the return leg and maintaining the rate of circulation. PID of the system is given in Figure 4.2.

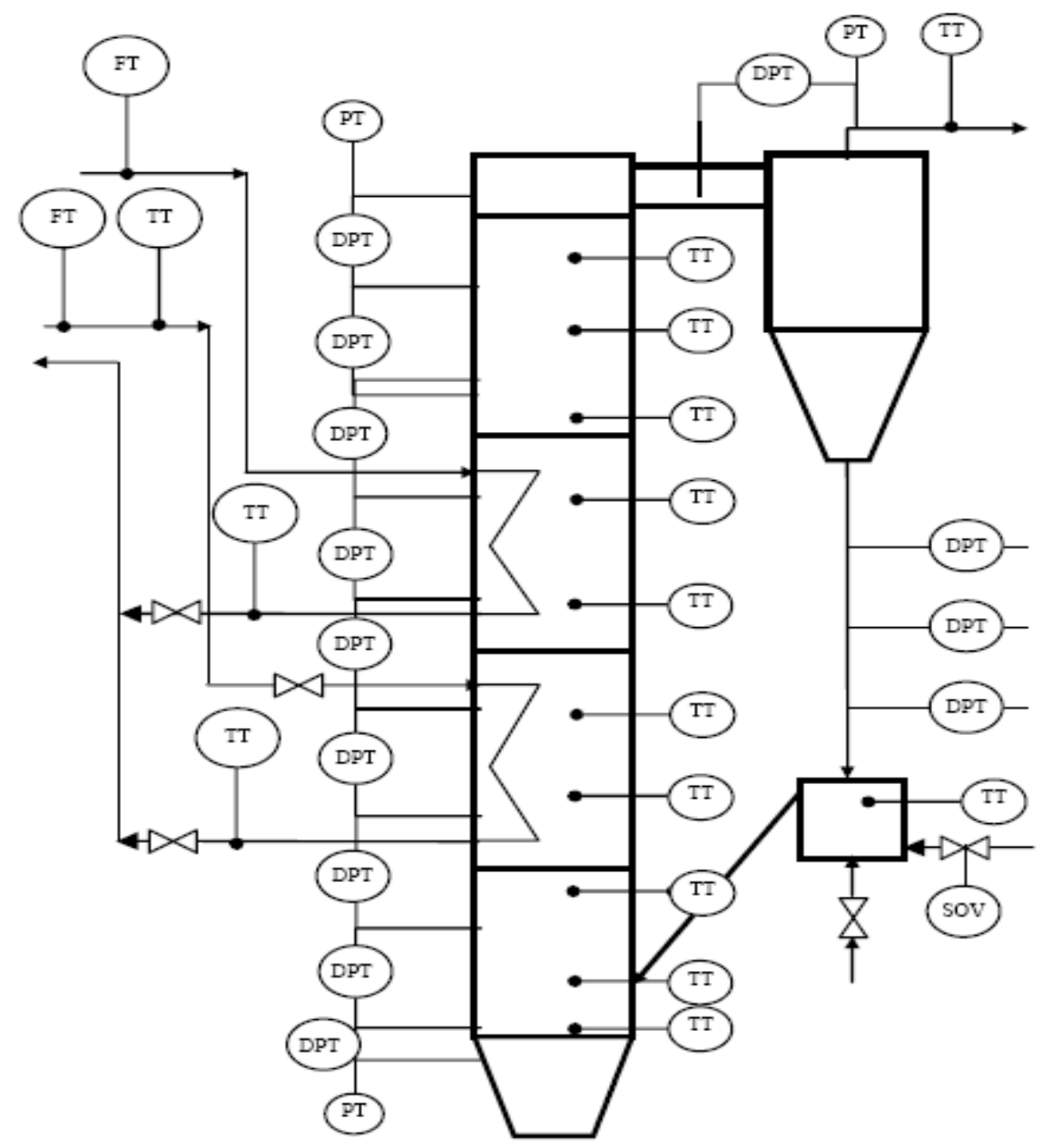

Figure 4.2 PID of combustor [6]. 
Temperature, pressure and pressure difference transmitters are located along the combustor. Received signals from these transmitters are logged into the computer both for process control and combustion results' evaluation.

Particle load distribution along the combustor is determined by the measurements obtained from pressure and differential pressure transmitters. Control parameters for control valves of blower and induced draft fan are the pressure data obtained from differential pressure transmitters.

Temperature along the combustor, and outlet temperatures of cooling water are the control parameters for combustion chamber temperature. Temperature data is checked by the operator, then regulation of the manual valves of cooling water is done.

Solid circulation may not be achived, if the particles cannot flow into the riser due to high inside pressure. In this case, the solenoid valve (SOV, activated manually when particle load in downcomer is high) for the compressed air is opened in order to convey the particles into the riser.

\subsubsection{Combustion Air System}

Blower, piping of combustion air, valves, rotameters and equipments for flow measurements compose the combustion air system. PID of the system is given in the Figure 4.3.

After the blower, the main combustion air stream line is divided into two which leads to primary and secondary air control valves. Measurement of the flow rate and pressure is done after these valves. Since no deviation of the temperature is expected between primary and secondary air lines, measurement of temperature is done only on primary air piping. While primary air goes to riser through the 
windbox, secondary air goes to collector feeding injection tubes and windbox of the loop seal.

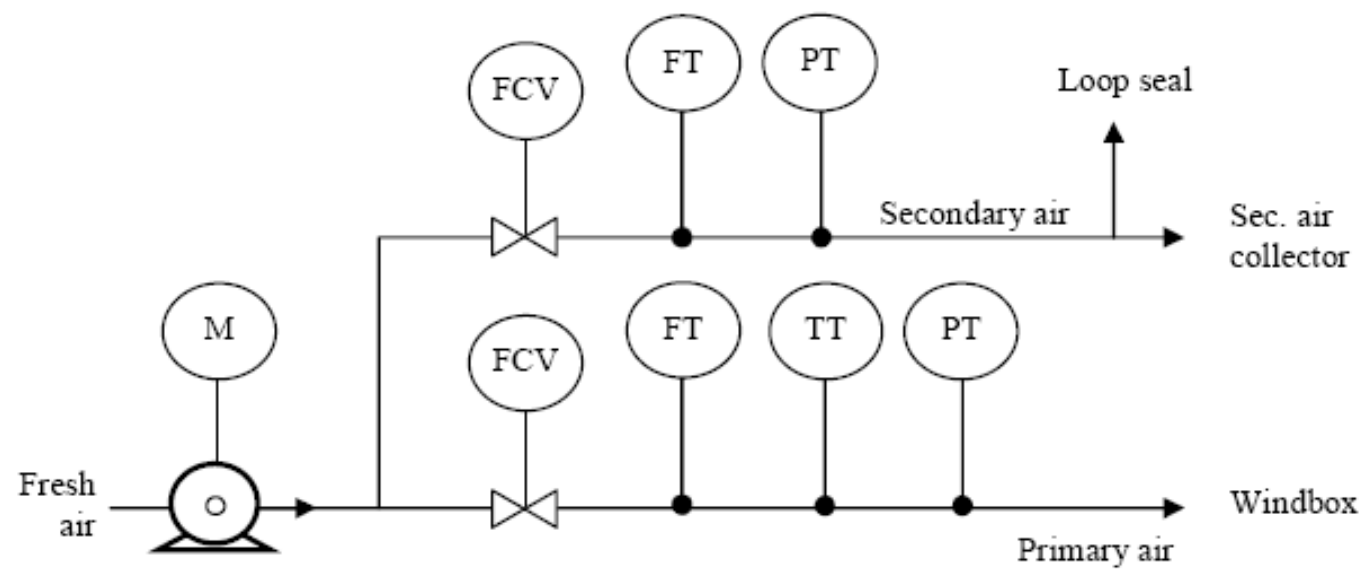

Figure 4.3 PID of combustion air system [6].

Coal flow rate to excess air ratio determines the air flow required by the furnace. Control valves are utilized to keep the air flow rate at the required value. The parameters that are used to control the valves are the air flow rate values obtained from application of temperature and pressure corrections to the pressure drop data through a flow element.

After the manual definition of the "Primary Air/Secondary Air" ratio, the system estimates the flow rate need by multiplication of this ratio with overall combustion air flow rate and regulation of the valve is achived according to this estimated flow rate. Regulation of the secondary air valve is done according to the data from the flow transmitter.

Independent of the variations in the overall air flow rate, the control system regards the secondary air ratio as the control parameter and maintains the ratio at required value. 


\subsubsection{Solids Handling and Feeding System}

Coal, limestone and bed material handling, solids feeding, solids circulation system and ash removal system constitute the solids handling and feeding system. Solids flow through screw feeders which are connected to main bunker for mixing. Then, with the utilization of an air lock type main feeder which is located at the bottom of this bunker, solids are fed via an inclined leg to the riser. In order to isolate the furnace from solids feeding system, this main feeder is selected as air lock. The system's PID is given in Figure 4.4.

In order to remove bed ash from the system, a discharge line is placed at the bottom of the riser. This line is designed for the discharge of the particles by the utilization of compressed air conveying system.

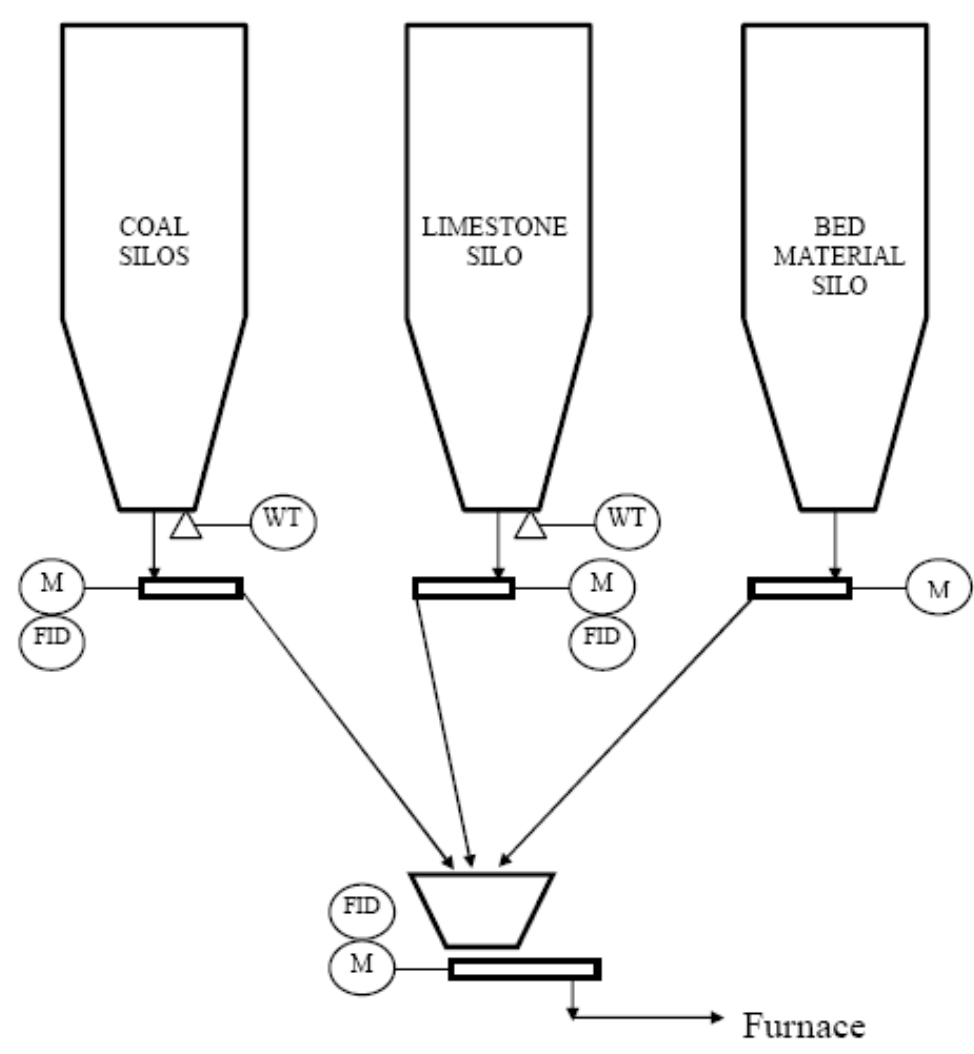

Figure 4.4 PID of solids handling and feeding system [6]. 
When there is a requirement to decrease the particle load in the system, the outlet pipe of the J-valve is utilized for particle discharge. After the combustion run, draining of the system is achived via the help of this outlet line.

Weight signals received from coal and limestone silos' load cells are used to estimate the flow rates of solid streams. Rate of change of weight with respect to time is calculated from the difference in weight within a time interval which is then converted to flow rate of each species.

Regulation of the flow rate of coal according to the variations in many parameters such as riser temperature, pressure, $\mathrm{CO}, \mathrm{CO}_{2}$ and $\mathrm{O}_{2}$ concentrations can be achived manually. Manual regulation of the frequencies of the screw feeders can be done which are placed at the bottom of silos to feed the solids at required flow rates.

Differential pressure data within the dense zone of the riser is utilized for the operation of bed drain discharge system. When increase in the particle load in the riser occurs, the system is turned on.

When the particle accumulation in the downcomer is higher than the required value, the excess fly ash particles are drained from the system. The discharge of Jvalve is used for this purpose.

\subsubsection{Gas Analysis System}

There exist 6 gas sampling ports along the riser for combustion gas sampling. These ports are linked with the analyzers for the measurement of $\mathrm{CO}, \mathrm{NO}_{x}, \mathrm{SO}_{2}$ and $\mathrm{O}_{2}$ concentrations via the gas conditioning system. This system's PID is given in Figure 4.5. 


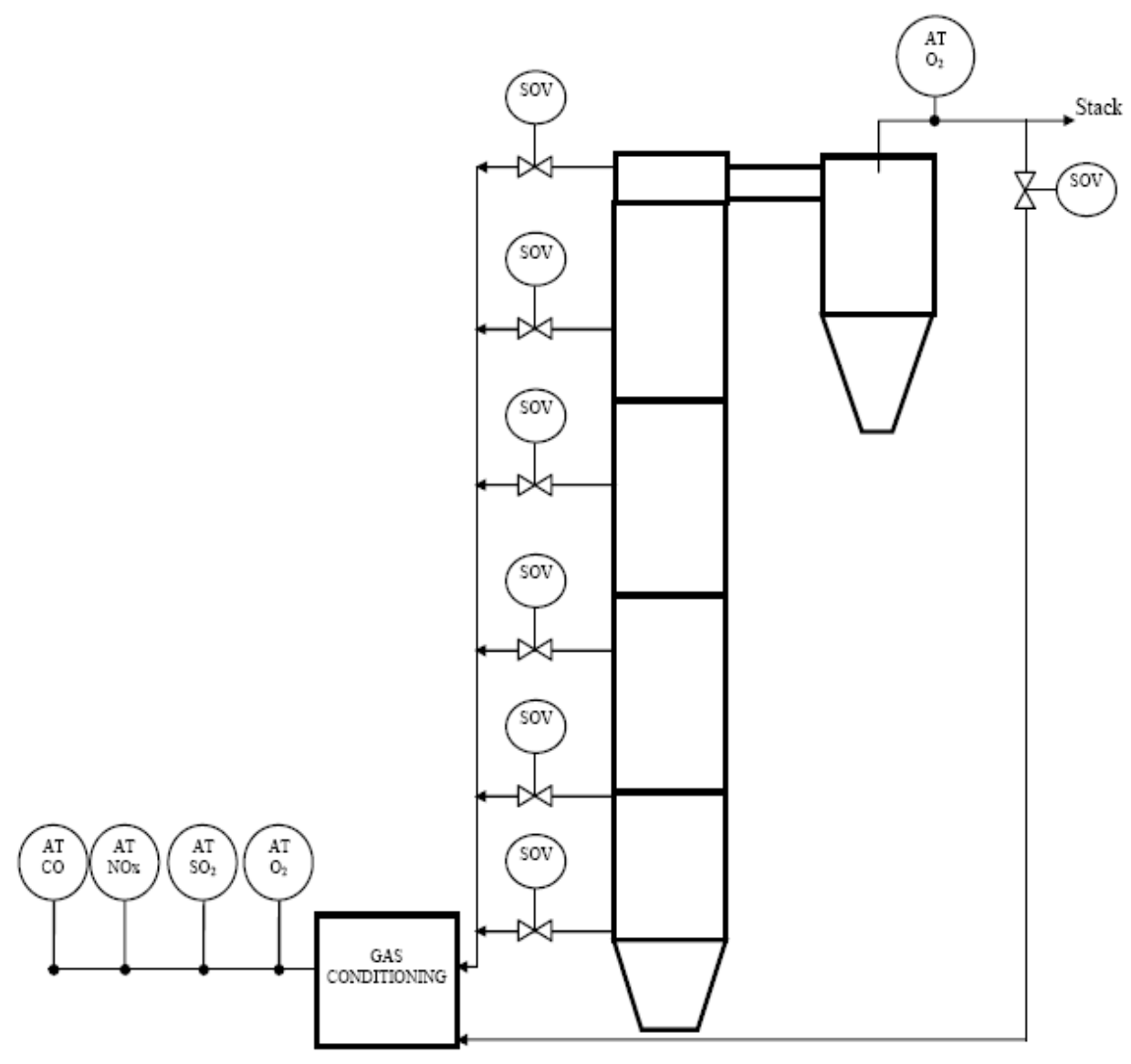

Figure 4.5 PID of gas analysis system [6].

In order to control combustion, gas concentration data received from the analyzer at the riser exit is taken into account. Measured oxygen concentration at the exit of cyclone is an indicator for excess air ratio in the riser.

Flue gas sampling is achived by following the procedure summarized below;

- Manual selection of the sampling port for the combustion gas.

- All valves other than the valve of the selected sampling port is closed.

- Sampling of the flue gas is achived which flows through the gas conditioning system and analyzers. 
Monitored gas concentrations are logged to the computer and followed manually in order to take action when necessary.

\subsubsection{Flue Gas System}

Bag filter, induced draft fan and flue gas lines constitute the flue gas system. The system's PID is given in Figure 4.6.

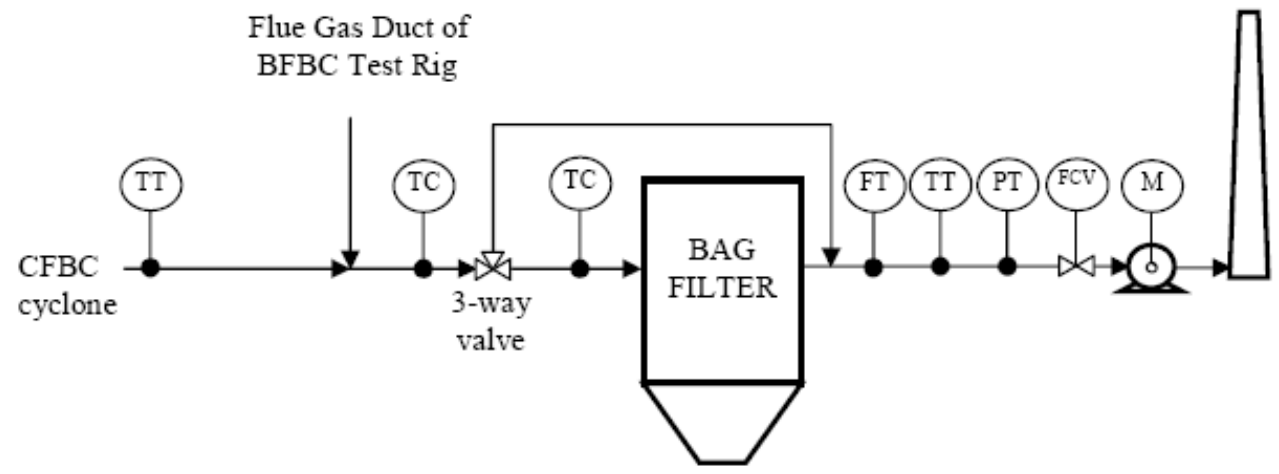

Figure 4.6 PID of flue gas system [6].

The cyclone and the flue gas line of the existing test rig is connected with the flue gas line of METU $150 \mathrm{~kW}_{\mathrm{t}}$ in which there is a 3-way valve in order to by-pass the bag filter if temperature limits of the bag filter is exceeded. The flue gas system of the existing unit starts from this by-pass valve.

Thermocouples are placed through the existing flue gas system in order to measure the flue gas temperature which is a control parameter for the by-pass valve. After the bag filter; pressure, temperature and flow transmitters, flue gas damper control valve and induced draft fan are located before the stack.

In order to balance the pressure at the exit of combustor together with the blower, flow control valve is placed before the induced draft fan. The control parameters 
for the flue gas system are the data obtained from the pressure transmitter before the damper valve.

\subsection{EXPERIMENTAL CONDITIONS}

Çan lignite was fired in the experiment, which represents a typical indigenous lignite having low calorific value and high ash content. Analysis of the lignite used in the experiment is given in Table 4.1.

As can be seen from Table 4.1, low calorific value indigenous lignite with high VM/FC ratio and high ash content is utilized. Due to its high ash content, the experiment was carried out by burning lignite in its own ash, the analysis of which is illustrated in Table 4.2. Lignite has a wide size distribution typical for fluidized bed combustion and it has a $d_{50}$ of $1.29 \mathrm{~mm}$. Operating conditions of the experiment are presented in Table 4.3. 
Table 4.1 Characteristics of Çan lignite.

\begin{tabular}{|c|c|c|c|c|c|}
\hline Sieve & alysis & $\begin{array}{r}\text { Proxin } \\
\text { (a }\end{array}$ & $\begin{array}{l}\text { Analysis } \\
\text { ed) }\end{array}$ & Ultim & nalysis \\
\hline $\begin{array}{c}\mathbf{D}_{\mathrm{p}} \\
(\mathbf{m m})\end{array}$ & $\begin{array}{c}\text { Weight } \\
(\%)\end{array}$ & & $\begin{array}{c}\text { Weight } \\
(\%)\end{array}$ & & $\begin{array}{c}\text { Weight } \\
(\%)\end{array}$ \\
\hline $6.30-4.75$ & 5.88 & Moist. & 16.24 & $\mathrm{C}$ & 41.05 \\
\hline $4.75-3.35$ & 15.64 & Ash & 32.72 & $\mathrm{H}$ & 3.31 \\
\hline $3.35-2.00$ & 12.65 & VM & 29.20 & $\mathrm{O}$ & 12.18 \\
\hline $2.00-1.00$ & 22.27 & $\mathrm{FC}$ & 21.44 & $\mathrm{~N}$ & 1.10 \\
\hline $1.00-0.60$ & 11.02 & \multirow{5}{*}{\multicolumn{2}{|c|}{$\begin{array}{c}\text { LHV: } 3085 \mathrm{kcal} / \mathrm{kg} \\
\mathrm{d}_{50}: 1.29 \mathrm{~mm} \\
\rho_{\text {bulk: }}: 932 \mathrm{~kg} / \mathrm{m}^{3}\end{array}$}} & $\mathrm{~S}_{\mathrm{comb}}$ & 3.30 \\
\hline $0.60-0.43$ & 6.88 & & & $\mathrm{~S}_{\mathrm{tot}}$ & 4.59 \\
\hline $0.43-0.18$ & 10.72 & & & Ash & 39.06 \\
\hline $0.18-0.11$ & 5.11 & & & & \\
\hline $0.11-0.00$ & 10.02 & & & & \\
\hline
\end{tabular}


Table 4.2 Çan lignite ash composition.

\begin{tabular}{|c|c|}
\hline Compound & Weight \% \\
\hline $\mathrm{SiO}_{2}$ & 57.29 \\
\hline $\mathrm{Al}_{2} \mathrm{O}_{3}$ & 19.67 \\
\hline $\mathrm{Fe}_{2} \mathrm{O}_{3}$ & 12.05 \\
\hline $\mathrm{CaO}$ & 4.85 \\
\hline $\mathrm{MgO}$ & 0.82 \\
\hline $\mathrm{SO}_{3}$ & 2.00 \\
\hline $\mathrm{Na}_{2} \mathrm{O}$ & 1.58 \\
\hline $\mathrm{K}_{2} \mathrm{O}$ & 0.21 \\
\hline $\mathrm{TiO}_{2}$ & 1.53 \\
\hline
\end{tabular}


Table 4.3 Opearating parameters of the METU $150 \mathrm{~kW}_{\mathrm{t}} \mathrm{CFBC}$.

\begin{tabular}{|c|c|}
\hline Parameter & Value \\
\hline Coal Flow Rate, $\mathrm{kg} / \mathrm{h}$ & 48.55 \\
\hline Primary Air Flow Rate, $\mathrm{kmol} / \mathrm{h}$ & 7.95 \\
\hline Secondary Air Flow Rate, $\mathrm{kmol} / \mathrm{h}$ & 1.01 \\
\hline Total Air Flow Rate, $\mathrm{kmol} / \mathrm{h}$ & 8.96 \\
\hline Excess Air, $\%$ & 16.5 \\
\hline Primary Air/Secondary Air, $\%$ & $88.7 / 11.3$ \\
\hline Cooling Water Inlet Temperature, ${ }^{\circ} \mathrm{C}$ & 16.7 \\
\hline
\end{tabular}




\section{CHAPTER 5}

\section{RESULTS AND DISCUSSION}

Predictive accuracy of the model is tested by applying it to the simulation of METU $150 \mathrm{~kW}_{\mathrm{t}}$ CFBC Test Rig and comparing its predictions with measurements available on the same rig.

Figure 5.1 illustrates comparison between the measured and predicted pressure profiles for the experiment under consideration. Location of pressure measurements in this figure are demonstrated in Figure 3.2. As can be seen from Figure 5.1, favorable comparisons are obtained between the predicted and measured pressure profiles.

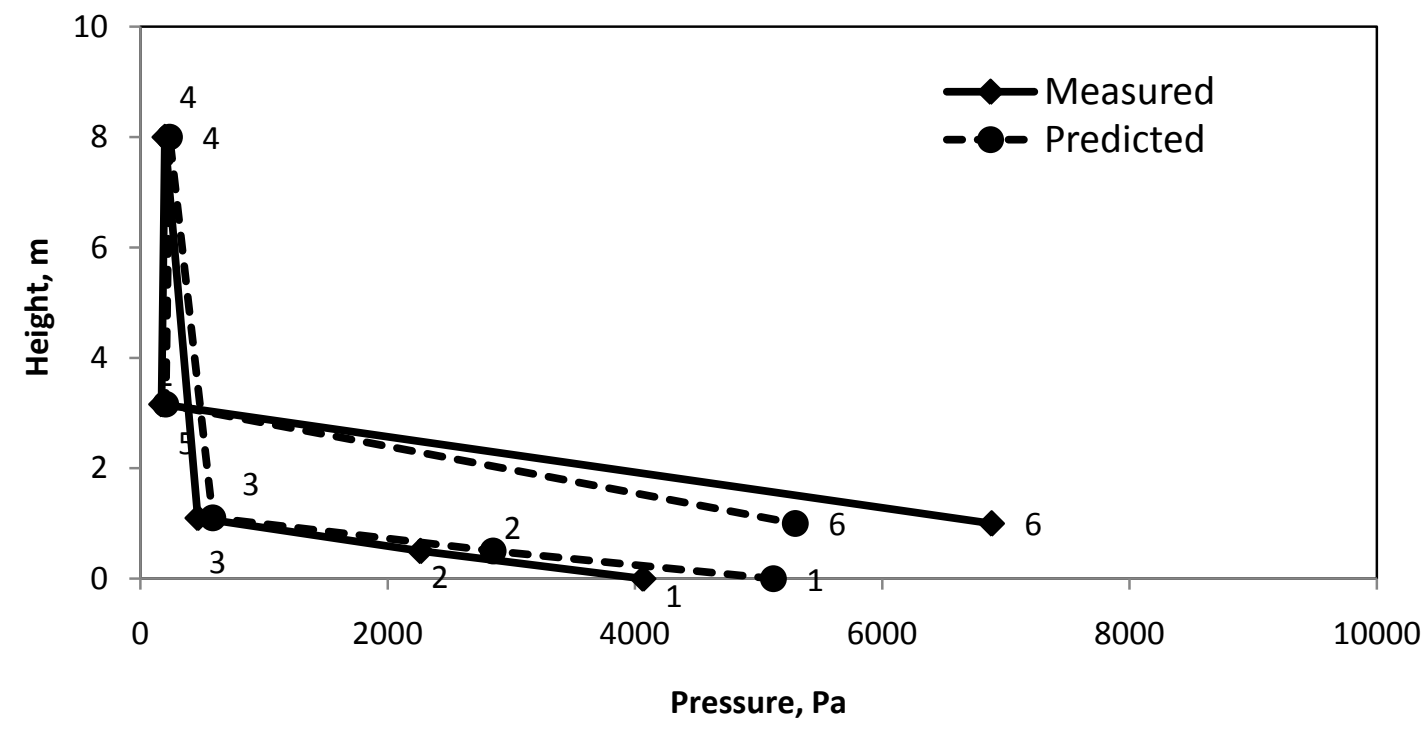

Figure 5.1 Pressure profile. 
Comparison between the predicted and measured temperature along the combustor is shown in Figure 5.2. There is a reasonable agreement between the predictions and measurements.

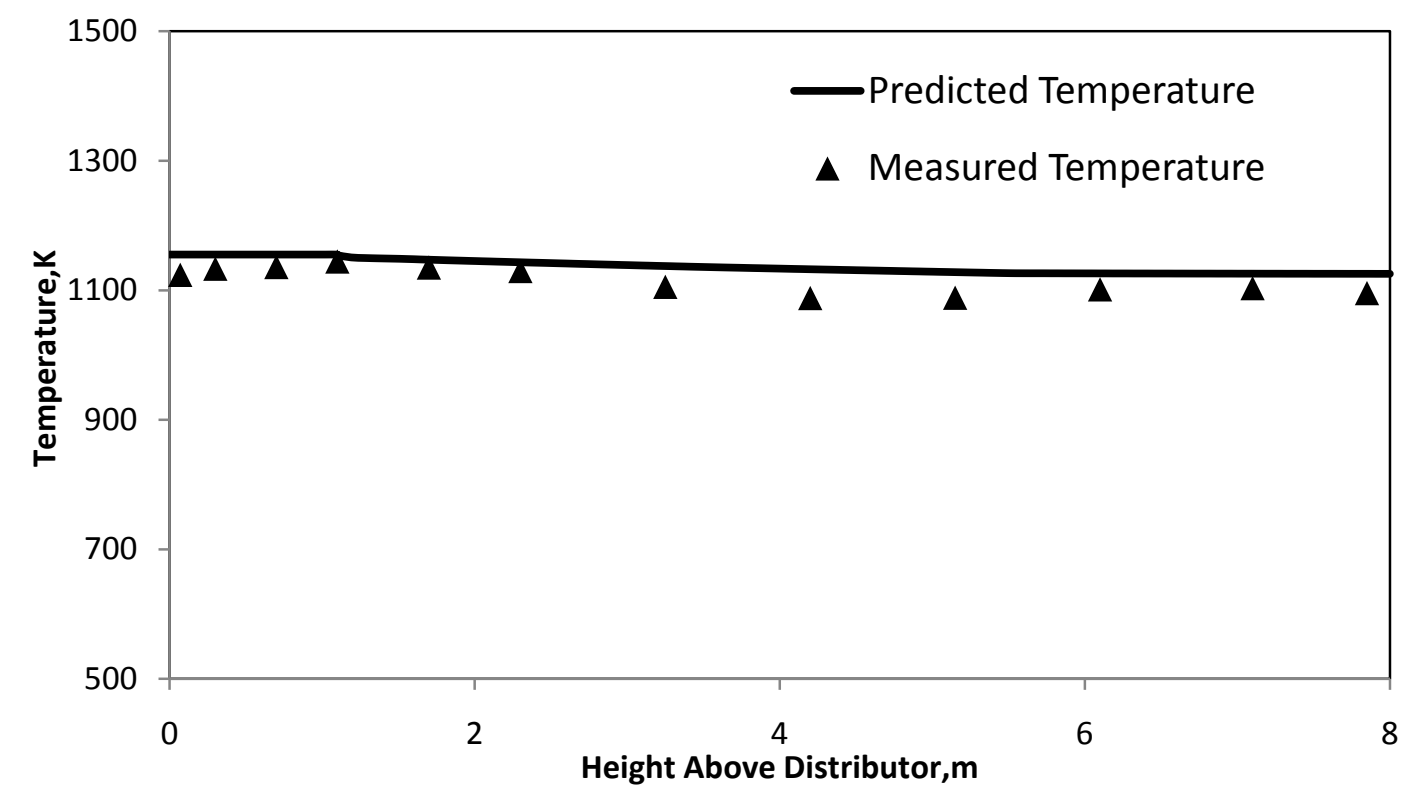

Figure 5.2 Temperature profile.

Figure 5.3 illustrates the predicted concentrations of $\mathrm{O}_{2}, \mathrm{CO}_{2}$, and $\mathrm{CO}$ along the combustor as well as their measured emissions. The profiles show physically expected trends and predicted and measured emissions are reasonably in good agreement with each other. 


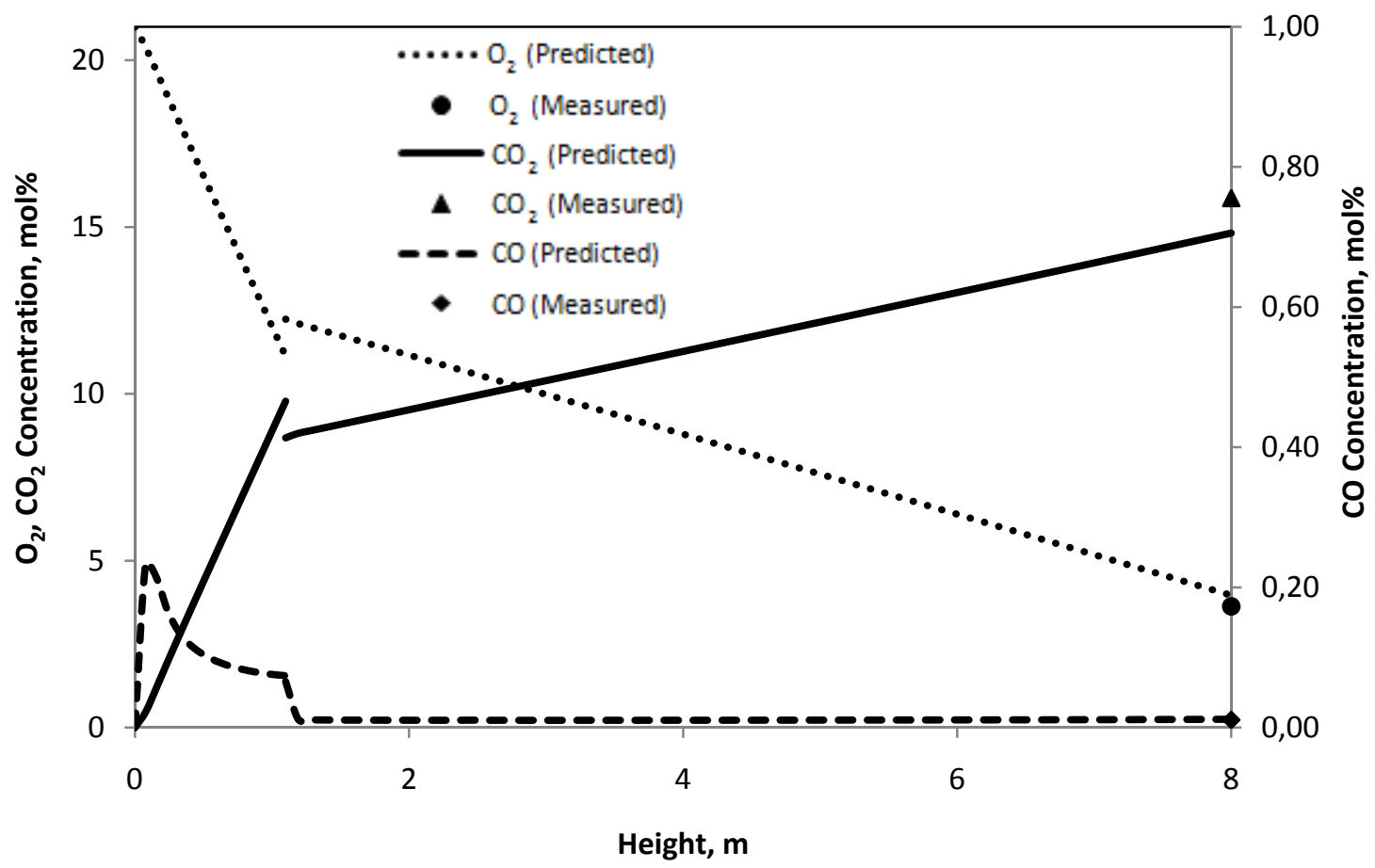

Figure 5.3 Concentration profiles along the combustor and emissions.

Predicted concentration profile of $N O$ together with measured $N O$ emission are illustrated in Figure 5.4. As can be seen from the figure, $N O$ concentration rise steeply in the dense zone and gradually decrease along the dilute zone. Heterogeneous reactions gain importance in the net formation of $N O$ in the dense zone owing to the fact that $N O$ is known to form preferentially in the emulsion phase where fuel particles are devolatilized. 


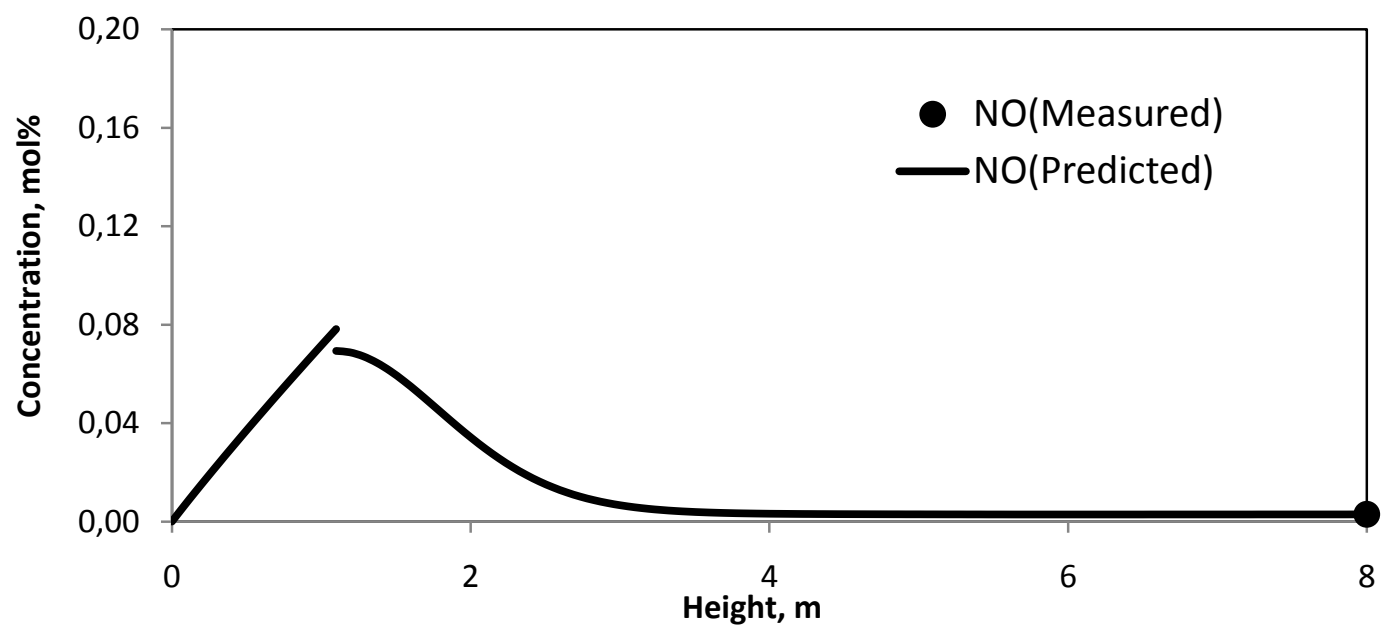

Figure 5.4 NO concentration profile along the combustor and emission.

Comparison between predicted and measured emissions is illustrated in Table 5.1. As presented in table, favorable agreement exists between the predicted emissions and the measurements.

Table 5.1 Experimental and predicted emissions.

\begin{tabular}{|c|c|c|c|c|}
\hline & $\mathrm{CO}$ & $\mathrm{CO}_{2}$ & $\mathrm{O}_{2}$ & $\mathrm{NO}$ \\
\hline $\begin{array}{c}\text { Measured } \\
\text { Concentration, \% }\end{array}$ & 0.0108 & 15.87 & 3.63 & 0.00298 \\
\hline $\begin{array}{c}\text { Predicted } \\
\text { Concentration, \% }\end{array}$ & 0.0119 & 14.82 & 3.95 & 0.00290 \\
\hline
\end{tabular}

Figure 5.5 displays the comparison between predicted and measured particle size distributions of the bed drain and recycle streams. Favorable comparisons are obtained for the bed drain. Discrepancy between finer fractions of predicted and measured recycle streams is attributed to the inefficiency of cyclone to capture the fine fraction. 


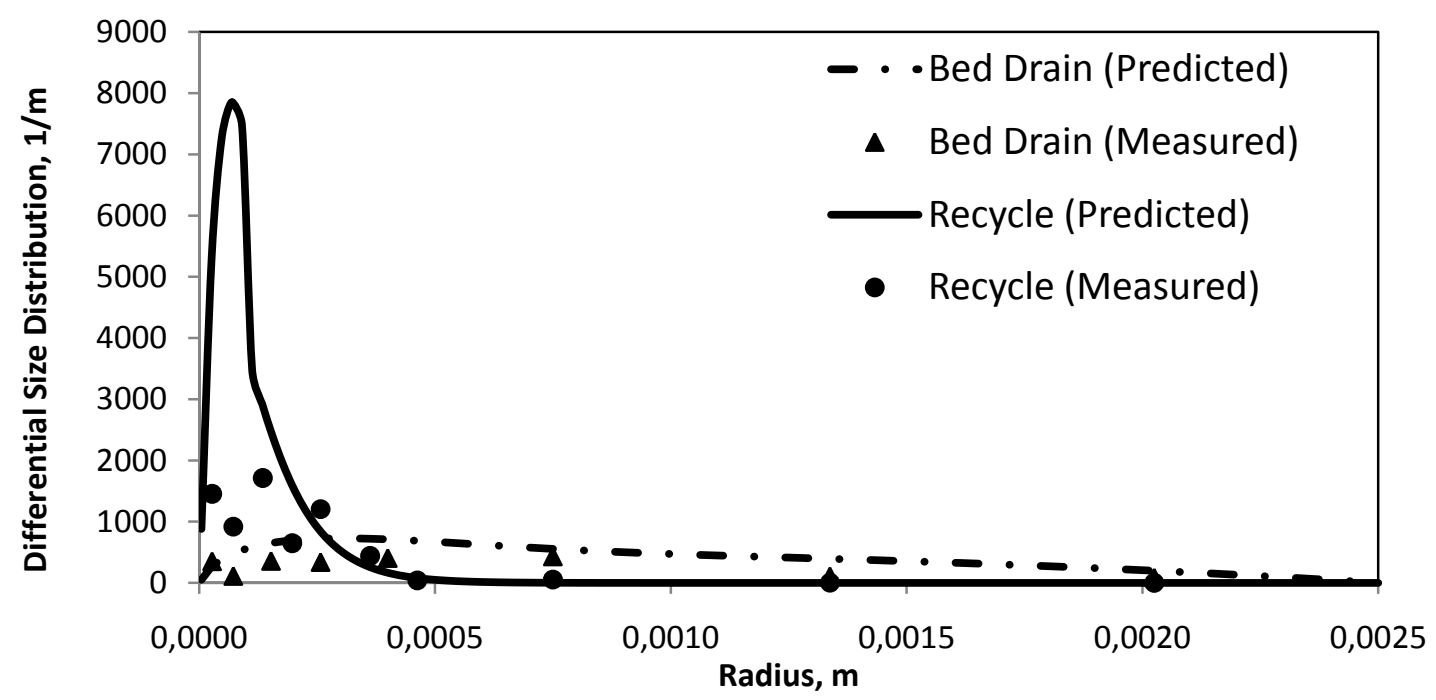

Figure 5.5 Predicted and experimental particle size distributions. 


\section{CHAPTER 6}

\section{CONCLUSIONS}

\subsection{GENERAL}

A CFBC model recently developed and validated against the experimental data obtained from 0.3 $\mathrm{MW}_{\mathrm{t}}$ CFBC fired with high calorific value coal burning in sand is extended to incorporate $N O$ formation and reduction reactions and pressure drops around cyclone, downcomer and loop seal. Predictive accuracy of the model was tested by applying it to the simulation of METU $150 \mathrm{~kW}_{\mathrm{t}}$ CFBC burning low calorific value indigenous lignite with high $\mathrm{VM} / \mathrm{FC}$ ratio in its own ash and comparing the predictions with measurements. The model includes dense and dilute zone hydrodynamics, devolatilization and volatile combustion, char combustion, particle size distribution and heat transfer to both refractory and cooling water channels.

The input data of the model were obtained from the steady-state operation of METU $150 \mathrm{~kW}_{\mathrm{t}}$ CFBC which are the configuration of the rig and its internals, air and coal flow rates, coal analysis, all solid and gas properties, inlet temperatures of air, cooling water and feed solids and the size distribution of feed solids deduced from sieve analysis. On the basis of comparisons between steady-state predictions of the model and measurements, the following conclusions have been reached; 
- Temperature profile prediction is in good agreement with the measurements.

- Model can predict pressure profile around the combustor reasonably well.

- Emission predictions for $\mathrm{O}_{2}, \mathrm{CO}, \mathrm{CO}_{2}$ and $\mathrm{NO}$ are in good agreement with the measurements.

- Predicted char particle size distribution agrees fairly well with the experimental data.

The model presented in this study proves to be a useful tool in predicting steadystate performance of CFBCs utilizing Turkish lignite.

\subsection{SUGGESTIONS FOR FUTURE WORK}

In order to improve the mathematical model presented in this study, the following suggestions can be made;

- Development of the dynamic system model and its validation against unsteady-state experimental measurements.

- Extension of the model for sulfur retention and validation against the measurements obtained from an experiment with limestone addition.

- For a better prediction of particle size distribution, fragmentation and attrition of particles should be incorporated.

- To predict the radial variations of the parameters, core-annulus flow structure in the dilute zone may be employed.

- Temperature profile prediction can be improved by coupling heat transfer model with a radiation model. 


\section{REFERENCES}

[1]. U.S. Energy Information Administration, Independent Statistics and Analysis http://www.eia.doe.gov (Last accessed on 31/10/2010).

[2]. BP statistical review of World Energy 2010, URL: http://www.bp.com/productlanding.do?categoryId $=6929 \&$ contentId $=7044$ 622 (Last accesses on 31/10/2010).

[3]. International Energy Outlook 2010, Energy Information Administration, Office of Integrated Analysis and Forecasting, U.S. Department of Energy, Washington, DC, April 2010.

[4]. Electricity Generation Company of Turkey (EÜAŞ), 2009 Annual Report

[5]. Ünver T., Ünal V., “Türkiye'nin Enerji Planlamasında Linyit Kaynaklarının Yeri”, TMMOB Elektrik Mühendisleri Odası Türkiye II. Enerji Sempozyumu, II. Bask1, p.137, Mayıs 2000.

[6]. Batu A., "Investigation of Combustion Characteristics of Indigenous Lignite In a 150 kWt Circulating Fluidized Bed Combustor", Ph.D Thesis, Middle East Technical University, Ankara, Turkey, 2008.

[7]. Selçuk N., “Akışkan Yatakta Yakma Teknolojileri”, TMMOB Kimya Mühendisleri Odası - TMMOB Maden Mühendisleri Odası, Türkiye'de Kömür Politikaları ve Temiz Kömür Teknolojileri Sempozyumu, Ankara, 21-22 Ekim 1999.

[8]. Hyppanen T., Lee Y. Y., Rainio A., "A Three-Dimensional Model for Circulating Fluidized Bed Boilers", Fluidized Bed Combustion ASME, pp.439-448, 1991. 
[9]. Hannes J., Renz U. and Van Den Bleek C. M., “The IEA Model for Circulating Fluidized Bed Combustion”, Fluidized Bed Combustion ASME, Vol.1, 1995.

[10]. Hannes J. P., Renz U. and Van Den Bleek C. M., "Mathematical Modelling of CFBC in Industrial Scale Power Plants", Fluidized Bed Combustion, ASME, Vol.2, 1997.

[11]. Remberg C. G., Nemet A., "Towards a More General Process Model for Power Plants with Atmospheric or Pressurized Fluidized Bed Combustion”, Fluidized Bed Combustion, ASME, Vol.2, 1997.

[12]. Gharebaagh R. S., Legros R., Chaouki J. and Paris J., "Simulation of Circulating Fluidized Bed Reactors Using ASPEN PLUS", Fuel, Vol.77, No.4, pp. 327-337, 1998.

[13]. Ducarne E. D., Dolignier J. C., Marty E., Martin G. and Delfosse L., "Modelling of Gaseous Pollutants Emissions in Circulating Fluidized Bed Combustion of Municipal Refuse", Fuel, Vol. 77, No. 13, pp. 1399-1410, 1998.

[14]. Knoebig T., Luecke K., Werther J., "Mixing and Reaction in the Circulating Fluidized Bed - A Three-dimensional Combustor Model", Chemical Engineering Science, Vol.54, pp. 2151-2160, 1999.

[15]. Huilin L., Guangbo Z., Rushan B., Yongjin C. and Gidaspow D., “A Coal Combustion Model for Circulating Fluidized Bed Boilers", Fuel, Vol.79, pp.165-172.

[16]. Adanez J., Gayan P., Grasa G., De Diego L. F., Armesto L., Cabanillas A., "Circulating Fluidized Bed Combustion in Turbulent Regime: Modelling of Carbon Combustion Efficiency and Sulphur Retention”, Fuel, pp.1405-1414, 2001. 
[17]. Göğebakan Y., "Simulation of Circulating Fluidized Bed Combustors", Ph.D Thesis, Middle East Technical University, Ankara, Turkey.

[18]. Werther J., Wein J., AIChE Symposium Ser 1994;90(301):31.

[19]. Adanez J., Gayan P., Garcia-Labiano F., and De Diego L. F., "Axial Voidage Profiles in Fast Fluidized Beds", Powder Technology, Vol.81, pp.259-268, 1994.

[20]. Mao D., Edwards J.R., Kuznetsov A. V., Srivastava R. K., "Threedimensional Numerical Simulation of a Circulating Fluidized Bed Reactor for Multi-Pollutant Control”, Chemical Engineering Science, Vol.59, pp.4279-4289, 2004.

[21]. Hua Y., Flamant G., Jidong L., Gauthier D., “3D Modelling of Radiative Heat Transfer in Circulating Fluidized Bed Combustors: Influence of the Particulate Composition", International Journal of Heat and Mass Transfer, Vol.48, pp.1145-1154, 2005.

[22]. Gnanapragasam N. V., Reddy B. V., "Modeling of Axial Bed-to-Wall Heat Transfer in a CFB Combustor with Abrupt Riser Exit Geometries", International Journal of Heat and Mass Transfer, Vol.51, pp.6102-6109, 2008.

[23]. Shuyan W., Lijie Y., Huilin L., Ding J., Yu L., Xiang L., "Numerical Analysis of Particulate Clustering Effects on Desulphurization and NO Emission in a Circulating Fluidized Bed Combustor", Fuel, Vol.87, pp.870-877, 2008.

[24]. Gnanapragasam N. V., Reddy B. V., "Numerical Modeling of Bed-toWall Heat Transfer in a Circulating Fluidized Bed Combustor Based on Cluster Energy Balance", International Journal of Heat and Mass Transfer, Vol.51, pp.5260-5268. 
[25]. Gungor A., Eskin N., "Analysis of Environmental Benefits of CFB Combustors via One-Dimensional Model”, Chemical Engineering Journal, Vol.131, pp.301-317, 2007.

[26]. Gungor A., "One-Dimensional Numerical Simulation of Small Scale CFB Combustors", Energy Conversion and Management, Vol.50, pp.711$722,2009$.

[27]. Gungor A., "Prediction of $\mathrm{SO}_{2}$ and $\mathrm{NO}_{x}$ Emissions for Low-Grade Turkish Lignites in CFB Combustors", Chemical Engineering Journal, Vol.146, pp.388-400, 2009.

[28]. Gungor A., "Simulation of $\mathrm{NO}_{\mathrm{x}}$ Emission in Circulating Fluidized Bed Burning Low-Grade Fuels”, Energy\&Fuels, Vol.23, pp.2475-2481, 2009.

[29]. Rhodes M.J., and Geldart D., "A Model for the Circulating Bed", Powder Technology, Vol.53, 1987.

[30]. Svensson A., Johnsson F., and Leckner B., "Fluid Dynamics of the Bottom Bed of CFB Boilers", in Proceedings of the $12^{\text {th }}$ International Conference on FBC (Rubow N. L., Ed.), ASME, Vol.1, pp.887-897, San Diego, California, USA, May 9-13, 1993.

[31]. Adanez J., Gayan P., Garcia-Labiano F., and De Diego L. F., “Axial Voidage Profiles in Fast Fluidized Beds", Powder Technology, Vol.81, pp.259-268, 1994

[32]. Johnsson F., and Leckner B., "Vertical Distribution of Solids in a CFB Furnace", in Proceedings of the $13^{\text {th }}$ International Conference on FBC (Heinschel K. J., Ed.), ASME, Vol.1, pp.671-679, Orlando, Florida, USA, May 7-10, 1995.

[33]. Basu P. and Fraser S. A., "Circulating Fluidized Bed Boilers: Design and Operations", Butterworth-Heinemann, 1991. 
[34]. Andersson S., Johnsson F. and Leckner B., "Fluidization Regimes in Non-Slugging Fluidized Beds", in Proceedings of the $10^{\text {th }}$ International Conference on FBC (Manaker A. M., Ed.), ASME, Vol.1, pp.239-247, San Francisco, USA, 30 April - 3 May, 1989.

[35]. Zijerveld R. C., Johnsson F., Marzoccella A., Schouten J. C. and Van Den Bleek C. M. "Fluidization Regimes and Transitions from Fixed Bed to Dilute Transport Flow”, Powder Technology, Vol.95, pp.185-204, 1998.

[36]. Schnitzlein M. and Weinstein H., "Flow Characterization in High Velocity Fluidized Beds Using Pressure Fluctuations", Chemical Engineering Science, Vol.43, pp.2605-2614, 1988.

[37]. Bai D., Shibuya E., Masuda Y., Nakagawa N. and Kato K., "Flow Structure in a Fast Fluidized Bed", Chemical Engineering Science, Vol.51, pp.957-966, 1996.

[38]. Bi H. T., Ellis N., Abba I. A. and Grace J. R. "A State of the Art Review of Gas-Solid Turbulent Fluidization", Chemical Engineering Science, Vol.55, pp.4789-4825, 2000.

[39]. Lee G. S. and Kim S. D., "Pressure Fluctuations in Turbulent Fluidized Beds", Journal of Chemical Engineering Japan, Vol.21, pp.515-521, 1988.

[40]. Leu L. P., Huang J. W. and Gua B. B. “Axial Pressure Distribution in Turbulent Fluidized Beds", in Proceedings of the $2^{\text {nd }}$ Asian Conference on Fluidized Bed and Three Phase Reactors (Lu W. M. and Leu L. P., Eds.), pp.71-79, Kenting, Taiwan, 1990.

[41]. Horio M., "Hydrodynamics of Circulating Fluidization: Present Status and Research Needs", in Proceedings of the $3^{\text {rd International Conference }}$ on CFB (Basu P., Horio M., and Hasatani M., Eds.), Pergamon Press, pp.3-14, Nagoya, Japan, October 14-18, 1990. 
[42]. Nakajima M., Harada M., Asai M., Yamazaki R. and Jimbo G., "Bubble Fraction and Voidage in an Emulsion Phase in the Transition to a Turbulent Fluidized Bed", in Proceedings of the $3^{\text {rd }}$ International Conference on CFB (Basu P., Horio M., and Hasatani M., Eds.), Pergamon Press, pp.79-84, Nagoya, Japan, October 14-18, 1991.

[43]. Bi H.T., and Grace J.R., "Effects of Measurement Method on Velocities Used to Demarcate the Transition to Turbulent Fluidization", Chemical Engineering Journal, Vol.57, pp.261-267, 1995.

[44]. Johnsson F., Andersson S., and Leckner B., "Expansion of a Freely Bubbling Fluidized Bed”, Powder Technology, Vol.68, pp.117-123, 1991.

[45]. Davidson J. F. and Harrison D., "Fluidized Particles", New York, Cambridge University Press, 1963.

[46]. Darton R. C., La Nauze R. D., Davidson J. F. and Harrison D., "Bubble Growth Due to Coalesence in Fluidized Beds", Transactions of the American Institute of Chemical Engineers, Vol.55, pp.274-283, 1977.

[47]. Broadhurst T. E. and Becker H. A. "Onset of Fluidization and Slugging in Beds of Uniform Particles”, AIChE Journal, Vol.21, No.2, pp.238-247, 1975.

[48]. Ergun S., "Fluid Flow Through Packed Columns", Chemical Engineering Progress, Vol.48, pp.89-94, 1952.

[49]. Koeningsdorff R. and Werther J., "Gas-Solid Mixing and Flow Structure Modeling of the Upper Dilute Zone of a Circulating Fluidized Bed”, Powder Technology, Vol.82, pp.317-329, 1995.

[50]. Hartge E. U., Rensner D., and Werther J., "Solids Concentration and Velocity Patterns in Circulating Fluidized Beds", in Proceedings of the $2^{\text {nd }}$ International Conference on CFB (Basu P. and Large J. F., Eds.), Pergamon Press, pp.165-180, Compiegne, France, May 14-18, 1988. 
[51]. Werther J., Hartge E. U., and Kruse M., "Radial Gas Mixing in the Upper Dilute Core of a Circulating Fluidized Bed", Powder Technology, Vol.70, No.3, pp.293-301, 1992.

[52]. Wang Q., Luo Z., Li X., Fang M., Ni M. and Cen K., “A Mathematical Model for a Circulating Fluidized Bed (CFB) Boiler", Energy, Vol.24, pp.633-653, 1999.

[53]. Horio M., Morishita K., Tachibana O., and Murata M. "Solids Distribution and Movement in Circulating Fluidized Beds", in Proceedings of the $2^{\text {nd }}$ International Conference on CFB (Basu P. and Large J. F., Eds.), Pergamon Press, pp.147-154, Compeigne, France, May 14-18, 1988.

[54]. Li H., Xia Y., Tung Y., and Kwauk M., "Micro-Visualization of TwoPhase Structure in a Fast Fluidized Bed", in Proceedings of the $3^{\text {rd }}$ International Conference on CFB (Basu P., Horio M., and Hasatani M., Eds.), Pergamon Press, pp.183-188, Nagoya, Japan, October 14-18, 1991.

[55]. Harris B. J. and Davidson F., "Modelling Options for Circulating Fluidized Beds: A Core/Annulus Depositions Model”, in Proceedings of the $4^{\text {th }}$ International Conference on CFB (Avidan A. A., Ed.), American Institute of Chemical Engineers, pp.32-39, Somerset, Pennysylvania, USA, August 1-5, 1994.

[56]. Pita J. P. and Sundaresan S., "Developing Flow of a Gas-Particle Mixture in a Vertical Riser", AIChE Journal, Vol.39, No.4, pp.541-552, 1993.

[57]. Pugsley T. S. and Berruti F., "A Predictive Hydrodynamic Model for Circulating Fluidized Bed Risers", Powder Technology, Vol.89, pp.57-69, 1996.

[58]. Johnsson F., and Leckner B., "Vertical Distribution of Solids in a CFB Furnace", in Proceedings of the $13^{\text {th }}$ International Conference on FBC 
(Heinschel K. J., Ed.), ASME, Vol.1, pp.671-679, Orlando, Florida, USA. May 7-10, 1995.

[59]. Choi J. H., Chang I. Y., Shun D. W., Yi C. K., Son J. E. and Kim S. D. "Correlation on the Particle Entrainment Rate in Gas Fluidized Beds", Industrial and Engineering Chemistry Research, Vol. 38, pp.2491-2496, 1999.

[60]. Kunii D. and Levenspiel O., "Entrainment of Solids from Fluidized Beds I. Hold-up of Solids in the Freeboard II. Operation of Fast Fluidized Beds", Powder Technology, Vol.61, pp.193-206, 1990.

[61]. De Nevers N., “Air Pollution Control Engineering”, McGraw Hill Inc., 1995.

[62]. Kim S. W., Kim S. D., and Lee D. H., "Pressure Balance Model for Circulating Fluidized Beds with a Loop-Seal”, Industrial Engineering Chemistry Research, Vol. 41, pp.4949-4956, 2002.

[63]. Park D., Levenspiel O., and Fitzgerald T. J., "Plume Model for Large Particle Fluidized Bed Combustors”, Fuel, Vol.60, pp.295-306, 1981.

[64]. Brereton C., "Combustion Performance" in Circulating Fluidized Beds (Grace J. R., Knowlton T. M., and Avidan A. A., Eds.), Springer, London, UK, 1996.

[65]. Anthony D. B. and Howard J. B., "Coal Devolatilization and Hydrogasification", AIChE Journal, Vol.22, No.4, pp.625-656, 1976.

[66]. Suuberg E. M., Peters W. A., and Howard J. B., "Product Composition and Kinetics of Lignite Pyrolysis", Industrial and Engineering Process Design and Development, Vol.17, No.1, pp.37-46, 1978.

[67]. Kobayashi H., Howard J. B. and Sarofim A. F., "Coal Devolatilization at High Temperatures" in Proceedings of $16^{\text {th }}$ International Conference on Combustion, The Combustion Institute, 411-425, Pittsburgh, USA, 1976. 
[68]. Smoot L. D., "Pulverized Coal Diffusion Flames: A Perspective Through Modeling", in Proceedings of the $18^{\text {th }}$ International Conference on Combustion, The Combustion Institute, pp.1185-1202, Pittsburgh, USA, 1981.

[69]. Stubington J. F., and Chan S. W., "The interpretation of Oxygen-Probe Measurements in Fluidized Bed Combustors", Journal of Instituta of Energy, Vol.63, 139-142, 1990.

[70]. Hayhurst A. N. and Tucker R. F., "The combustion of Carbon Monoxide in a Two-Zone Fluidized Bed", Combustion and Flame, Vol.79, pp.175$189,1990$.

[71]. Hesketh R. P. And Davidson J. F., "Combustion of Methane and Propane in an Incipiently Fluidized Bed”, Combustion and Flame, Vol.85, pp.449-467, 1991.

[72]. Van der waart D. R. "Mathematical Modelling of Methane Combustion in a Fluidized Bed", Industrial and Engineering Chemistry Research, Vol.31, 999-1007, 1992.

[73]. Field M. A., Gill D. W., Morgan R. B. and Hawksley P. G. W., "Combustion of Pulverized Coal", British Coal Utilization Research Association, 1967, Leatherhead, Great Britain.

[74]. Mon E. and Amundson N. R., "Diffusion and Reaction in a Stagnant Boundary Layer About a Carbon Particle: 2. An Extension”, Industrial and Engineering Chemistry Fundamentals, Vol.17, No.4, pp.313-321, 1978.

[75]. Ross I. B., Patel M. S., and Davidson J. F., "The Temperature of Burning Carbon Particles in Fluidized Beds", Transactions of Institution of Chemical Engineers, Vol.59, pp.83-88, 1981. 
[76]. Linjewile T. M. and Agarwal P. K., "The Influence of Product $[\mathrm{CO}] /\left[\mathrm{CO}_{2}\right]$ Ratio of the Ignition and Temperature History of Petroleum Coke Particles in Incipiently Gas-Fluidized Beds", Fuel, Vol.74, No.1, pp.12-16, 1995.

[77]. Fuertes A. B., Marban G., and Pis J. J., "Combustion Kinetics of Coke Particles in a Fluidized Bed Reactor", Fuel Processing Technology, Vol.38, pp.193-210, 1994.

[78]. Overturf B. W., and Reklaitis G. V., "Fluidized Bed Reactor Model with Generalized Particle Balances Part II: Coal Combustion Application", AIChE Journal, Vol.29, No.5, pp.820-829, 1983.

[79]. Smith I. W., “The Intrinsic Reactivity of Carbons to Oxygen”, Fuel, Vol.57, pp.409-414, 1978.

[80]. Basu P. and Subbarao D., "An Experimental Investigation of Burning Rate and Mass Transfer in a Turbulent Fluidized Bed", Combustion and Flame, Vol.66, No.3, pp.261-269, 1986.

[81]. Hottel H. C., Williams G. C., Nerheim N. M., and Schneider G. R., "Kinetic Studies on Stirred Reactors, Combustion of Carbon Monoxide and Propane", in Proceedings of the $10^{\text {th }}$ International Symposium on Combustion, The Combustion Institue, pp.111-121, Pittsburgh, USA, 1965.

[82]. Göğebakan Y., Selçuk N., "Assessment of a Model with Char Attrition for a Bubbling Atmospheric Fluidized Bed Combustor", Combustion Science and Technology, Vol.176, pp.799-818, 2004.

[83]. Geldart D., Cullinan J., Georghiades S., Gilvray D., and Pope D. J., "The Effect of Fines on Entrainment from Fluidized Beds", Transactions of the Institute of Chemical Engineers, Vol.57, pp.269-275, 1979. 
[84]. Johnsson J.E., and Dam-Johansen K., "Formation and Reduction of $N O_{x}$ in a Fluidized Bed Combustor", 11th International Conference on Fluidized Bed Combustion, ASME, pp.1389-1396, 1991.

[85]. Duo W., Dam-Johansen K., and Ostergaard K., "Kinetics of the GasPhase Reaction Between Nitric-Oxide, Ammonia and Oxygen", Canadian Journal of Chemical Engineering, Vol.70, No.5, pp.1014-1020, 1992.

[86]. Weimer A. W. and Clough D. E., "Modelling of Char Particle Size Conversion Distributions in a Fluidized Bed Gasifier: Non-Isothermal Effects", Powder Technology, Vol.27, pp.85-103, 1980.

[87]. Wakao N., Kaguei S., and Funazkri T., "Effects of Fluid Dispersion Coefficients on Particle to Fluid Heat Transfer Coefficients in Packed Beds", Chemical Engineering Science, Vol.34, No.3, pp.325-336, 1979.

[88]. Basu P. and Nag P.K., "Heat Transfer to Walls of a Circulating Fluidized Bed Furnace", Chemical Engineering Science, Vol.51, No.1, pp.126,1996 .

[89]. Hannes J., "Mathematical Modeling of Circulating Fluidized Bed Combustion”, Ph.D., RWTH, Aachen, Germany, 1996.

[90]. Radhakrishnan, K., and Hindmarsh, A. C., 1993, “Description and Use of LSODE, the Livermore Solver for Ordinary Differential Equations," Lawrence Livermore National Laboratory Report No: UCRL-ID-113855.

[91]. Shampine, L. F., Allen Jr., R. C., and Pruess, S., 1997, “Fundamentals of Numerical Computing,', 1st ed., John Wiley and Sons, New York.

[92]. Batu A., Selçuk N., Kulah G., "Design Assessment of a 150 kW CFBC $_{\mathrm{t}}$ Test Unit", Experimental Thermal and Fluid Science, Vol.34, No.3, pp.275-281, 2010. 
[93]. Patience G. S. and Chaouki J., "Gas Phase Hydrodynamics in the Riser of a Circulating Fluidized Bed", Chemical Engineering Science, Vol.48, pp.3195-3205, 1993.

[94]. Werther J., "Fluid Mechanics of Large Scale CFB Units", in Proceedings of the $5^{\text {th }}$ International Conference on CFB (Kwauk M. and Li J., Eds.) Science Press, pp.1-14, Beijing, China, August 1-5, 1994.

[95]. Zhang W., Johnsson F., and Leckner B. "Fluid-Dynamic Boundary Layers in CFB Boilers", Chemical Engineering Science, Vol.50, No.2, pp.201-210, 1995.

[96]. Bai D., Shibuya E., Masuda Y. and Nishio K., Nakagawa N. and Kato K., "Distinction Between Upward and Downward Flows in Circulating Fluidized Beds", Powder Technology, Vol.84, pp.75-81, 1995.

[97]. Harris A. T., Thorpe R. B. and Davidson J. F., "Characterization of the Annular Film Thickness in Circulating Fluid-Bed Risers", Chemical Engineering Science, Vol.57, pp.2579-2587, 2002.

[98]. Sandler S. I., "Chemical and Engineering Thermodynamics", New York, USA, John Wiley and Sons, $3^{\text {rd }}$ Ed., 1999. 


\section{APPENDIX A}

\section{DERIVATION OF CARBON AND CHAR-N CONSUMPTION RATE}

Flow rate of volatile matter is obtained from;

$$
F_{v m}=F_{c o a l} x_{v m}
$$

Rate of consumption of fixed carbon is;

$$
\left\{\begin{array}{c}
\text { Rate of } \\
\text { char } \\
\text { depletion }
\end{array}\right\}=\rho_{c}\left\{\begin{array}{c}
\text { number of } \\
\text { particles in the } \\
\text { interval } \Delta r
\end{array}\right\}\left\{\begin{array}{c}
\text { decrease } \\
\text { of particle volume } \\
\text { due to combustion }
\end{array}\right\}
$$

Expressing in mathematical terms;

$$
\left\{\begin{array}{c}
\text { rate of } \\
\text { char } \\
\text { depletion }
\end{array}\right\}=\rho_{c} \frac{M_{d} P_{d}(r) d r}{\rho_{c} \frac{4}{3} \pi r^{3}}\left(\frac{d V}{d t}\right)
$$

$d V$ can be substituted by $4 \pi r^{2}$ in Equation A.2;

$$
\left\{\begin{array}{c}
\text { rate of } \\
\text { char } \\
\text { depletion }
\end{array}\right\}=\frac{3 M_{d} P_{d}(r) \Re(r) d r}{r}
$$


The total char depletion is;

$$
\left\{\begin{array}{c}
\text { rate of } \\
\text { char } \\
\text { depletion }
\end{array}\right\}=3 M_{d} \int_{r_{\text {min }}}^{r_{\max }} \frac{P_{d}(r) \Re(r) d r}{r}
$$

In Equation A.5, rate of char depletion is in $\mathrm{kg} / \mathrm{s}$. In order to have rate of char depletion in $\mathrm{mol} / \mathrm{s}$, Equation A.6 should be utilized.

$$
\left\{\begin{array}{c}
\text { rate of } \\
\text { char } \\
\text { depletion }
\end{array}\right\}=3 M_{d} \frac{x_{f c}}{x_{f c}+x_{a s h}} \frac{1}{M_{C}} \int_{r_{\min }}^{r_{\max }} \frac{P_{d}(r) \Re(r) d r}{r}
$$

Since, char particles are only considered to exist in emulsion phase, Equation A.6 is divided by the total volume of the emulsion phase;

$$
\left\{\begin{array}{c}
\text { mass of } \\
\text { carbon } \\
\text { depleted }
\end{array}\right\}=\frac{3 M_{d}}{V_{d}(1-\delta) \varepsilon_{m f}} \frac{x_{f c}}{x_{f c}+x_{a s h}} \frac{1}{M_{C}} \int_{r_{\min }}^{r_{\max }} \frac{P_{d}(r) \Re(r)}{r} d r
$$

Rate of depletion of char bound nitrogen is found by following the same procedure. Molar carbon depletion and molar char bound nitrogen consumption are given in Equations A.8 \& A.9 respectively.

$$
\begin{aligned}
& n_{C, e}=\frac{3 M_{d}}{V_{d}(1-\delta) \varepsilon_{m f}} \frac{x_{f c}}{x_{f c}+x_{a s h}} \frac{1}{M_{C}} \int_{r_{\text {min }}}^{r_{\max }} \frac{P_{d}(r) \Re(r)}{r} d r \\
& n_{N, e}=\frac{3 M_{d}}{V_{d}(1-\delta) \varepsilon_{m f}} \frac{x_{f c}}{x_{f c}+x_{a s h}} \frac{1}{M_{C}} \int_{r_{\min }}^{r_{\max }} \frac{P_{d}(r) \Re(r)}{r} d r
\end{aligned}
$$




\section{APPENDIX B}

\section{DERIVATION OF ROSIN-RAMMLER SIZE DISTRIBUTION FUNCTIONS}

Coal particles' size distribution are defined by sieve analysis results and these results are fitted to a mathematical function. Rosin-Rammler Size Distribution Function is one of these size distribution representing functions. This function is defined as;

$$
W\left(d_{p}\right)=\exp \left(-b d_{p}^{n}\right)
$$

Representation of this function in terms of particle radius yields;

$$
W(r)=\exp \left(-b 2^{n} r^{n}\right)
$$

$P_{0}(r) \Delta r$ represents the fraction of particles having radius between $r$ and $r+\Delta r$.

Equating this to the fractional mass obtained from Equation B.2 results in,

$$
P_{0}(r) \Delta r=-\frac{d W(r)}{d r} \Delta r
$$

Cancelling $\Delta r$; 


$$
P_{0}(r)=-\frac{d W(r)}{d r}
$$

Right-hand side of Equation B.4 is obtained by taking derivative of both sides of Equation B.2;

$$
\frac{d W(r)}{d r}=-b n 2^{n} r^{n-1} \exp \left(-b 2^{n} r^{n}\right)
$$

Substituting Equation B.5 into Equation B.4 yields;

$$
P(r)=b n 2^{n} r^{n-1} \exp \left(-b 2^{n} r^{n}\right)
$$

where coeffcients $b$ and $n$ are obtained by non-linear curve fitting for sieve analysis data of the feed coal. In this study, $b$ and $n$ are calculated as 203.6 and 0.843 respectively. 


\section{APPENDIX C}

\section{EXPERIMENTAL DATA}

Table C.1 Steady-State temperature measurements along the combustor.

\begin{tabular}{|c|c|}
\hline Height (m) & Measurement $\left({ }^{\circ} \mathrm{C}\right)$ \\
\hline 0.07 & 850.8 \\
\hline 0.30 & 860.3 \\
\hline 0.70 & 862.9 \\
\hline 1.10 & 871.4 \\
\hline 1.70 & 862.1 \\
\hline 2.30 & 856.7 \\
\hline 3.25 & 832.3 \\
\hline 4.20 & 815.0 \\
\hline 5.15 & 815.5 \\
\hline 6.10 & 828.4 \\
\hline 7.10 & 830.3 \\
\hline 7.85 & 822.6 \\
\hline
\end{tabular}


Table C.2 Steady-State pressure measurements along the combustor.

\begin{tabular}{|c|c|}
\hline Height (m) & Measurement $\left(\mathbf{m m H}_{\mathbf{2}} \mathbf{O}\right)$ \\
\hline 0.02 & 527.8 \\
\hline 0.50 & 414.6 \\
\hline 1.00 & 47.4 \\
\hline 2.15 & 49.2 \\
\hline 3.30 & 49.2 \\
\hline 4.45 & 52.2 \\
\hline 5.60 & 49.3 \\
\hline 6.75 & 30.9 \\
\hline 7.80 & 17.9 \\
\hline
\end{tabular}


Table C.3 Chemical analysis of bag filter ash and bed drain.

\begin{tabular}{|c|c|c|}
\hline & Bed Drain & Bag Filter Ash \\
& Weight $\%$ & Weight $\%$ \\
\hline $\mathrm{SiO}_{2}$ & 58.09 & 56.51 \\
\hline $\mathrm{Al}_{2} \mathrm{O}_{3}$ & 19.48 & 20.25 \\
\hline $\mathrm{Fe}_{2} \mathrm{O}_{3}$ & 7.10 & 0.41 \\
\hline $\mathrm{CaO}$ & 1.84 & 0.64 \\
\hline $\mathrm{MgO}$ & 1.34 & 5.24 \\
\hline $\mathrm{SO}_{3}$ & 7.29 & 2.31 \\
\hline $\mathrm{Na}_{2} \mathrm{O}$ & 1.46 & 0.42 \\
\hline $\mathrm{K}_{2} \mathrm{O}$ & 1.48 & 1.97 \\
\hline $\mathrm{TiO}_{2}$ & & \\
\hline & & \\
\hline & & \\
\hline
\end{tabular}


Table C.4 Particle size distribution of loop seal ash.

\begin{tabular}{|c|c|}
\hline$D_{p}, m m$ & Weight, \% \\
\hline$>6.3$ & 0.00 \\
\hline $6.30-4.75$ & 0.00 \\
\hline $4.75-3.35$ & 0.17 \\
\hline $3.35-2.00$ & 0.36 \\
\hline $2.00-1.00$ & 4.04 \\
\hline $1.00-0.85$ & 1.87 \\
\hline $0.85-0.60$ & 15.97 \\
\hline $0.60-0.43$ & 31.03 \\
\hline $0.43-0.36$ & 12.79 \\
\hline $0.36-0.18$ & 23.12 \\
\hline $0.18-0.11$ & 6.66 \\
\hline $0.11-0.00$ & 4.00 \\
\hline$d_{50}$ & 0.44 \\
\hline
\end{tabular}


Table C.5 Particle size distribution of bed drain.

\begin{tabular}{|c|c|}
\hline$D_{p}, m m$ & Weight, \% \\
\hline$>6.3$ & 0.25 \\
\hline $6.30-4.75$ & 3.19 \\
\hline $4.75-3.35$ & 17.55 \\
\hline $3.35-2.00$ & 14.47 \\
\hline $2.00-1.00$ & 32.35 \\
\hline $1.00-0.60$ & 16.22 \\
\hline $0.60-0.43$ & 8.74 \\
\hline $0.43-0.18$ & 5.46 \\
\hline $0.18-0.11$ & 0.81 \\
\hline $0.11-0.00$ & 0.97 \\
\hline$d_{50}, \mathrm{~mm}$ & 1.55 \\
\hline
\end{tabular}


Table C.6 Particle size distribution of bag filter ash.

\begin{tabular}{|c|c|}
\hline$D_{p}, \mu m$ & Weight, \% \\
\hline $282.508-251.785$ & 0.04 \\
\hline $251.785-224.404$ & 0.07 \\
\hline $224.404-200.000$ & 0.2 \\
\hline $200.000-178.250$ & 0.45 \\
\hline $178.250-158.866$ & 0.79 \\
\hline $158.866-141.589$ & 1.15 \\
\hline $141.589-126.191$ & 1.53 \\
\hline $126.191-112.468$ & 1.97 \\
\hline $112.468-100.237$ & 2.42 \\
\hline $100.237-89.337$ & 2.87 \\
\hline $89.337-79.621$ & 3.29 \\
\hline $79.621-70.963$ & 3.66 \\
\hline $70.963-63.246$ & 3.95 \\
\hline $63.246-56.368$ & 4.16 \\
\hline $56.368-50.238$ & 4.27 \\
\hline $50.238-44.774$ & 4.31 \\
\hline
\end{tabular}


Table C.6 Particle size distribution of bag filter ash (cont'd).

\begin{tabular}{|c|c|}
\hline$D_{p}, \mu m$ & Weight, \% \\
\hline $44.774-39.905$ & 4.27 \\
\hline $39.905-35.566$ & 4.17 \\
\hline $35.566-31.698$ & 4.03 \\
\hline $31.698-28.251$ & 3.85 \\
\hline $28.251-25.179$ & 3.67 \\
\hline $25.179-22.440$ & 3.47 \\
\hline $22.440-20.000$ & 3.27 \\
\hline $20.000-17.825$ & 3.08 \\
\hline $17.825-15.887$ & 2.90 \\
\hline $15.887-14.159$ & 2.72 \\
\hline $14.159-12.619$ & 2.56 \\
\hline $12.619-11.247$ & 2.39 \\
\hline $11.247-10.024$ & 2.23 \\
\hline $10.024-8.934$ & 2.08 \\
\hline $8.934-7.962$ & 1.92 \\
\hline $7.962-7.096$ & 1.77 \\
\hline
\end{tabular}


Table C.6 Particle size distribution of bag filter ash (cont'd).

\begin{tabular}{|c|c|}
\hline$D_{p}, \mu m$ & Weight, \% \\
\hline $7.096-6.325$ & 1.63 \\
\hline $6.325-5.637$ & 1.49 \\
\hline $5.637-5.024$ & 1.36 \\
\hline $5.024-4.477$ & 1.26 \\
\hline $4.477-3.991$ & 1.15 \\
\hline $3.991-3.557$ & 1.06 \\
\hline $3.557-3.170$ & 0.97 \\
\hline $3.170-2.825$ & 0.89 \\
\hline $2.825-2.518$ & 0.81 \\
\hline $2.518-2.244$ & 0.73 \\
\hline $2.244-2.000$ & 0.64 \\
\hline $2.000-1.783$ & 0.56 \\
\hline $1.783-1.589$ & 0.54 \\
\hline $1.589-1.416$ & 0.37 \\
\hline $1.416-1.262$ & 0.36 \\
\hline $1.262-1.125$ & 0.34 \\
\hline
\end{tabular}


Table C.6 Particle size distribution of bag filter ash (cont'd).

\begin{tabular}{|c|c|}
\hline$D_{p}, \mu m$ & Weight, \% \\
\hline $1.125-1.002$ & 0.32 \\
\hline $1.002-0.893$ & 0.32 \\
\hline $0.893-0.796$ & 0.33 \\
\hline $0.796-0.710$ & 0.31 \\
\hline $0.710-0.632$ & 0.31 \\
\hline $0.632-0.564$ & 0.27 \\
\hline $0.564-0.502$ & 0.24 \\
\hline $0.502-0.448$ & 0.16 \\
\hline $0.448-0.399$ & 0.07 \\
\hline $0.399-0.356$ & 0.00 \\
\hline
\end{tabular}




\section{APPENDIX D}

\section{THERMOPHYSICAL PROPERTIES}

Table D.1 Molecular weights of the elements.

\begin{tabular}{|c|c|}
\hline Specie & Molecular Weight $(\mathbf{k g} / \mathbf{m o l})$ \\
\hline$C$ & $12 \times 10^{-3}$ \\
\hline$H$ & $1 \times 10^{-3}$ \\
\hline$O$ & $16 \times 10^{-3}$ \\
\hline$N$ & $14 \times 10^{-3}$ \\
\hline$S$ & $32 \times 10^{-3}$ \\
\hline
\end{tabular}

Table D.2 Standard heats of combustion and vaporization.

\begin{tabular}{|c|c|c|}
\hline \multicolumn{2}{|c|}{ Latent Heat of Combustion, $\Delta \boldsymbol{H}$} & \multirow{2}{*}{ Value $(\boldsymbol{J} / \mathbf{m o l})$} \\
\cline { 1 - 2 } From & To & $1.10524 \times 10^{5}$ \\
\hline $\mathrm{C}$ & $\mathrm{CO}$ & $2.82989 \times 10^{5}$ \\
\hline $\mathrm{CO}$ & $\mathrm{CO}_{2}$ & $2.41827 \times 10^{5}$ \\
\hline $\mathrm{H}$ & $\mathrm{H}_{2} \mathrm{O}$ & $2.96813 \times 10^{5}$ \\
\hline $\mathrm{S}$ & $\mathrm{SO}_{2}$ & \\
\hline
\end{tabular}


Table D.3 Physical constants.

\begin{tabular}{|c|c|}
\hline Constant & Value \\
\hline Gravitational Acceleration, $g, m / \mathrm{s}^{2}$ & 9.807 \\
\hline Gas Constant, $R, \mathrm{~J} / \mathrm{mol} \cdot \mathrm{K}$ & 8.314 \\
\hline Stefan-Boltzmann Constant, $\sigma, \mathrm{W} / \mathrm{m}^{2} \cdot \mathrm{K}^{4}$ & $5.67 \times 10^{-8}$ \\
\hline
\end{tabular}

Table D.4 Thermophysical properties of gases [98].

\begin{tabular}{|c|c|}
\hline Property & Correlation \\
\hline Gas Density, & $\rho_{g}=323.76373(T-4.6996817)^{-0.99007228}$ \\
$\mathrm{~kg} / \mathrm{m}^{3}$ & \\
\hline Gas Viscosity, & $\mu_{g}=2.9901393 \times 10^{-7}(T+10.092613)^{0.71630135}$ \\
$\mathrm{~kg} / \mathrm{m} \cdot \mathrm{s}$ & \\
\hline Gas Thermal & $k_{g}=8.62496 \times 10^{-3}+5.60351 \times 10^{-5} \mathrm{~T}+2.70155$ \\
Conductivity, & $\times 10^{-9} \mathrm{~T}^{2}$ \\
$\mathrm{~J} / \mathrm{m} \cdot \mathrm{s} \cdot \mathrm{K}$ & \\
\hline
\end{tabular}




\section{APPENDIX E}

\section{INPUT DATA FILE}

!*****INPUT DATA FOR THE SIMULATION ARE SET.*****

subroutine input_data

use global

! TYPE DECLARATIONS

implicit none

! FOR THE GRID POINT LOCATIONS

ndense $=15$ ! NUMBER OF POINTS IN DENSE ZONE, -

ndilute $=77$ ! NUMBER OF POINTS IN DILUTE ZONE, -

nparticle $=117$ ! NUMBER OF POINTS FOR PARTICLE SIZE, -

nwa11 = 11 ! NUMBER OF POINTS IN THE WALL, -

! COMBUSTOR SPECIFIC PARAMETERS

norifice $=645$ ! NUMBER OF ORIFICES IN THE DISTRIBUTOR PLATE, -

diahopper $=0.25$ ! DIAMETER OF DENSE ZONE SECTION, $\mathrm{m}$

hhopper $=1.10$ ! HEIGHT OF DENSE ZONE SECTION, $\mathrm{m}$

diafurnace $=0.25$ ! DIAMETER OF DILUTE ZONE SECTION, $\mathrm{m}$

hfurnace $=6.90$ ! HEIGHT OF FURNACE SECTION, $m$

dcutcyclone $=7 d-5$ ! CUT SIZE OF CYCLONE, $m$ 
PHYSICAL PROPERTIES OF COMBUSTOR WALLS

kwa11 = $1.0 \quad$ ! THERMAL CONDUCTIVITY OF WALL MATERIAL, W/m.K thickwa11 $=0.1035$ ! THICKNESS OF WALL, $\mathrm{m}$

! PROXIMATE ANALYSIS OF COAL

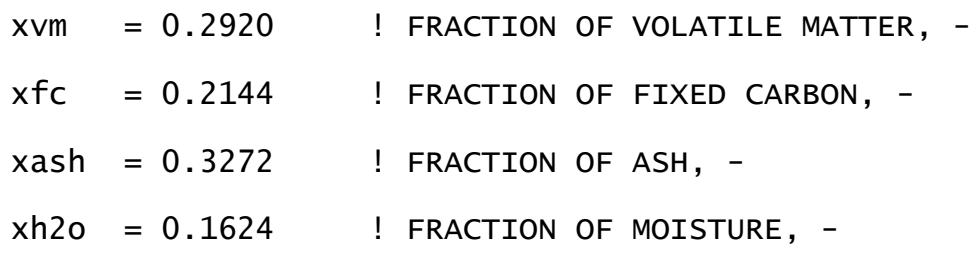

! ULTIMATE ANALYSIS OF COAL (DRY BASIS)

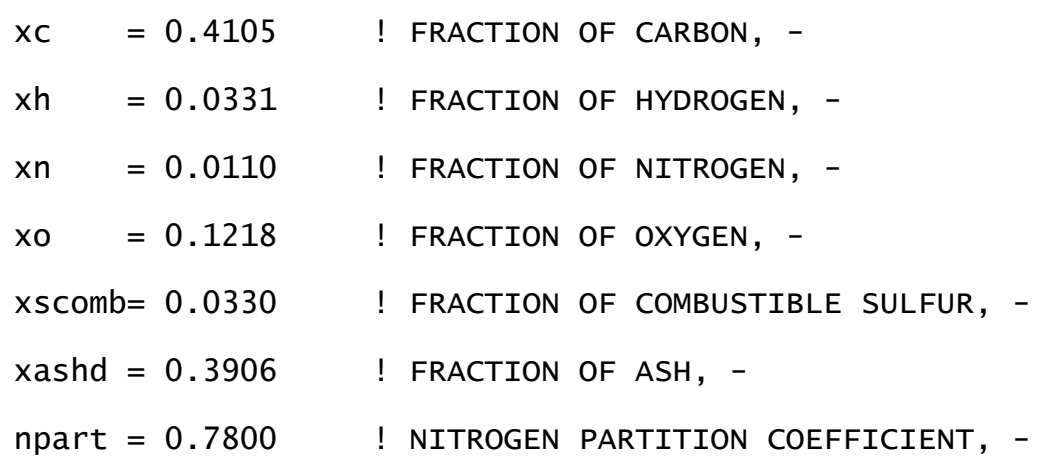


cpinert $=1412.08$ ! HEAT CAPACITY OF INERT BED MATERIAL, j/kg.K

! INPUT PARAMETERS FOR PRESSURE BALANCE MODEL

CCY $=10.0 \quad$ ! VELOCITY HEAD COEFFICIENT, -

Iw $\quad=0.50 \quad$ ! LENGHT OF WEIR SECTION, $\mathrm{m}$

dialoop $\quad=0.10 \quad$ ! DIAMETER OF LOOP SEAL, $\mathrm{m}$

Tva $=0.50 \quad$ ! LENGHT OF VERTICAL AERATION SECTION, $\mathrm{m}$

diaconnection $=0.18$ ! DIAMETER OF RISER-CYCLONE CONNECTION, m

ugh $=15.0 \quad$ ! AVERAGE VELOCITY AT CYCLONE DUCT, $\mathrm{m}$

acyclone $\quad=0.0126 \quad !$ INLET AREA OF CYCLONE, $\mathrm{m} \wedge 2$

! OPERATING PARAMETERS

\begin{tabular}{|c|c|c|}
\hline airrate1 & $=0.0495$ & ! PRIMARY AIR FLOW RATE, $\mathrm{Nm} \wedge 3 / \mathrm{s}$ \\
\hline airrate2 & $=0.0063$ & ! SECONDARY AIR FLOW RATE, $\mathrm{Nm} \wedge 3 / \mathrm{s}$ \\
\hline airtemp & $=313.15$ & ! FLUIDIZING AIR TEMPERATURE, $\mathrm{K}$ \\
\hline watertemp & $=313.95$ & ! COOLING WATER TEMPERATURE, $\mathrm{K}$ \\
\hline fcoal & $=0.0135$ & ! COAL FLOW RATE, $\mathrm{kg} / \mathrm{s}$ \\
\hline
\end{tabular}

! END OF THE SUBROUTINE

end subroutine input_data 